\title{
BIOPHYSIKALISCHE UND THERMODYNAMISCHE CHARAKTERISIERUNG DER NEURONALEN SNARE-KOMPLEXBILDUNG
}

\author{
Dissertation zur Erlangung des Doktorgrades \\ der Mathematisch-Naturwissenschaftlichen Fakultäten \\ der Georg-August-Universität zu Göttingen
}

vorgelegt von

\author{
KATRIN WIEDERHOLD \\ aus Bad Salzungen
}

Göttingen 2008 
D 7

Referent: Prof. Dr. Reinhard Jahn

Korreferent: Prof. Dr. Ralf Ficner

Tag der mündlichen Prüfung: 30. April 2008 


\section{Danksagung}

Prof. Reinhard Jahn möchte ich dafür danken, dass er mir diese interessante Arbeit ermöglicht hat und für die Übernahme des Referats.

Prof. Ralf Ficner danke ich für die Übernahme des Korreferats.

Mein ganz besonderer Dank gilt Dirk 'Capt. Future' Fasshauer, er hat mir gezeigt, was gute Wissenschaft bedeutet. Seine exzellente Betreuung und die zahlreichen, wertvollen Ratschläge und Diskussionen haben viel zum Gelingen dieser Arbeit beigetragen. Danke für Deine Geduld und, dass ich so viel von Dir lernen durfte.

Gottfried Mieskes, ohne Dich und Deine Hilfsbereitschaft wäre unser Labor verloren! Danke, dass Du mir viele Probleme des Laboralltags abgenommen hast und ich so befreit forschen konnte.

Der Arbeitsgruppe 'Strukturelle Biochemie', aka Team Future, danke ich für die hilfreichen Diskussionen, Hilfsbereitschaft, netten Kaffeerunden und die entspannte Arbeitsatmosphäre. Wolfgang, danke für Deine Hilfe bei der Reinigung von zahlreichen Proteinen.

Ich danke allen Mitarbeitern der Abteilung Neurobiologie für die interessanten Diskussionen und die angenehme Arbeitsatmosphäre.

Jakob Sörensen danke ich für die konstruktive Zusammenarbeit und die interessanten Einblicke in die Elektrophysiologie. Gert Weber und Simon Trowitzsch möchte ich für ihre außerordentliche Hilfsbereitschaft bei der Proteinkristallisation danken, wenn es auch leider nicht geklappt hat mit der Struktur.

Meine Freunde Alexander, Anand, Nickias und Pawel; ich bin dankbar, dass ich euch kennengelernt habe. Die Diskussionen und der Spass in und außerhalb des Labors haben mein Leben bereichert.

Ich danke besonders meinen Eltern, dass sie mir diese Ausbildung ermöglicht haben und mich auch sonst in jeglicher Hinsicht unterstützen.

Tobias Klöpper danke ich für die außerordentlich gute Zusammenarbeit im Bereich der Bioinformatik. Außerdem danke ich Dir für Deine Geduld und Hilfe besonders in den letzten drei Monaten. Danke für Deine Unterstützung und Liebe in den letzten zehn Jahren, die wie im Flug vergingen. Ich freue mich schon auf die nächsten... 


\title{
Abkürzungsverzeichnis
}

\author{
Abb. Abbildung \\ AS Aminosäure(n) \\ ATP Adenosin-5'-triphosphat \\ a.u. willkürliche Einheiten (arbitrary units) \\ BoNT Botulinumneurotoxin \\ CD Circulardichroismus \\ DNA Desoxyribonukleinsäure (deoxyribonucleic acid) \\ DNase Desoxyribonuklease \\ $\Delta$ N-Komplex SNARE-Komplex mit N-terminal verkürztem Synaptobrevin (Syb 49-96) \\ $\Delta$ C-Komplex SNARE-Komplex mit C-terminal verkürztem Synaptobrevin (Syb 1-70) \\ DTT Dithiothreitol \\ E. coli Escherichia coli \\ $\mathrm{Eb} \quad$ Endobrevin \\ EDTA Ethylendiamintetraessigsäure \\ EPR electron paramagnetic resonance \\ FRET fluorescence resonance energy transfer \\ GST Glutathion-S-Transferase \\ IPTG Isopropyl- $\beta$-D-1-thiogalaktopyranosid \\ ITC Isotherme Titrationskalorimetrie (isothermal titration calorimetry) \\ kDa Kilodalton \\ MALLS multi-angle laser light scattering \\ Ni-NTA Nickel-Nitrilo-triessigsäure \\ NMR Kernmagnetische Resonanz (nuclear magnetic resonance) \\ NSF N-ethylmaleimide-sensitive factor \\ ODx optische Dichte bei $\mathrm{xm}$ \\ PAGE Polyacrylamidgelelektrophorese \\ PCR Polymerasekettenreaktion (polymerase chain reaction) \\ $\mathrm{pH} \quad$ negativer dekadischer Logarithmus der $\mathrm{H}_{3} \mathrm{O}^{+}$-Ionenkonzentration \\ PMSF Phenylmethylsulfonylfluorid \\ rpm Umdrehungen pro Minute (rounds per minute) \\ RT Raumtemperatur \\ S Svedberg \\ SDS Natriumdodecylsulfat (sodium dodecyle sulfate) \\ SNAP soluble NSF attachment protein \\ SNAP-25 synaptosome-associated protein of $25 \mathrm{kDa}$ \\ SNARE SNAP-Rezeptor \\ Syb Synaptobrevin \\ Syx Syntaxin \\ SyxH3 SNARE-Motiv von Syntaxin \\ TeNT Tetanusneurotoxin (tetanus neurotoxin) \\ Tris Tris-(hydroxymethyl)-aminomethan \\ U Einheit der Enzymaktivität (units) \\ VAMP vesicle associated membrane protein \\ v/v Volumen/Volumen (volume/volume) \\ wt Wildtyp \\ w/v Masse/Volumen (weight/volume)
}




\section{Inhaltsverzeichnis}

1 Einleitung $\quad 11$

1.1 Intrazellulärer Membrantransport . . . . . . . . . . . . . . . . 11

1.2 SNARE-Hypothese . . . . . . . . . . . . . . . . . . . 12

1.3 Struktur des SNARE-Komplexes . . . . . . . . . . . . . . 14

1.4 Das Zipper-Modell und der SNARE-Zyklus . . . . . . . . . . . . . 18

1.5 SNARE-Komplexbildungsschritte . . . . . . . . . . . . . . 20

1.6 Regulierte Membranfusion in Neuronen . . . . . . . . . . . . . 25

1.7 Andere Membranfusionsarten . . . . . . . . . . . . . . . 26

1.8 Faltung $\alpha$-helikaler coiled coil-Strukturen . . . . . . . . . . . . 30

1.9 Ziel der Arbeit . . . . . . . . . . . . . . . . . . . . . . . 31

2 Material und Methoden 33

2.1 Material . . . . . . . . . . . . . . . . . . 33

2.1.1 Chemikalien . . . . . . . . . . . . . . 33

2.1.2 Enzyme, Kits, Bakterienstämme . . . . . . . . . . . 33

2.1.3 DNA-Konstrukte . . . . . . . . . . . . . . . 33

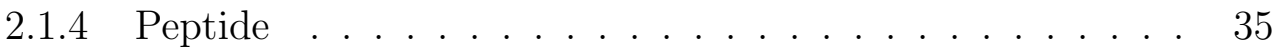

2.2 Methoden . . . . . . . . . . . . . . . . . 36

2.2.1 Proteinexpression und -reinigung . . . . . . . . 36

2.2.2 Biochemische Standardmethoden . . . . . . . . . . . . 38

2.2.3 Reinigung von SNARE-Komplexen . . . . . . . . . . . . . 39

2.2.4 Limitierte Proteolyse . . . . . . . . . . . . . . . . . . . . . 39

2.2.5 Circular Dichroismus (CD)-Spektroskopie . . . . . . . . . 40

2.2.6 Fluoreszenzspektroskopie . . . . . . . . . . . . . . . . 40

2.2.7 Isothermale Titrationskalorimetrie (ITC) . . . . . . . . . . 42 
3.1 Die N-terminale Initiationsreaktion der Q-SNARE-Proteine . . . . 46

3.1.1 Die Integrität der N-terminalen Region der beiden SNAREMotive von SNAP-25 ist essenziell für den Initiationsschritt der Komplexbildungsreaktion . . . . . . . . . . . . 46

3.1.2 Die zentrale Region von SNAP-25 hat einen Einfluss auf die SNARE-Komplexbildung . . . . . . . . . . . . . . . . 49

3.1.3 Veränderung der Stabilität der Komplexe mit N-terminalen und zentralen Mutationen in SNAP-25 . . . . . . . 51

3.2 Die Bindung von Synaptobrevin an den Qabc-Akzeptorkomplex . 52

3.2.1 Kinetische Charakterisierung der Synaptobrevinbindung . 54

3.2.2 Thermodynamische Charakterisierung der Synaptobrevinbindung . . . . . . . . . . . . . . . 5 55

3.2.3 Charakterisierung der Synaptobrevinbindungsstelle des $\Delta$ N-Komplexes . . . . . . . . . . . . . . 58

3.2.4 Bindung von N-terminalen Synaptobrevinmutanten an den $\Delta$ N-Komplex . . . . . . . . . . . . 60

3.2.5 Die Region zwischen -4 und -1-Layer von Synaptobrevin ist wichtig für die Bindung an den $\Delta$ N-Komplex . . . . . . . 63

3.2.6 Spezifität der R-SNARE-Bindung . . . . . . . . . . . . 68

3.2.7 Veränderungen in der konservierten N-terminalen Region beeinflussen die Synaptobrevinbindung an den Akzeptorkomplex ..................... 73

3.3 Die C-terminale Zipper-Reaktion . . . . . . . . . . . . . . . 76

3.3.1 Partiell unstrukturierte SNARE-Komplexe . . . . . . . 76

3.3.2 Thermodynamik des C-terminalen Zipper-Schrittes . . . . 80

4 Diskussion $\quad 84$

4.1 Bildung des Akzeptorkomplexes . . . . . . . . . . . . 85

4.1.1 N-terminale Initiationsreaktion . . . . . . . . . . . 85

4.1.2 Der Einfluss zentraler Mutationen im SNARE-Komplex . . 87

4.2 Synaptobrevinbindung an den Akzeptorkomplex . . . . . . . . . . 89

4.2.1 Die Synaptobrevinbindungsreaktion . . . . . . . . . . . . . 89 
4.2.2 Spezifität der Synaptobrevinbindung . . . . . . . . . . 96

4.3 Partiell unstrukturierte trans-Komplexe . . . . . . . . . . . . . . . 99

4.4 Kinetische und Thermodynamische Aufgliederung . . . . . . . . . 102

4.5 Modell der SNARE-Komplexbildung . . . . . . . . . . . . 109

$\begin{array}{lll}5 & \text { Zusammenfassung } & 111\end{array}$

$\begin{array}{llr}6 & \text { Summary } & 113\end{array}$

$\begin{array}{lr}\text { Literaturverzeichnis } & 114\end{array}$

$\begin{array}{lr}\text { Publikationsliste } & 132\end{array}$ 


\section{Abbildungsverzeichnis}

1.1 Eukaryotische Zelle . . . . . . . . . . . . . . . . . . . . . . . 11

1.2 Domänen und Struktur des SNARE-Komplexes . . . . . . . . . 15

1.3 Die Zuordnung von SNARE-Proteinen zu bestimmten Wegen des Membranverkehrs in Säugerzellen . . . . . . . . . . . . . 17

1.4 Der SNARE-Zyklus . . . . . . . . . . . . . . . . . . . . . . . . . . 19

1.5 SNARE-Komplexbildungsschritte . . . . . . . . . . . . . 22

1.6 Fusionsmaschinerie der viralen und mitochondrialen Membranfusion 28

3.1 Schematische Darstellung des SNARE-Komplexes . . . . . . . 45

3.2 Die SNARE-Komplexbildung ist mit N-terminalen SNAP-25 Mutanten beeinträchtigt. . . . . . . . . . . . . . . . . . 48

3.3 Die Q-SNARE-Komplexbildung ist mit zentralen SNAP-25 Mutanten teilweise beeinträchtigt. . . . . . . . . . . . . . . 50

3.4 Die Stabilität der Komplexe mit N-terminalen und zentralen SNAP-25-Mutanten ist reduziert. . . . . . . . . . . . . . 52

3.5 Ein stabilisierter Akzeptorkomplex erlaubt eine schnelle Synaptobrevinbindung. . . . . . . . . . . . . . . . . 53

3.6 Bestimmung der Bindungsgeschwindigkeit von Synaptobrevin an den Akzeptor-Komplex. . . . . . . . . . . . . . . . 55

3.7 Der Akzeptor-Komplex bietet eine hochaffine Bindungstelle für Synaptobrevin an. . . . . . . . . . . . . . 57

3.8 Charakterisierung der Synaptobrevinbindungsstelle des $\Delta \mathrm{N}$ Komplexes . . . . . . . . . . . . . . . . . . . . . . . . . . 59

3.9 Der N-Terminus von Synaptobrevin ist nicht essenziell für die Bindung an den Akzeptorkomplex. . . . . . . . . . . . . . . . . 61 
3.10 Bindung von C-terminal verkürzten Synaptobrevinen an den $\Delta \mathrm{N}$ Komplex. . . . . . . . . . . . . . . . . 66

3.11 Synaptobrevin 1-52 kann an den $\Delta$ N-Komplex binden. . . . . . . 67

3.12 Bindung von homologen R-SNARE-Proteinen an den $\Delta$ N-Komplex 69

3.13 Konservierung der R-SNARE-Motive . . . . . . . . . . . . . . . . 72

3.14 Mutationen der Synaptobrevinregion Layer -4 bis -2 inhibieren die Bindung an den Akzeptorkomplex . . . . . . . . . . . . . 74

3.15 Bestimmung der Bindungsgeschwindigkeit von Synaptobrevin (-3) an den Akzeptor-Komplex. . . . . . . . . . . . . . . . 75

3.16 Bindungskinetik und Stabilität der SNARE-Komplexe mit Cterminalen SNAP-25-Mutanten. . . . . . . . . . . . 77

3.17 Die Mutation im SNAP-25 Layer +5 zeigt einen dramatischen Phänotyp in vivo. . . . . . . . . . . . . . . . . . . . . . . . 79

3.18 Limitierte Proteolyse des SNAP-25 +5-Komplexes. . . . . . . . . 81

3.19 Thermodynamik der C-terminalen Komplexfaltung . . . . . . . . 83

4.1 Thermodynamische Übersicht der SNARE-Komplexbildung . . . . 105

4.2 Kinetik und Energieprofil der SNARE-Komplexbildung . . . . . . 108

4.3 Zwischenschritte der SNARE-Komplexbildung . . . . . . . . . 110 


\section{Tabellenverzeichnis}

2.1 Verwendete DNA-Konstrukte . . . . . . . . . . . . . . 34

3.1 Zusammenfassung der ermittelten Bindungsgeschwindigkeiten . . 62

3.2 Zusammenfassung aller ITC-Experimente . . . . . . . . . . . . 64 


\section{Einleitung}

\subsection{Intrazellulärer Membrantransport}

Die eukaryotische Zelle wird durch Membranen sowohl nach außen hin begrenzt, als auch im Inneren in bestimmte Bereiche unterteilt. Die Ausbildung dieser Bereiche, so genannte Kompartimente, bringt der eukaryotischen Zelle viele evolutionäre Vorteile. Die Membranen bilden z. B. eine Barriere zwischen den verschiedenen Organellen und dem Zellplasma und ermöglichen so, dass gleichzeitig unterschiedliche chemische Prozesse innerhalb einer Zelle stattfinden können. Zusätzlich können innerhalb der Kompartimente ideale Bedingungen für verschiedene enzymatische Reaktionen geschaffen werden. Des Weiteren können auf Organellmembranen genau die Proteine konzentriert werden, welche für die Funktion der Organelle wichtig sind.

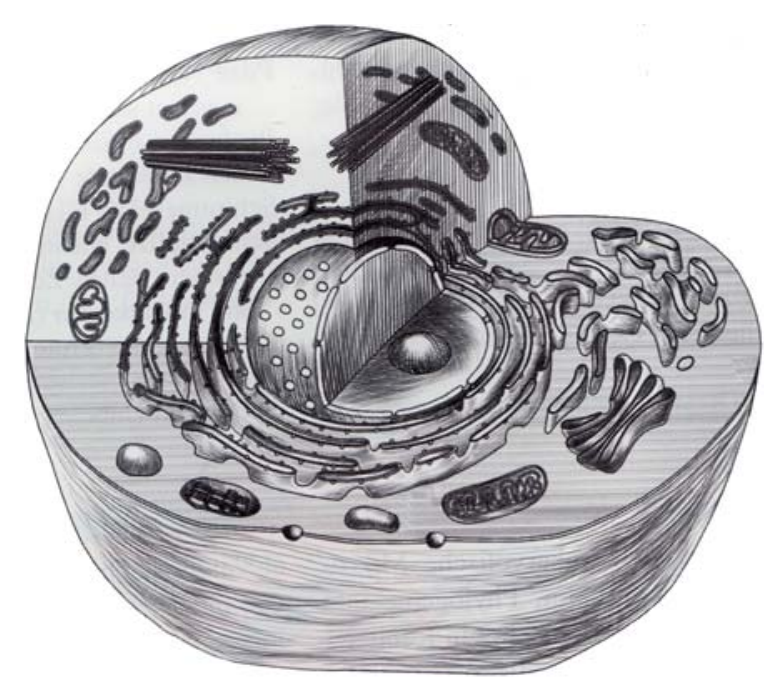

Abbildung 1.1: Eukaryotische Zelle. Schematische Ansicht einer aufgeschnittenen eukaryotischen Zelle. Abbildung wurde entnommen aus [89]. 
Einer der wichtigen Prozesse in einer eukaryotischen Zelle ist der Austausch von Makromolekülen zwischen den Kompartimenten, welcher als intrazellulärer Membrantransport bezeichnet wird. Der gerichtete Transport zwischen Kompartimenten oder von einem Kompartiment zur Plasmamembran (Sekretion) wird durch Vesikel vermittelt, welche zunächst von der Donororganelle abgeschnürt werden und anschließend mit der Akzeptormembran fusionieren. Diese Prozesse, wie das Abschnüren des Vesikels, die Erkennung der Akzeptormembran und darauffolgende Fusion mit der Akzeptormembran, werden von konservierten Proteinmaschinerien ausgeführt. Dabei wird die Fusion des Vesikels mit der Akzeptormembran in den unterschiedlichen Membrantransportschritten durch die Bildung eines Komplexes aus einem Satz bestimmter SNARE-Proteine (SNAPRezeptoren) vermittelt.

Einer der in der Forschung oft betrachteten Membrantransportschritte ist die Neurotransmission, welche durch die Sekretion von Neurotransmittern in den synaptischen Spalt gekennzeichnet ist. Bei diesem Prozess fusionieren synaptische Vesikel mit der Plasmamembran der Synapse und setzen dabei Neurotransmitter frei. Diese wiederum binden an Rezeptoren der postsynaptischen Membran. Die so genannte Neuroexozytose wird ebenfalls von SNARE-Proteinen vermittelt.

\section{$1.2 \quad$ SNARE-Hypothese}

Der Entdeckung der neuronalen SNARE-Proteine gingen Studien zu intrazellulären Transportmechanismen des Golgi-Apparates voraus. Rothman und Kollegen gelang es erstmals den intrazellulären Transport, insbesondere den Membrantransport des Golgi-Apparates, in einem zellfreien System zu rekonstituieren $[43,4]$. Dabei wurde beobachtet, dass der Transport ATP-abhängig ist und durch N-Ethylmaleimid (NEM) blockiert werden kann [48]. Ein Jahr später wurde der NEM-sensitive Faktor NSF isoliert [8]. NSF ist eine lösliche ATPase mit einem Molekulargewicht von $76 \mathrm{kDa}$. Des Weiteren wurden drei lösliche Proteine identifiziert, $\alpha-, \beta$ - und $\gamma$-SNAP (soluble NSF attachment protein), welche mit NSF interagieren $[21,22,146]$. Ursprünglich ging man davon aus, dass NSF die Membranfusion katalysiert und suchte nach den membranständigen Rezeptoren für NSF. Wie ich später genauer erläutern werde (1.4), musste diese Idee 
aufgegeben werden, da erkannt wurde, dass NSF und die $\alpha$-, $\beta$ - und $\gamma$-SNAPProteine die ATP-abhängige Dissoziation der eigentlichen Fusionsmaschinerie katalysieren. Bei Bindungsversuchen mit NSF und $\alpha$-, $\beta$ - und $\gamma$-SNAP-Proteinen wurde aus Rattenhirnhomogenat ein Komplex isoliert, welcher einen Sedimentationskoeffizienten von $20 \mathrm{~S}$ auswies [126]. Dieser 20S-Komplex enthielt neben NSF und SNAPs noch die drei Membranproteine Syntaxin 1a, Synaptobrevin 2 und SNAP-25 (synaptosome-associated protein of $25 \mathrm{kDa}$ ), welche als SNAPRezeptoren (SNARE) bezeichnet wurden. Sie wurden entsprechend ihres Vorkommens an Vesikel (vesicle)- oder Zielmembran (target) in die Gruppen v- bzw. t-SNARE-Proteine eingeteilt [126].

Die bedeutende Rolle der SNARE-Proteine für die Neuroexozytose wurde durch zeitgleiche Studien verdeutlicht, welche zeigten, dass die clostridialen Neurotoxine, wie z.B. Botulinumtoxine und Tetanustoxin, die synaptischen SNARE-Proteine angreifen. Die genannten Toxine sind spezifische Proteasen, welche die SNARE-Proteine Syntaxin, Synaptobrevin und SNAP-25 selektiv spalten $[85,121,6,7]$. Dies führt zur Blockierung der Neurotransmitterausschüttung und dadurch zu den typischen Lähmungen und Muskelkrämpfen, die beim Wundstarrkrampf und Botulismus zu beobachten sind.

Anhand von Versuchen mit transgenen Tieren, in denen das Zielgen so verändert wurde, dass die Expression des Proteins nicht mehr erfolgt (knockout), konnte eine essentielle Bedeutung der SNARE-Proteine für die Neuroexozytose gezeigt werden. Studien mit der Fruchtfliege (Drosophila melanogaster) ergaben, dass die Abwesenheit von Syntaxin zu einer Blockierung der Embryonalentwicklung führt. In den untersuchten embryonalen Zellen fand an der neuromuskulären Endplatte keine Neurotransmission mehr statt [123]. Bei weiteren Untersuchungen wurde in Abwesenheit von Synaptobrevin in Mäusen (Mus Musculus) gezeigt, dass die spontane synaptische Vesikelfusion etwa 90 Prozent reduziert und die kalziuminduzierte Neuroexozytose sogar um mehr als 99 Prozent vermindert ist [122]. Auch die Unterdrückung der Expression von SNAP-25 in Mäusen zeigt drastische Effekte: Sie sterben ebenfalls schon als Embryonen. Elektrophysiologische Untersuchungen an Neuronen der SNAP-25-knockout-Mäuse ergaben, dass zwar die spontane Neurotransmission stattfinden kann, die aktionspotentialabhängige Neuroexozytose jedoch blockiert ist [140]. Diese Ergebnisse verdeutli- 
chen den Stellenwert von SNARE-Proteinen während der Fusion von synaptischen Vesikeln mit der Plasmamembran der Synapse.

Weitere entscheidende Experimente wurden 1998 im Labor von James Rothman durchgeführt. Es konnte gezeigt werden, dass in Membranen rekonstituierte SNARE-Proteine die Fusion von Liposomen vermitteln [142]. Dies weist darauf hin, dass SNARE-Proteine allein in der Lage sind, die Fusion zweier Membranen zu vermitteln und sie somit die minimale Fusionsmaschinerie des intrazellulären Membrantransports darstellen [142].

\subsection{Struktur des SNARE-Komplexes}

SNARE-Proteine kommen in allen eukaryotischen Zellen vor. Charakteristisch für die SNARE-Proteine ist ein meist C-terminal gelegener Bereich von 60-70 Aminosäuren, welcher als SNARE-Motiv bezeichnet wird. Das SNARE-Motiv enthält acht so genannte heptad repeats, welche typisch für coiled coil-bildende $\alpha$ Helices sind (siehe auch Abschnitt 1.8). Vier verschiedene SNARE-Motive bilden ein paralleles, langgestrecktes Vier-Helixbündel, einen SNARE-Komplex.

Die Aktivität von SNARE-Proteinen ist am besten für die neuronalen SNARE-Proteine beschrieben, welche die synaptische Neurosekretion vermitteln. Synaptobrevin 2, ein vesikuläres Protein, und die Plasmamembranproteine Syntaxin 1a und SNAP-25 bilden hierbei einen Komplex. Syntaxin und Synaptobrevin besitzen jeweils ein SNARE-Motiv, an welches sich C-terminal eine Transmembranregion (TMR) anschließt. Das Syntaxin-SNARE-Motiv wird auch als SyntaxinH3 (SyxH3) bezeichnet. Syntaxin besitzt zusätzlich eine N-terminale Domäne, die Habc-Domäne (Abb. 1.2). Das Protein Syntaxin kann in zwei verschiedenen Konformationen vorkommen, der offenen und der geschlossenen Konformation. In der geschlossenen Konformation interagiert die Habc-Domäne mit dem SNAREMotiv und bildet ein Vier-Helixbündel aus [39,27]. Dabei ist in der geschlossenen Konformation das SNARE-Motiv nicht für die SNARE-Komplexformierung zugänglich. Im Gegensatz zu Syntaxin und Synaptobrevin besitzt SNAP-25 zwei SNARE-Motive, welche über eine längere Linkerregion miteinander verbunden sind. Außerdem besitzt SNAP-25 keine TMR, sondern ist mittels palmitoylierten Cysteinresten im Linker mit der Membran verbunden. 


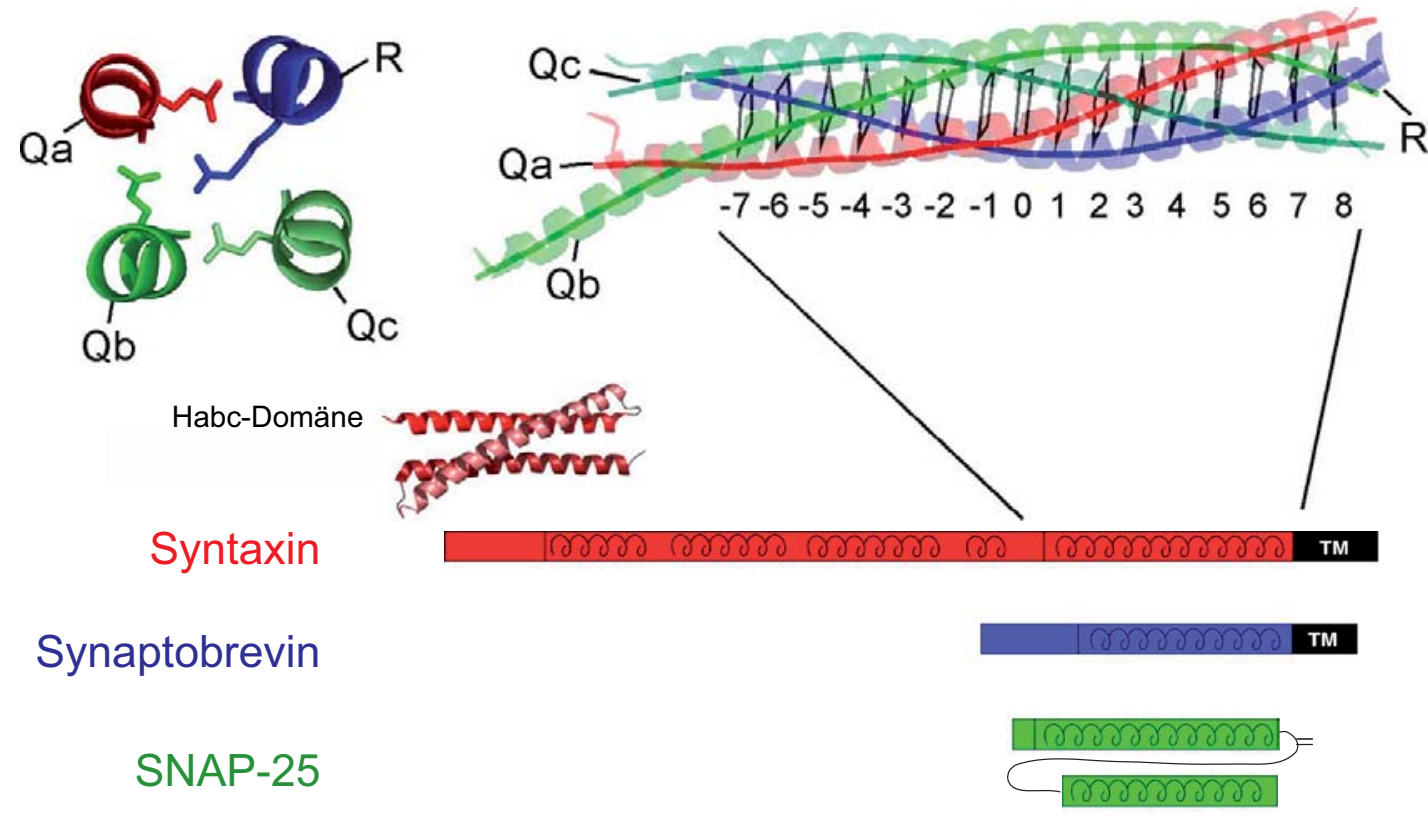

Abbildung 1.2: Domänen und Struktur des SNARE-Komplexes. Die Struktur des neuronalen SNARE-Komplexes ist oben rechts als Vier-Helixbündel dargestellt (blau, rot, grün für Synaptobrevin 2, Syntaxin 1a, and SNAP-25). Die Interaktionsebenen der hydrophoben Kontakte im Inneren des Bündels (-7 bis 8) sind gekennzeichnet. Ein Querschnitt des zentralen 0 -Layer ist links oben eingezeichnet [135]. Die Domänenstruktur der neuronalen SNAREs sind unten abgebildet. Syntaxin 1a besitzt C-terminal neben dem SNARE-Motiv eine Transmembranregion (TMR) und eine N-terminale Habc-Domäne. Auch Synaptobrevin 2 ist mit einer TMR in der Membran verankert. SNAP-25 besitzt in der Linkerregion zwischen den beiden SNARE-Motiven Cysteine, welche palmityoliert werden können (modifiziert nach [74]).

Die meisten strukturellen Untersuchungen und Interaktionsstudien wurden mit rekombinanten Proteinen ohne TMR durchgeführt, wobei festgestellt wurde, dass die einzelnen SNARE-Motive hauptsächlich ungefaltet vorliegen [36]. Wenn alle drei SNARE-Proteine miteinander interagieren, findet eine große strukturelle Umlagerung statt und die SNARE-Motive bilden ein äußerst stabiles $\alpha$-helikales Vier-Helixbündel aus [36,33,64,90]. Die Kristallstruktur des SNARE-Komplexes zeigt, dass die Proteine ein langgestrecktes coiled coil aus vier umeinander verdrehten und parallel angeordneten $\alpha$-Helices bilden (Abb. 1.2) [135].

Die Fusion von frühen bzw. späten Endosomen, sowie die Exozytose der Bäckerhefe (Saccharomyces cerevisiae), wird ebenfalls durch SNARE-Proteine vermittelt, welche einen SNARE-Komplexe ausbilden. Der Vergleich der Kristallstrukturen dieser Komplexe mit der des neuronalen SNARE-Komplexes ergab, 
dass sie fast deckungsgleich sind $[1,155,134]$. Dies legt eine starke Konservierung des SNARE-Helixbündels und der einzelnen SNARE-Motive nahe.

Im hydrophoben Zentrum des langgestreckten Helixbündels befinden sich 16 senkrecht zur Längsachse angeordnete Interaktionsebenen der Aminosäureketten, die so genannten layer, die vom N-zum C-Terminus verlaufen und von -7 bis 8 nummeriert sind. Eine Ausnahme bildet der zentrale, so genannte 0Layer, in dem die hydrophilen Aminosäuren Glutamin und Arginin interagieren. In diesem layer steuert Syntaxin ein Glutamin bei (Qa), zwei weitere Glutamine werden von den beiden Helices des SNAP-25 (Qbc) und das Arginin von Synaptobrevin $(\mathrm{R})$ bereitgestellt. Diese Aminosäuren sind hoch konserviert, weswegen eine strukturell begründete Reklassifizierung der SNARE-Proteine in Q- und RSNARE-Proteine erfolgte [37,144]. Man geht davon aus, dass SNARE-Komplexe immer aus diesen vier verschiedenen SNARE-Motiv-Typen (Qa, Qb, Qc und R) zusammengesetzt sind [37].

Die in der Zelle vorkommenden verschiedenen Membrantransportschritte werden jeweils von einem bestimmten Satz SNARE-Proteinen vermittelt. Eine Übersicht dieser Sätze, welche einen Komplex innerhalb einer Säugetierzelle bilden, ist in Abbildung 1.3 illustriert. Wie durch die hohe strukturelle Konservierung bereits zu vermuten, konnte gezeigt werden, dass SNARE-Proteine in vitro promiskuitiv miteinander interagieren können, d. h. dass sie Aufgaben von benachbarten SNARE-Proteinen übernehmen können [31,149]. Es ist außerdem bekannt, dass SNARE-Proteine während des Membrantransports auch in Membranen von Kompartimenten vorkommen, in denen sie ihre Funktion nicht erfüllen [2]. Jedoch konnte bisher nicht im Detail geklärt werden, wie die Spezifität der SNARE-Interaktion kontrolliert bzw. organisiert wird. Es gibt verschiedene Hinweise, wie die Spezifität gesichert werden könnte. So besitzen manche SNAREProteine neben dem SNARE-Motiv N-terminale Domänen, welche regulatorische Aufgaben übernehmen könnten. Eine weitere Möglichkeit ist, dass die Spezifität der SNARE-Interaktionen von regulatorischen Proteinen vermittelt wird. Des Weiteren wurde vorgeschlagen, dass die Spezifität der SNARE-Interaktion durch das SNARE-Motiv selbst definiert sein könnte [104,106]. Dies wird jedoch sehr kontrovers diskutiert, da in vitro nur bedingt eine Spezifität der Interaktionen beobachtet werden konnte $[11,155]$. So können z.B. in vitro alle sekretorischen 
SNARE-Proteine miteinander Komplexe bilden [149].

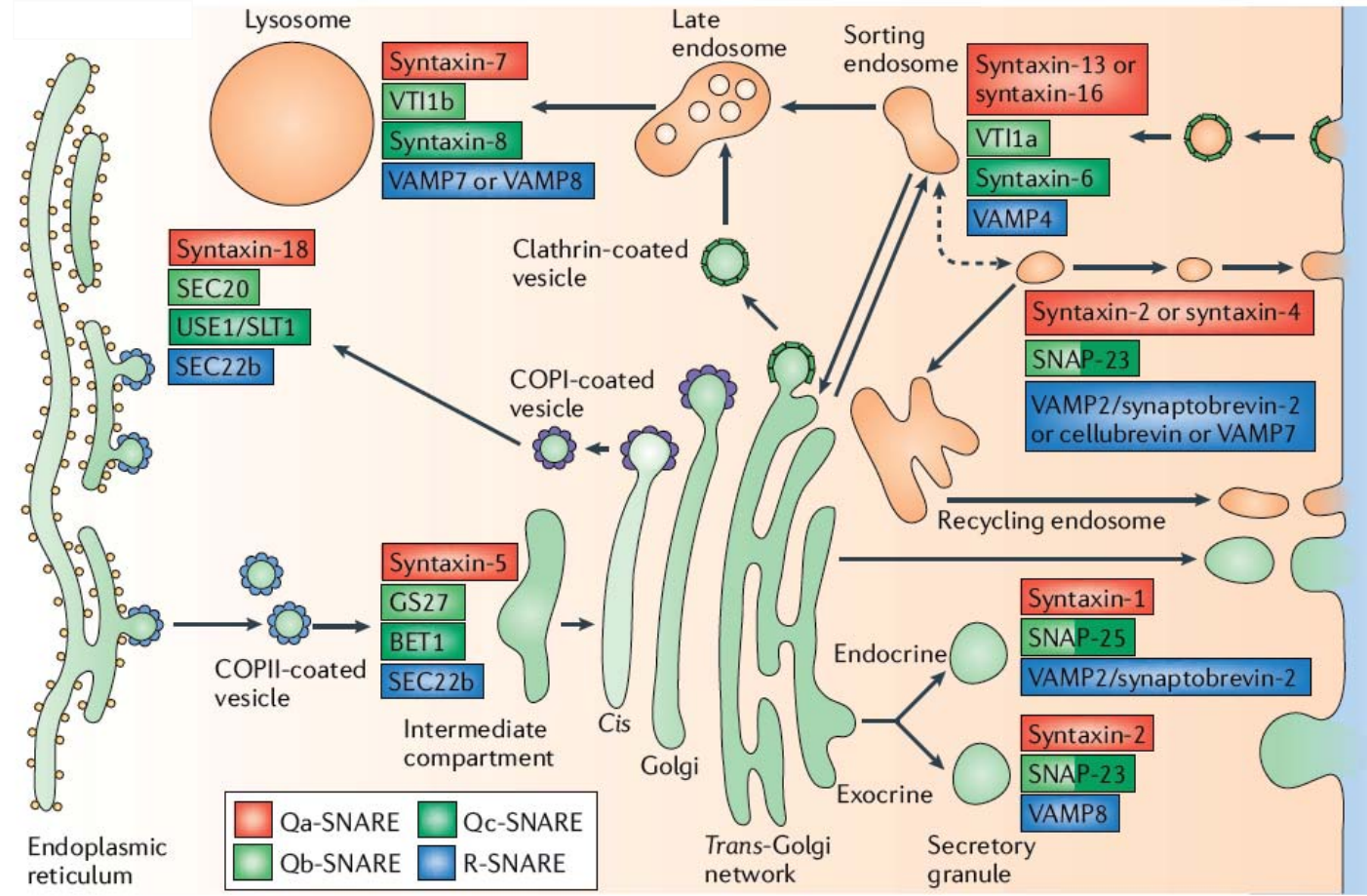

Abbildung 1.3: Die Zuordnung von SNARE-Proteinen zu bestimmten Wegen des Membranverkehrs in Säugerzellen. Die anterograde Transportroute beginnt am ER und führt mit COPII-umhüllten Vesikeln zum Golgi-Apparat. Vom TGN ausgehend kommt es zur Bildung von sekretorischen Vesikeln, welche mit der Plasmamembran fusionieren. Der retrograde Transportweg beginnt mit der Endozytose an der Plasmamembran und führt über die endosomalen Kompartimente zurück zum Golgi-Apparat oder zu den Lysosomen. Sortierende Endosomen können auch homotypisch miteinander fusionieren. Für einige der Fusionsreaktionen konnten die beteiligten SNARE-Proteine noch nicht zweifelsfrei bestimmt werden.

ER, Endoplasmatischen Retikulum; COPI/II, coatomer protein complex-I/II; TGN, TransGolgi-Netzwerk; GS27, Golgi SNARE of $27 \mathrm{kDa}$; Use1/USE1, unconventional SNARE in the ER protein-1; VAMP, vesicle-associated membrane protein; Vti1/VTI1, Vps ten interacting1.(modifiziert nach [68]) 


\subsection{Das Zipper-Modell und der SNARE-Zyklus}

\section{Das Zipper-Modell}

Mitte der neunziger Jahre wurde davon ausgegangen, dass die SNARE-Proteine zwischen der Vesikel- und Plasmamembran einen antiparallelen Komplex bilden, an den die ATPase NSF und der Cofaktor $\alpha$-SNAP binden. Es wurde postuliert, dass aufgrund der ATP-abhängigen Dissoziation des SNARE-Komplexes die Membranfusion durch NSF initiiert wird.

Einige Jahre später konnte diese These jedoch widerlegt werden und es wurde erkannt, dass nicht die ATPase NSF direkt die Fusion vermittelt, sondern SNARE-Proteine die entscheidende Rolle bei der Fusion spielen. Hinweise auf eine parallele Anordnung der Helices im neuronalen SNARE-Komplex, welche schließlich durch die Kristallstruktur bestätigt werden konnten, machten es nötig, das ursprüngliche Modell zu revidieren [84,59,135].

Die Transmembrandomänen von Syntaxin 1a und Synaptobrevin 2 sind neben dem SNARE-Motiv am C-Terminus lokalisiert und in beiden Membranen verankert. Man geht davon aus, dass die SNAREs mit den N-Termini der SNARE-Motive zuerst miteinander interagieren und die sukzessive Faltung der Proteine in Richtung C-Terminus fortgesetzt wird. Dieser Prozess könnte zu einer Annäherung der Membranen führen. Da man sich dies als ein reißverschlussartiges Aufwinden vorstellt, wurde diese Theorie als Zipper-Modell bezeichnet $[59,84,58]$.

Obwohl bisher nur Indizien darauf hinweisen, konnte sich dieses Modell allgemein durchsetzen $[40,148,20]$. Es werden aber weiterhin andere Modelle diskutiert, wie z. B. die SNARE-Komplexformierung vom C-Terminus in Richtung N-Terminus. Darauf weisen Studien hin, in denen Synaptobrevin, durch die C-terminale Interaktion mit der Membran, daran gehindert wird, SNAREKomplexe auszubilden [65, 78, 79].

\section{Der SNARE-Zyklus}

SNARE-Proteine liegen in der Zelle in verschiedenen Zuständen vor. Nach der Fusion der Membranen bilden sie trans-Komplexe zwischen den Membranen und 


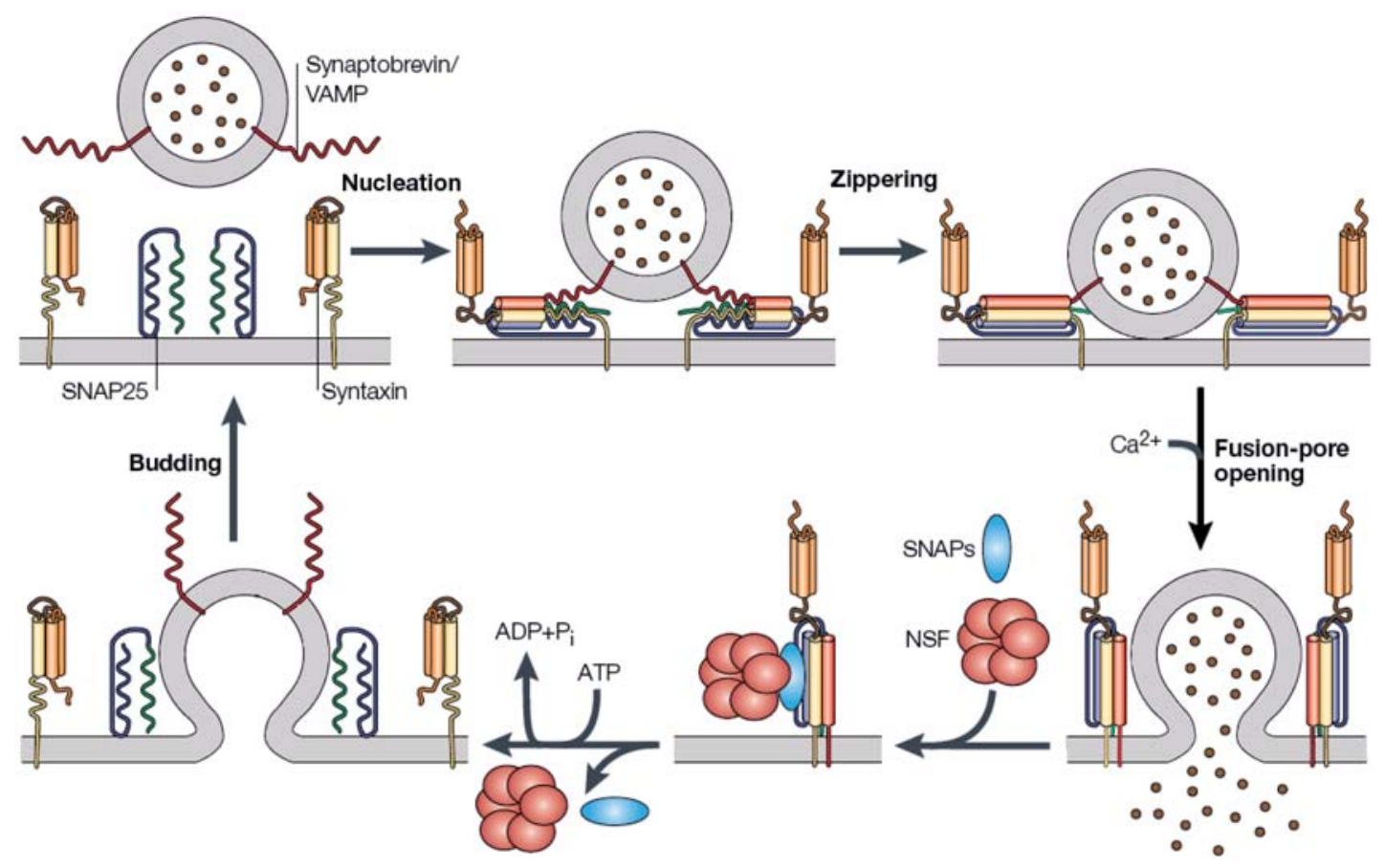

Abbildung 1.4: Der SNARE-Zyklus. Q-SNARE-Proteine sind auf der Akzeptormembran und R-SNARE-Proteine auf der Vesikelmembran lokalisiert. Die Q-SNARE-Motive formieren einen Akzeptorkomplex. Der Akzeptorkomplex und das R-SNARE interagieren am N-Terminus der Motive miteinander und die Formierung des trans-SNARE-Komplexes erfolgt durch ein reißverschlussartiges Aufwinden (zippering), bei dem ein Helixbündel ausgebildet wird. Dies bewirkt die Annäherung der Membranen, worauf die Öffnung der Fusionspore folgt. In der regulierten Exozytose wird dieser Prozess von verschiedenen Proteine wie Complexin und dem Kalziumsensor Synaptotagmin kontrolliert. Die entstandenen cis-Komplexe, welche sich nun in derselben Membran befinden, werden von der ATPase NSF und dem Cofaktor $\alpha$-SNAP unter Verbrauch von ATP in die Einzelproteine dissoziiert. Die Q- und R-SNAREs werden in die jeweilige Bestimmungsmembran sortiert und können erneut in den Membranfusionszyklus eintreten. (Abb. modifiziert nach [113])

liegen nach der Membranfusion als cis-Komplex in einer Membran vor. Abschließend werden die cis-Komplexe dissoziiert. Diese Vorgänge sind in der Abbildung 1.4 in Form eines Zyklus dargestellt.

Im Allgemeinen wird davon ausgegangen, dass Synaptobrevin sich auf der Vesikelmembran befindet, wogegen SNAP-25 und Syntaxin auf der Akzeptormembran lokalisiert sind. Die drei Q-SNARE-Motive (Qabc) von SNAP-25 und Syntaxin bilden zusammen einen Akzeptorkomplex aus. Dieser Prozess wird wahrscheinlich durch Sec1p/Munc18-Proteine reguliert [137]. Am Akzeptorkomplex kann es dann zu der N-terminalen Bindung von Synaptobrevin kommen 
und die Formierung des trans-SNARE-Komplexes beginnt. Die vier SNAREMotive bilden durch reißverschlussartiges Aufwinden bis zum C-Terminus ein Helixbündel aus. Dies hat zur Folge, dass sich die Membranen annähern und die Abstoßungskräfte der Membranen überwunden werden und die Öffnung der Fusionspore initiiert wird. In der regulierten Exozytose wird die Komplexbildung von verschiedenen Proteinen wie z.B. Complexin und dem Kalziumsensor Synaptotagmin kontrolliert [45,111]. Nach der Fusion liegen die Komplexe in einer Membran vor. Diese cis-Komplexe sind so stabil, dass sie von der ATPase NSF und deren Co-Faktor $\alpha$-SNAP unter Verbrauch von ATP in die Einzelproteine dissoziiert werden müssen. Anschließend können die SNARE-Proteine wieder in den Membranfusionszyklus eintreten.

\subsection{SNARE-Komplexbildungsschritte}

In den bisherigen Ausführungen habe ich erwähnt, dass die SNARE-Proteine einen äußerst stabilen Komplex bilden. Wie aber verläuft die Ausbildung dieses Komplexes? Die Beantwortung dieser Frage ist wichtig, um die Abläufe der SNARE-vermittelten Membranfusion zu verstehen.

\section{N-terminale Initiationsreaktion}

In den vergangenen Jahren konnten wichtige Einblicke in den Prozess der SNARE-Komplexbildung gewonnen werden. Wie schon erläutert, ergaben strukturelle Studien der löslichen Bestandteile von SNARE-Proteinen, dass die vier Motive in Lösung weitgehend unstrukturiert vorliegen. Werden alle vier Proteine zusammengegeben, kommt es zu großen strukturellen Umlagerungen, wobei der Anteil an $\alpha$-helikaler Struktur zunimmt [36]. Die Lösung der Struktur des formierten SNARE-Komplexes Ende der neunziger Jahre trug entscheidend zu dem grundlegenden Verständnis der Funktion der SNARE-Proteine bei. Diese Struktur zeigt ein paralleles Vier-Helixbündel [135]. Des Weiteren konnte gezeigt werden, dass Syntaxin 1a und SNAP-25 allein einen $\alpha$-helikalen Komplex bilden können. Dieser Komplex wird auch als binärer $\mathrm{Syx}_{2} / \mathrm{SN} 25_{1}$-Komplex bezeichnet und besitzt anstelle eines Synaptobrevins ein weiteres Syntaxin 1a [33]. 
Da Syntaxin und SNAP-25 beide in der Plasmamembran lokalisiert sind, wurde vermutet, dass sie eine Art Akzeptorkomplex bilden, um die schnelle Bildung des SNARE-Komplexes zu vereinfachen. Außerdem deutete eine Studie mit dem SNARE-Komplex aus der Bäckerhefe im Jahre 1999 darauf hin, dass ein Komplex aus Sso1p und Sec9p (Syntaxin 1a oder SNAP-25-Homolog) existiert und dieser als Bindungsstelle für Snc1/2p (ein Synaptobrevin-Homolog) dienen könnte [40]. Weiterführende Denaturierungsexperimente ergaben, dass sich der neuronale SNARE-Komplex bei unterschiedlichen Bedingungen entfaltet bzw. zurückfaltet. Diese Hysterese deutet ebenfalls auf ein Intermediat während der Komplexbildung hin [32]. Wie bereits oben erwähnt, beschreibt das Zipper-Modell die Komplexformierung als eine N - zu C-terminale Reaktion [58]. Dies erscheint aus topologischen Gründen, die Transmembranregionen befinden sich am C-Terminus, plausibel. In der Arbeit von Fiebig und Kollegen wurde anhand von NMRSpektroskopie gezeigt, dass der N-Terminus des Sso1p/Sec9p-Komplexes stärker gepackt ist, wogegen der C-Terminus eher unstrukturiert vorzuliegen scheint [40]. Weitere Experimente zeigten, dass die Störung der N-terminalen Interaktion die SNARE-Komplexbildung inhibieren. So können monoklonale Antikörper, welche an den N-Terminus von SNAP-25 binden, die SNARE-Komplexformierung blockieren [148]. Des Weiteren ist die SNARE-Komplexbildung sowohl mit Nterminal verkürztem SyxH3 als auch N-terminal verkürztem SNAP-25 inhibiert [35]. Interessanterwise haben die verkürzten C-Termini dieser Proteine kaum einen Einfluss auf die Komplexformierung [35]. Während die N-Termini von SyxH3 und SNAP-25 zwingend vorhanden sein müssen, haben weder N-terminale noch C-terminale Verkürzungen von Synaptobrevin einen Effekt auf die Komplexbildung [35].

Zusammenfassend deutet es darauf hin, dass die N-Termini der SNAREMotive von Syntaxin und SNAP-25 wichtig für die Bildung des SNAREKomplexes sind. Die N-terminalen Regionen von Syntaxin (Qa) und SNAP-25 (Qbc) bilden wahrscheinlich einen kurzlebigen $\mathrm{Syx}_{1} / \mathrm{SN} 25_{1}$-Komplex aus, welcher, im Gegensatz zum binären $\mathrm{Syx}_{2} / \mathrm{SN} 25_{1}$-Komplex, kein zweites Syntaxin enthält. Dieser Qabc-Komplex stellt ein Intermediat dar (Abb. 1.5A) und dient als eigentliche Bindungsstelle für Synaptobrevin. Die Bildung dieses Akzeptorkomplexes in Lösung ist eine sehr langsame Reaktion $\left(6000 \mathrm{M}^{-1} \mathrm{~s}^{-1}\right)$ und ist 
der geschwindigkeitsbestimmende Schritt der SNARE-Komplexbildung [35]. Da der Akzeptorkomplex in vitro reaktiv und damit instabil ist, kann anstelle des Synaptobrevins ein zweites Syntaxin an ihn binden. Man geht aber davon aus, dass diese binäre $\mathrm{Syx}_{2} / \mathrm{SN} 25_{1}$-Komplexbildung eine Art Sackgasse (off-pathway) darstellt und in vivo wahrscheinlich nicht vorkommt (Abb. 1.5B).

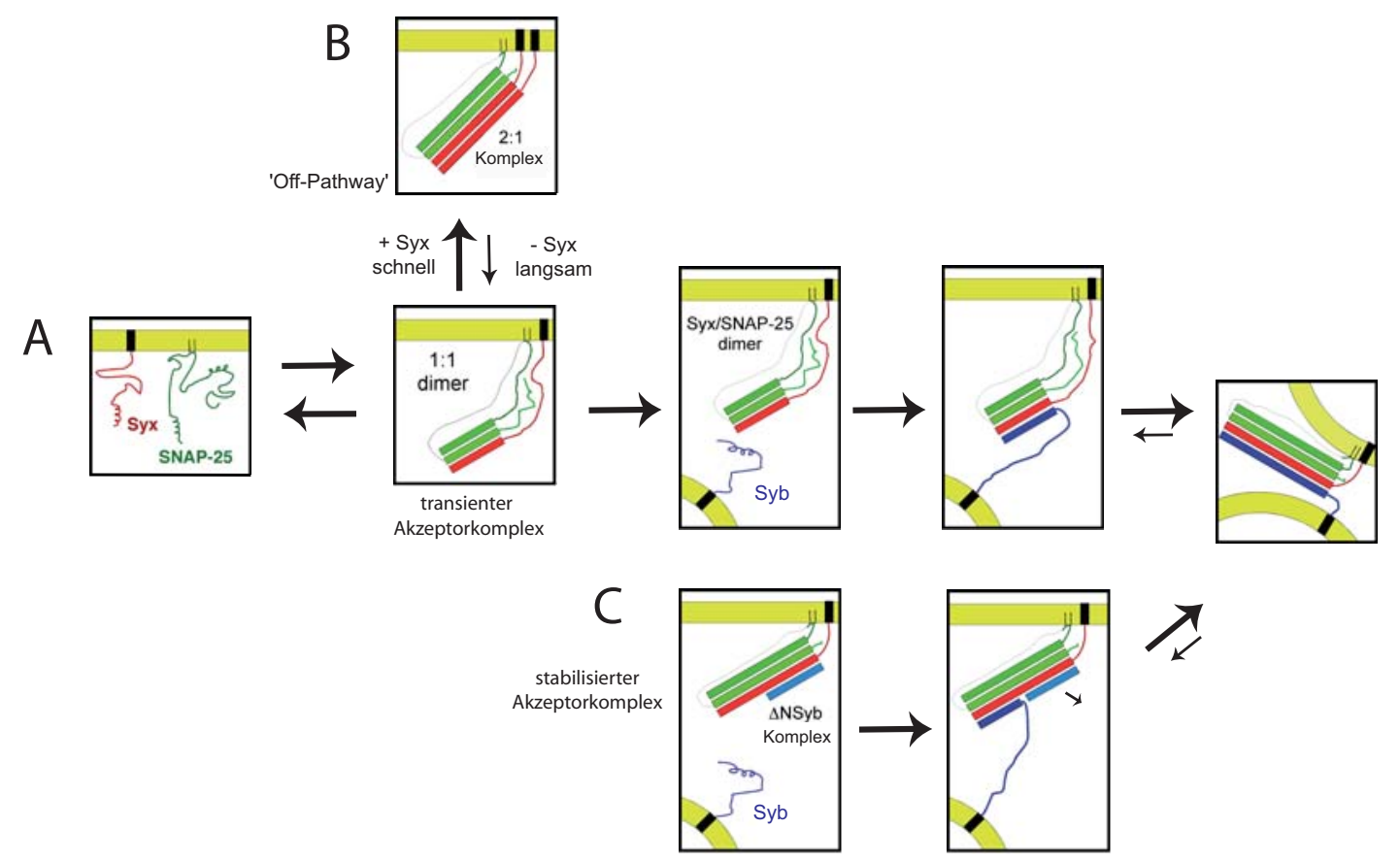

Abbildung 1.5: SNARE-Komplexbildungsschritte. (A) Syntaxin und SNAP-25 liegen in der Plasmamembran hauptsächlich unstrukturiert vor. Syntaxin ist hier ohne die Nterminale Habc-Domäne dargestellt. Beide Proteine interagieren am N-Terminus miteinander und bilden einen transientes $\mathrm{Syx}_{1} / \mathrm{SN}_{2} 5_{1}$-Dimer, welches als Akzeptorkomplex für das ebenfalls unstrukturierte vesikuläre Synaptobrevin fungiert. Dies führt zum N- zu C-terminalen reißverschlussartigen Aufwinden der Helices und der Ausbildung eines coiled coil-Komplexes, welcher die Entfernung der Membranen zueinander reduziert und damit wahrscheinlich die Fusion einleitet. (B) An das transiente $\mathrm{Syx}_{1} / \mathrm{SN} 25_{1}$-Dimer kann in vitro sehr schnell ein zweites Syntaxinmolekül binden, was zu einer Blockierung der Bindungstelle für Synaptobrevin führt. Erst nach langsamer Dissoziation des zweiten Syntaxins kann Synaptobrevin binden. Man geht davon aus, dass diese Reaktion ein off-pathway ist. (C) Um das transiente Intermediat in vitro zu stabilisieren und um die off-pathway-Reaktion zu vermeiden, kann ein Komplex mit einem C-terminalen Synaptobrevinpeptid verwendet werden ( $\Delta \mathrm{N}$-Komplex). An den $\Delta \mathrm{N}$-Komplex bindet Synaptobrevin sehr schnell und bildet, nach dem Verdrängen des Peptids, einen stabilen SNARE-Komplex aus [109]. Die Illustrationen wurden freundlicherweise von D. Fasshauer zur Verfügung gestellt. 


\section{Synaptobrevinbindung an den Qabc-Akzeptorkomplex}

Der aus einem Syntaxin und einem SNAP-25 bestehende Qabc-Komplex liegt im Allgemeinen als Akzeptorkomplex für die Bindung von Synaptobrevin vor. Nach der Bindung des Synaptobrevins an den Akzeptorkomplex erfolgt die Strukturierung des C-Terminus. Dies bringt die Membranen in eine räumliche Nähe zueinander (Abb. 1.5A).

Aufgrund der oben beschriebenen off-pathway-Reaktion konnte die Synaptobrevinbindung bisher nicht direkt untersucht werden, da in vitro ein zweites Syntaxin die Bindungsstelle des Synaptobrevins blockiert. In dieser Konstellation ist die Synaptobrevinbindung an den Akzeptorkomplex abhängig von der Dissoziationgeschwindigkeit des zweiten Syntaxins. Während der Anfertigung dieser Arbeit konnte durch Mitarbeiter unserer Abteilung gezeigt werden, dass das transiente Qabc-Intermediat durch ein C-terminales Synaptobrevinpeptid stabilisiert werden kann [109]. Dieser Komplex wird als $\Delta$ N-Komplex bezeichnet (Abb. $1.5 \mathrm{C})$.

Im $\Delta$ N-Komplex steht die für die Synaptobrevinbindung wichtige, Nterminal liegende Bindungstelle frei zur Verfügung. Gleichzeitig wird die Formierung des $\mathrm{Syx}_{2} / \mathrm{SN} 25_{1}$-Komplexes verhindert, da sich die Bindungstelle für das zweite Syntaxin eher im C-terminalen Bereich des Intermediats befindet. Diese künstlich erzeugte Konstellation erlaubt nun die direkte kinetische Untersuchung der Synaptobrevinbindung [109] (Abb. 1.5C). Bereits 2002 wurde eine Beschleunigung der SNARE-vermittelten Liposomenfusion mittels einem C-terminalen Synaptobrevinpeptid beobachtet. Dies wurde jedoch damit interpretiert, dass das Peptid durch die Interaktion mit einem partiell gebildeten SNARE-Komplexes mit der N-terminalen Habc-Domäne des Syntaxins kompetiert [94]. Für diese Interpretation wurden aber keine stichhaltigen Beweise vorgelegt.

\section{Partiell unstrukturierte SNARE-Komplexe}

Nachdem Synaptobrevin an den N-Terminus des Qabc-Akzeptorkomplexes gebunden hat, erfolgt das reißverschlussartige Aufwinden des übrigen Komplexes bis zum C-terminalen Ende der SNARE-Motive, d.h. in Richtung der Transmembranregionen (Abb. 1.5A). Bisher konnte noch nicht im Detail geklärt werden, 
ob dies in einem Schritt passiert oder ob es mehrere Reaktionsschritte während der coiled coil-Bildung gibt. Ein C-terminal unvollständig strukturiertes VierHelixbündel könnte ein weiteres Intermediat der SNARE-Komplexbildung darstellen. Die einzelnen Reaktionsschritte des C-terminalen Aufwindens der Helices könnten dabei möglicherweise durch interagierende Proteine reguliert werden. Eine solche Aufgabe wurde z.B. für die Proteine Synaptotagmin und Complexin vorgeschlagen $[136,47,120]$. Auf der anderen Seite könnten auch intrinsische Eigenschaften der SNARE-Motive die verschiedenen Reaktionsschritte während der Strukturierung steuern. Es wäre möglich, dass ein Gleichgewicht zwischen den Abstoßungskräften beider Membranen und der während der Komplexformierung freigesetzten Reaktionsenergie existiert. In diesem Fall wäre ein zusätzlicher regulatorischer Schritt notwendig, um die letzte Energiehürde vor der Membranfusion zu überwinden.

\section{Energiefreisetzung während der SNARE-Komplexbildung}

Der Übergang der SNARE-Proteine von der unstrukturierten zur strukturierten Konformation ist wahrscheinlich mit einer Energiefreisetzung verbunden [36]. Der stabile SNARE-Komplex könnte ein Energieminimum darstellen, aus der die Proteine nur durch NSF und unter Energieverbrauch befreit werden können. Der Übergang in dieses Minimum könnte die mechanische Antriebskraft freisetzen, die nötig ist, um zwei Membranen zu fusionieren. Dies konnte bisher jedoch nicht bestätigt werden. Da es eine Hysterese zwischen Faltung und Entfaltung des Komplexes gibt, war man bislang nicht in der Lage die freie Energie der SNARE-Komplexbildung direkt zu messen. Im Übrigen ist nicht bekannt, wieviel Energie zur Fusion von einem Vesikel mit der Plasmamembran benötigt wird und demnach konnte bisher auch nicht bestimmt werden, wieviele SNARE-Komplexe an der Fusion eines Vesikels beteiligt sein müssen. Pro Fusion eines Vesikels mit der Plasmamembran nimmt man eine Zahl von drei bis 15 beteiligten SNAREKomplexen an (Zusammenfassung in [96]). 


\subsection{Regulierte Membranfusion in Neuronen}

Um die Neuroexozytose schnell und effizient ablaufen lassen zu können, existieren verschiedene regulierende Faktoren, welche direkt mit SNARE-Proteinen interagieren können. Einige der wichtigsten, bekannten Proteine, welche bei der synaptischen Transmission eine Rolle spielen, möchte ich hier kurz vorstellen:

$\mathrm{Zu}$ den SNARE-regulierenden Proteinen gehören die Sec1p/Munc18 (SM)Proteine, von denen sieben Homologe in Vertebraten und vier in der Bäckerhefe bekannt sind. Munc18a bildet einen Komplex mit der geschlossenen Konformation von Syntaxin 1a [27,95]. Wie bereits erläutert, ist das SNARE-Motiv in der geschlossenen Konformation von Syntaxin nicht zugänglich und damit die Interaktion mit den SNARE-Partnern blockiert. Diese Ergebnisse deuten auf eine negativ regulierende Aufgabe des Proteins hin. Allerdings zeigen knockoutStudien, dass Munc18 essentiell für eine schnelle Neuroexozytose ist, also postiv regulierend wirkt [139]. Aufgrund dieser widersprüchlichen Befunde ist die genaue Aufgabe der SM-Proteine bisher noch nicht bekannt.

Ein weiteres regulierendes Protein ist Tomosyn, welches löslich ist und ein C-terminales R-SNARE-Motiv, jedoch keine Transmembranregion besitzt. Das SNARE-Motiv kann einen Komplex mit Syntaxin und SNAP-25 bilden [61]. Die Kristallstruktur dieses Komplexes zeigt eine strukturelle Ähnlichkeit mit dem neuronalen SNARE-Komplex [108]. Man geht davon aus, dass Tomosyn eine Platzhalterfunktion für Synaptobrevin übernehmen könnte oder die Neuroexozytose durch die Bildung von nicht fusogenen SNARE-Komplexen reguliert.

Ein drittes wichtiges Protein zur Regulation ist Synaptotagmin I, ein kalziumbindendes Protein, welches in Tieren vorkommt. Die Neuroexozytose wird durch ein an der Präsynapse einlaufendes elektrisches Signal, das Aktionspotential, ausgelöst und führt zur Öffnung von Kalziumkanälen. Kalzium wird in die präsynaptische Nervenendigung freigesetzt. Die erhöhte Kalziumkonzentration induziert die Neuroexozytose. Synaptotagmin kommt auf synaptischen Vesikeln vor und besitzt zwei Domänen (C2A, C2B), welche bereits Kalziumbindungsstellen besitzen $[107,12]$. In der Gegenwart von Kalzium interagieren diese Domänen mit Phospholipiden [12]. Genetische Untersuchungen in den Organismen Fadenwurm (C. elegans) und Fruchtfliege konnten nachweisen, dass Synaptotagmin essen- 
tiell für die Neurotransmission ist $[26,86,101]$. Des Weiteren ergaben Experimente mit knockout-Mäusen, dass der Verlust von Synaptotagmin einen Einfluss auf die regulierte Neurozytose besitzt, jedoch nicht auf die kalziumunabhängige, spontane Neurotransmitterausschüttung [45]. Zusätzlich bindet Synaptotagmin kalziumabhängig sowohl an die einzelnen SNARE-Proteine Syntaxin 1a und SNAP-25, als auch an den binären Syx/SNAP-25-Komplex und den ternären SNARE-Komplex $[25,46,112,153]$.

Des Weiteren gehört Complexin zu den regulierenden Proteinen, welche mit dem SNARE-Komplex interagieren. Es ist ein kleines lösliches Protein, welches ausschließlich an den ternären SNARE-Komplex, nicht aber an die Einzelproteine bindet [103]. Eine Kristallstruktur zeigt, dass Complexin mit einer kurzen Helix an die Furche zwischen Syntaxin und Synaptobrevin bindet [9, 18]. Experimente mit Mäusen ergaben, dass der Verlust von ComplexinI/II die kalziumvermittelte Neuroexozytose behindert, jedoch nicht vollständig blockiert. Man geht davon aus, dass Complexin die Funktion von Synaptotagmin unterstützt [111].

\subsection{Andere Membranfusionsarten}

Neben der SNARE-vermittelten intrazellulären Membranfusion existieren weitere Arten der Membranfusion. Die Fusion von eukaryotischen Zellen miteinander ist ein äußerst seltener Vorgang. Dazu gehört die Fusion des Spermiums mit der Eizellmembran, um die Befruchtung durch die Verschmelzung der beiden Keimzellen zu ermöglichen [93]. Des Weiteren ist die Verschmelzung von Muskelbildungszellen (Myoblasten) essentiell zum Aufbau von Muskelgewebe [17].

Weiterhin können sich Mitochondrien in der Zelle sowohl teilen, als auch miteinander fusionieren, um die Anzahl der Mitochondrien konstant zu halten. Eine weitere Art der Membranfusion stellt die Fusion von der Virusmembran, z.B. von Hüllviren, mit der Wirtszelle dar, bei der das Erbgut des Virus in die Wirtszelle entlassen wird und dies die Infektion zur Folge hat. Diese beiden Membranfusionsarten werden in den folgenden Abschnitten ausführlicher beschrieben.

Die verschiedenen Arten der Membranfusion weisen eine strukturelle Ähnlichkeit zur SNARE-Fusionsmaschinerie auf, obwohl sie sehr wahrscheinlich aus mehreren, evolutionär unabhängigen, Entwicklungen stammen. 


\section{Virale Fusion}

Hüllviren sind von einer Membranschicht umgeben und um das genetische Material in die Wirtszelle zu schleusen, erfolgt die Membranfusion der Virus- und der Wirtszellenmembran. Um diesen wichtigen Schritt der Virusinfektion zu gewährleisten, besitzen Viren Fusionsproteine, welche auf der Membranoberfläche verankert sind. Es gibt mehrere Klassen von Fusionsproteinen, die nach ihren strukturellen Eigenschaften unterteilt werden. Fusionsproteine der Klasse I sind vorwiegend aus $\alpha$-helikalen Strukturen aufgebaut, wohingegen Fusionsproteine der Klasse II aus $\beta$-Faltblättern bestehen [127]. Kürzlich wurde eine weitere Klasse der Fusionsproteine identifiziert. Das Glycoprotein G des Vesicular Stomatitis Virus kombiniert Strukturelemente von Fusionsproteinen der Klasse I und II [114,115].

Das am besten charakterisierte virale Fusionsprotein ist Hämagglutinin, was auf dem Influenza-Virus vorkommt. Für die Funktionsweise dieses Protein wurde ein Modell postuliert, was weitgehend akzeptiert ist $[125,73,67,30]$.

Hämagglutinin gehört zur Klasse I und bildet im nativen Zustand eine homotrimere Struktur aus. Ein Monomer setzt sich wiederum aus zwei Untereinheiten, HA1 (distal) und HA2 (membranständig), zusammen, welche über Disulfidbrücken verbunden sind. Die Untereinheit HA1 stellt einen Rezeptor für verschiedene Zelloberflächenmoleküle der Wirtszelle dar. Durch die Interaktion von Rezeptor und Oberflächenmolekülen wird die Bindung des Virus an die Wirtszelle vermittelt. Für die eigentliche Fusionsreaktion ist die Untereinheit HA2 verantwortlich. Hämagglutinin wird als ein Protein synthetisiert und durch Proteolyse entstehen die beiden Untereinheiten, wobei die Untereinheit HA2 eine konservierte hydrophobe Region am N-Terminus, das Fusionspeptid besitzt, welches in einer hydrophoben Tasche verborgen ist. Dieser Zustand ist metastabil. Das bedeutet, das Protein ist stabil gefaltet, es kann jedoch durch Aktivierung eine thermodynamisch günstigere Struktur ausbilden. Die Aktivierung des Fusionsproteins erfolgt im Fall des Hämagglutinins durch den niedrigen pH des Endosoms und bewirkt die erste Konformationsänderung des Fusionsproteins. Man nimmt an, dass das N-terminale Fusionspeptid in Richtung der Wirtsmembran geschleudert wird und dort irreversibel verankert bleibt (Abb. 1.6A). Anschließend kommt es zur letzten Konformationsänderung. Dabei wird ein Sechs-Helixbündel ausgebildet, 
welches die thermodynamisch stabilste Struktur darstellt. Dadurch werden die Transmembranregionen in Richtung der verankerten Fusionspeptide gezogen und die beiden Membranen nah genug aneinander gebracht, um die Vermischung der Lipidschichten zu ermöglichen. Folglich werden die Abstoßungskräfte der Membranen durch die Ausbildung eines sehr stabilen Helixbündels zwischen den Membranen überwunden.

A

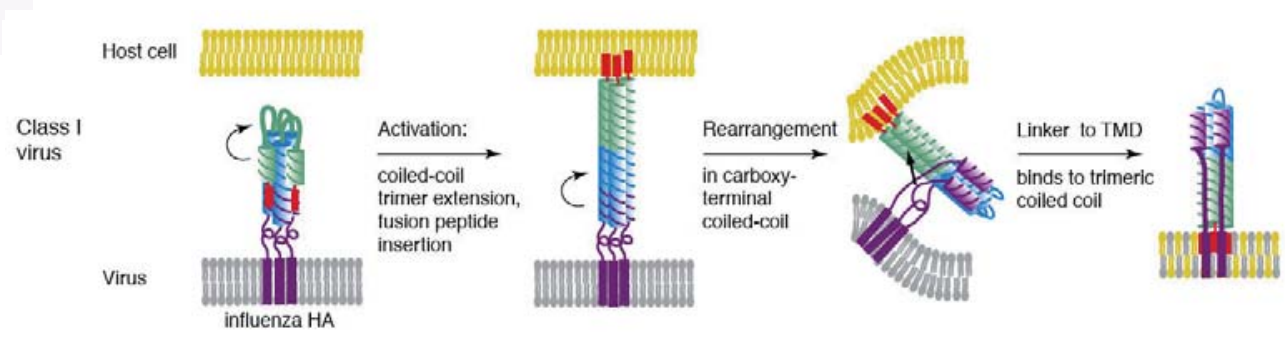

B

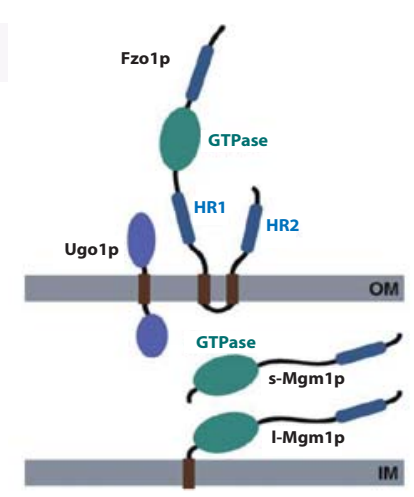

C

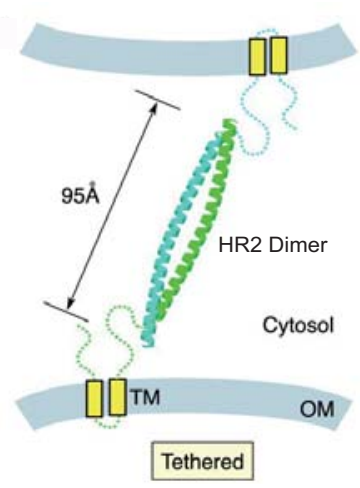

Abbildung 1.6: Fusionsmaschinerie der viralen und mitochondrialen Membranfusion. (A) Virale Fusion am Beispiel des Influenza A Hämagglutinin. Das Fusionspeptid ist rot gekennzeichnet und Konformationsänderungen sind mit Pfeilen dargestellt. Nur die HA2Domäne des Hämagglutinin ist dargestellt. (Abb. nach [127] modifiziert) (B) Der mitochondriale Fusionskomplex der Hefe. Fzolp besitzt zwei Transmembrandomänen (TMR), durch die die GTPase-Domäne (grün) und die heptad repeat-Regionen (HR; blau) nach außen gerichtet sind, um die Fusion vermitteln zu können. Die GTPasen Mgm1p befinden sich im Intermembranraum. Ugo1p interagiert mit Fzo1p und Mgm1p, und koordiniert wahrscheinlich die Fusion der inneren Membranen. (modifiziert nach [51]) (C) Modell der HR2-Domäne in einem trans-Mitofusin1Komplex in der äußeren Mitochondrienmembran (OM). Mitofusin ist das Säugerortholog von Fzo1p. Die Bildung eines antiparallen HR2-Helixbündels könnte die mitochondrialen Membranen näher zueinander bringen. GTPase- und HR1-Domäne sind nicht dargestellt. (modifiziert nach $[77])$ 


\section{Mitochondriale Fusion}

Mitochondrien können sich in der Zelle teilen oder auch mit anderen Mitochondrien fusionieren. Es wird davon ausgegangen, dass durch Teilung und Fusion die Anzahl der Mitochondrien in der Zelle reguliert wird. Genetische Studien in der Bäckerhefe identifizierten die beteiligten Proteine, jedoch wurde der Fusionsprozess bisher noch nicht umfassend aufgeklärt. Die Fusion der mitochondrialen Membranen wird wahrscheinlich durch je eine GTPase in der äußeren (Fzo1p/Mitofusin) und der inneren Membran (Mgm1p/OPA1) vermittelt, welche durch ein Adaptorprotein (Ugo1p) im Intermembranraum verbunden sind (Abb. 1.6C) (Details in $[51,15])$.

Fzo1p vermittelt wahrscheinlich die homotypische Fusion der Mitochondrien auf der äußeren Membran. Eine direkte Rolle von Fzo1p konnte zumindest beim tethering nachgewiesen werden, möglicherweise übernimmt es auch eine Aufgabe beim Fusionsschritt. Fzo1p/Mfn-Proteine werden zu den Dynaminverwandten GTPasen gezählt. Sie enthalten zwei Transmembrandomänen und C- und N-terminale Regionen liegen frei im Zytosol vor. Der N-Terminus besitzt eine GTPase-Domäne, sowie eine heptad repeat-Region (HR1). Eine weitere heptad repeat-Region (HR2) folgt am C-Terminus (Abb. 1.6B). Heptad repeats sind typisch für $\alpha$-Helices, welche coiled coils ausbilden. Durch die Nähe der heptad repeat-Regionen zu den Transmembrandomänen wird spekuliert, dass die HRRegionen fusogene Strukturen wie z.B. bei den viralen Fusionsproteinen ausbilden. Tatsächlich wurde die Struktur eines HR2-Dimers des Mitofusins gelöst, die ein anti-paralleles coiled coil darstellt ( [77], 1.6C). Die Ausbildung eines coiled coil zwischen zwei Membranen könnte die Annäherung der Membranen bewirken. Inwieweit die GTPase an der Fusionsreaktion beteiligt ist, wurde bisher nicht geklärt. Neben einer regulatorischen bzw. Signalfunktion der GTPase wird eine analoge Funktion zur Dynamin-GTPase diskutiert, die die GTP-Hydrolyse an einen mechanochemischen Prozess knüpfen kann. Dies könnte eine Deformation der Membran herbeizuführen oder die Membranen in die notwendige räumliche Nähe zueinander zu bringen [51].

Die zweite GTPase Mgm1p ist in der inneren Mitochondrienmembran verankert und zeigt in den Intermembranraum. Möglicherweise vermittelt sie die 
Fusion der inneren Membranen, nachdem die äußeren Membranen fusioniert sind.

Das Adaptorprotein Ugo1p ist mit seiner Transmembranregion in der äußeren Mitochondrienmembran verankert, dabei zeigt die N-terminale Domäne in Richtung Cytosol und die C-terminale Region in den Intermembranraum. Da Ugo1p mit beiden GTPasen Fzo1p und Mgm1p interagiert, wird davon ausgegangen, dass Ugo1p ein Gerüst zur Koordination der Fusion von äußerer und innerer Membran bildet (Details in [51]).

Die Kopplung der Konformationsänderung der Proteine - von einem energetisch höheren Zustand zu einem thermodynamisch günstigeren Zustand - scheint eine evolutionär erfolgreiche Strategie zur Vermittlung der Membranfusion darzustellen. Möglicherweise bilden coiled coil-Strukturen die einfachsten Strukturelemente mit denen mechanische Energie auf Membranen übertragen werden kann.

\subsection{Faltung $\alpha$-helikaler coiled coil-Strukturen}

Die $\alpha$-Helices gehören zu den stabilsten Konformationen einer Aminosäuresequenz und kommen in vielen Proteinen vor. Sie sind rechtshändig gedrehte Spiralen mit etwa 3,6 Aminosäureketten pro Umdrehung. Helices können sich aufgrund hydrophober Wechselwirkungen zusammenlagern und eine Superhelix (coiled coil) ausbilden (Zusammenfassungen in [23,88]). Dabei zeigen die hydrophoben Aminosäuren in das Innere und formieren die so genannten 'layer' (siehe auch Abb. 1.2); die hydrophilen Aminosäuren sind vorrangig auf der Oberfläche eines Helixbündels lokalisiert. Diese definierten Aminosäuresequenzen der $\alpha$-Helixwindungen werden als heptad repeats bezeichnet. Die Aminosäuren eines heptad repeat werden mit den Buchstaben a - g benannt, wobei die Positionen a und d für die hydrophoben Reste stehen, die zum Ausbilden der Struktur entscheidend beitragen.

Coiled coils können unterschiedlich viele Helices enthalten, z.B. besteht das GCN4 Leucinreißverschlussprotein (leucin zipper protein) aus zwei parallel angeordneten Helices. Die HA2-Domäne des Influenzafusionsprotein Hämagglutinin enthält drei Helices (siehe auch Abb. 1.6A), und der SNARE-Komplex stellt ein Beispiel für ein Vier-Helix-coiled coil dar. Je mehr Helices in einem coiled coil 
vorkommen, desto stabiler ist dieses Bündel [88]. Dies erklärt möglicherweise die hohe Stabilität des SNARE-Komplexes, welcher erst bei $82^{\circ} \mathrm{C}$ zerfällt und SDSresistent ist [34].

Die Entdeckung der Leucinreißverschlussproteine machte es aufgrund ihrer Simplizität möglich, grundlegende Erkenntnisse zum Aufbau und der Entstehung von coiled coils zu sammeln, wie z.B. die Faltung der $\alpha$-Helices und der Superhelices. Die $\alpha$-Helixbildung beginnt an jenen Positionen in der Aminosäuresequenz, in denen eine Vielzahl von Resten der Helixbildner (z. B. Leucin, Alanin und Valin) vorkommen. Die Struktur breitet sich von dieser Stelle beginnend aus, bis sie von einem spezifischen Signal abgebrochen wird.

Für die Bildung von Superhelixstrukturen wurde 1998 eine interessante Hypothese aufgestellt, in welcher die Existenz einer kurzen 'Trigger-Sequenz' vorgeschlagen wird, welche sich autonom $\alpha$-helikal faltet und eine Oligomerisierung bevorzugt [132]. In der Kristallstruktur von Cortexillin I wurde erkennbar, dass diese Trigger-Sequenz eine Vielzahl von inter- und intrahelikalen ionischen Interaktionen im Inneren des Helixbündels besitzt, welche zu einem festen Packen der Helices führen [13]. In den folgenden Jahren konnten Trigger-Sequenzen in verschiedenen coiled coil-Strukturen identifiziert werden [70,41,147].

\subsection{Ziel der Arbeit}

SNARE-Proteine bilden einen stabilen $\alpha$-helikalen Komplex zwischen der vesikulären Membran und der Akzeptormembran aus. Man vermutet, dass die SNARE-Komplexbildung in mehreren Reaktionsschritten abläuft. Zunächst interagieren wahrscheinlich SNAP-25 und Syntaxin miteinander und könnten einen Akzeptorkomplex für Synaptobrevin ausbilden. Nach der Bindung von Synaptobrevin an den Akzeptorkomplex würde die vollständige Ausbildung des SNAREKomplexes erfolgen.

Um den Prozess genauer verstehen zu können, soll in dieser Arbeit die Komplexbildung zunächst in die biochemisch zugänglichen Einzelschritte zerlegt werden. Hierfür werden die rekombinanten und löslichen Fragmente der SNARE-Proteine bakteriell expremiert sowie chromatographisch gereinigt und die SNARE-Komplexbildung in vitro mit einer Reihe von biophysikalischen und 
thermodynamischen Methoden untersucht.

Zunächst soll der Initiationsschritt der SNARE-Komplexbildung ausführlicher charakterisiert und die Minimalregion für die Interaktion von Syntaxin und SNAP-25 bestimmt werden. Dafür sollen Mutationen zielgerichtet in SNAP-25 eingeführt und deren Einfluss auf die Syntaxin/SNAP25-Akzeptorkomplexbildung untersucht werden. Der darauf folgende Komplexbildungsschritt, die Bindung Synaptobrevins an den Syntaxin/SNAP-25Akzeptorkomplex, soll anschließend charakterisiert werden. Eine fluoreszenzspektroskopische und thermodynamische Untersuchung des Einflusses verschiedener Mutationen in Synaptobrevin auf die Bindung an den Akzeptorkomplex, sowie die Verwendung von Verkürzungen und Synaptobrevin-Homologen soll einen Einblick in diesen Reaktionsschritt geben. Zusätzlich soll überprüft werden, ob es einen partiell unstrukturierten trans-SNARE-Komplex geben kann und ob der finale Schritt der SNARE-Komplexbildung thermodynamisch charakterisiert werden kann. Diese Analysen könnten die Frage beantworten, wieviel Energie während der SNARE-Komplexbildung freigesetzt wird und ob diese möglicherweise in mechanische Energie zur Überwindung der Abstoßungskräfte zwischen zwei Membranen überführt werden kann. 


\section{Material und Methoden}

\subsection{Material}

\subsubsection{Chemikalien}

Standardchemikalien (von analytischem Reinheitsgrad) wurden von den Firmen Biorad, Boehringer, Merck, Roth, Serva und Sigma bezogen. Fluoreszenzfarbstoffe zur Markierung von Cysteinen wurden von Molecular Probes/Invitrogen bezogen.

\subsubsection{Enzyme, Kits, Bakterienstämme}

Restriktionsendonucleasen waren von Boehringer, MBI Fermentas oder New England Biolabs, Pfu-Polymerase von Promega, T4 Ligase von MBI Fermentas oder New England Biolabs und Alkalische Phosphatase von Fermentas und New England Biolabs. Zur Aufreinigung von Plasmiden oder PCR-Produkten wurden Kits von Qiagen und Machery \& Nagel verwendet. Alle Klonierungen wurden mit dem Vektor pET28a (Novagen) durchgeführt. Für Klonierungen wurde der $E$. coli-Stamm XL1-Blue von Stratagene verwendet, für Proteinexpressionen der E. coli-Stamm BL21 (DE3) (Novagen).

\subsubsection{DNA-Konstrukte}

Alle Klonierungsarbeiten wurden nach molekularbiologischen Standardprotokollen durchgeführt [117]. Die in dieser Arbeit verwendeten Konstrukte sind in Tabelle 2.1 zusammengefasst. Die Sequenz aller Konstrukte wurde durch DNASequenzierung überprüft. Alle Sequenzen stammen aus der Ratte ( $R$. norvegi- 
cus), mit Ausnahme von Sec22, das aus der Bäckerhefe (S. cerevisiae) ist. Alle SNAP-25-Konstrukte wurden über die Restriktionsschnittstellen NheI und XhoI kloniert; Konstrukte mit Synaptobrevin oder Syntaxin wurden mit den Nukleasen NdeI und XhoI in den Vektor kloniert.

Alle SNAP-25 Konstrukte wurden auf der Basis des cysteinfreien SNAP25A (C84S, C85S, C90S, C92S) hergestellt. Die meisten der unten aufgeführten Konstrukte wurden der Einfachheit halber abgekürzt. Die Abkürzungen orientieren sich an der Lage der Mutation(en) innerhalb des SNARE-Motivs. Z.B. ist in SNAP-25a (T29A, L150A) der Layer -7 in beiden Helizes mutiert (SN25 [-7]).

Tabelle 2.1: Verwendete DNA-Konstrukte

\begin{tabular}{l|l|l|l|l} 
Gen & AS & Mutationen & Abkürzung & Referenz \\
\hline \hline SNAP-25a & $1-206$ & & SN25 wt & {$[31]$} \\
\hline SNAP-25a & $1-206$ & T29A, L150A & SN25 [-7] & {$[129]$} \\
\hline SNAP-25a & $1-206$ & $\begin{array}{l}\text { M32A, V153A, } \\
\text { c85T }\end{array}$ & SN25 [-6] & {$[129]$} \\
\hline SNAP-25a & $1-206$ & V36A, I157A & SN25 [-5] & J. Sörensen \\
\hline SNAP-25a & $1-206$ & S39A, L160A & SN25 [-4] & J. Sörensen \\
\hline SNAP-25a & $1-206$ & T46A, M167A & SN25 [-2] & J. Sörensen \\
\hline SNAP-25a & $1-206$ & L50A, I171A & SN25 [-1] & {$[129]$} \\
\hline SNAP-25a & $1-206$ & Q53A, Q174A & SN25 [0] & {$[129]$} \\
\hline SNAP-25a & $1-206$ & V60A, I181A & SN25 [+2] & {$[129]$} \\
\hline SNAP-25a & $1-206$ & I67A, N188A, & SN25 [+4] & J. Sörensen \\
\hline SNAP-25a & $1-206$ & M71A, I192A & SN25 [+5] & {$[129]$} \\
\hline SNAP-25a & $1-206$ & L78A, L81A, & SN25 [+7/+8] & {$[129]$} \\
\hline SNAP-25a & $1-197$ & M202A & & {$[34]$} \\
\hline SNAP-25a & $39-206$ & & SN25 BoNT/A & {$[35]$} \\
\hline \hline Syntaxin1a & $180-262$ & & & {$[35]$} \\
\hline Syntaxin1a & $212-262$ & & Syx wt & {$[34]$} \\
\hline Syntaxin1a & $180-262$ & S197C & & {$[35]$} \\
\hline \hline Synaptobrevin2 & $1-96$ & & & {$[90]$} \\
\hline & & & & {$[34]$} \\
\hline
\end{tabular}




\begin{tabular}{l|l|l|l|l}
\hline Synaptobrevin2 & $1-96$ & S28C & & \\
\hline Synaptobrevin2 & $1-96$ & S79C & & \\
\hline Synaptobrevin2 & $1-96$ & I45A, M46A & Syb [-3] & \\
\hline Synaptobrevin2 & $1-96$ & V49A, N50A & Syb [-2] & \\
\hline Synaptobrevin2 & $1-96$ & $\begin{array}{l}\text { L32A, T35A, } \\
\text { S28C }\end{array}$ & Syb [-7/-6] & A. Walter \\
\hline Synaptobrevin2 & $1-96$ & $\begin{array}{l}\text { V39A, V42A, } \\
\text { S28C }\end{array}$ & Syb [-5/-4] & A. Walter \\
\hline Synaptobrevin2 & $1-52$ & C53 & & O.Vites \\
\hline Synaptobrevin2 & $1-65$ & & & \\
\hline Synaptobrevin2 & $1-88$ & C88 & & {$[109]$} \\
\hline Synaptobrevin2 & $25-96$ & & & {$[31]$} \\
\hline Synaptobrevin2 & $49-96$ & & Eb & \\
\hline Synaptobrevin2 & $49-96$ & S79C & & W. Mischerikow \\
\hline \hline Endobrevin & $1-74$ & & & \\
\hline m-Tomosyn & $1031-1116$ & & & \\
\hline Vamp4 & $47-117$ & & & \\
\hline SaCe Sec22 & $126-186$ & & & \\
\hline mTomosyn & $1031-1116$ & G1100D, E1101I, & TomoSyb & \\
\hline
\end{tabular}

\subsubsection{Peptide}

Die in dieser Arbeit verwendeten Peptide wurden von der Firma BIOSYNTAN GmbH (Berlin) bezogen. Der Reinheitsgrad der Peptide betrug 95\% nach HPLCund Massenspektrometrischer Kontrolle.

Folgende Peptide wurden verwendet:

Synaptobrevin AS 17-44 C16: C GGPP APPPNLTSNR RLQQTQAQVD EVVD Synaptobrevin AS 22-44: PPPNLTSNR RLQQTQAQVD EVVD Synaptobrevin AS 71-96: QAGASQFETS AAKLKRKYWW KNLKMM 
Synaptobrevin AS 71-96 C97: QAGASQFETS AAKLKRKYWW KNLKMM C

\subsection{Methoden}

\subsubsection{Proteinexpression und -reinigung}

Für die Expression rekombinanter Histidin ( His $\left._{6}\right)$-Fusionsproteine wurden zunächst die Plasmide in kompetente Zellen (E. coli BL21 DE3) transformiert. Etwa $50 \mu \mathrm{l}$ tiefgefrorene Zellen wurden langsam auf Eis aufgetaut. Anschließend wurde $3 \mathrm{ng}$ DNA hinzugegeben und der Ansatz vorsichtig gemischt. Es folgte eine zehnminütige Inkubation auf Eis. Die gekühlten Zellen wurden $60 \mathrm{~s}$ bei $42^{\circ} \mathrm{C}$ inkubiert. Nun wurde $1 \mathrm{ml}$ vorgewärmtes LB-Medium, welches zusätzlich $20 \mathrm{mM}$ Glucose enthielt, zu den transformierten Zellen gegeben und etwa eine Stunde bei $37^{\circ} \mathrm{C}$ und $800 \mathrm{Upm}$ inkubiert. Danach wurden 50 bzw. $100 \mu$ l Bakteriensuspension auf Kanamycin $(30 \mu \mathrm{g} / \mathrm{ml}$ enthaltene LB-Platten ausgestrichen. Die Inkubation der Platten erfolgte über Nacht bei $37^{\circ} \mathrm{C}$. Um das $\mathrm{His}_{6}$-Fusionsprotein zu expremieren, wurde eine Vorkultur (100 ml LB-Medium, $30 \mu \mathrm{g} / \mathrm{ml}$ Kanamycin) mit einer Kolonie der transformierten Zellen angeimpft. Diese inkubierte bei $37^{\circ} \mathrm{C}$ und 220 Upm über Nacht. $15 \mathrm{ml}$ Vorkultur wurden zu $800 \mathrm{ml}$ TB-Medium (incl. $10 \% \mathrm{v} / \mathrm{v}$ TB-Salz) mit $30 \mu \mathrm{g} / \mathrm{ml}$ Kanamycin gegeben und bei $37^{\circ} \mathrm{C}$ geschüttelt. Sobald die Bakteriensuspension eine optische Dichte von etwa 1,0 bis 1,4 bei 600 $\mathrm{nm}\left(\mathrm{OD}_{600}\right)$ erreicht hatte, wurde mit 0,25 mM IPTG die Expression induziert. Es wurde weitere $3 \mathrm{~h}$ bei $37^{\circ} \mathrm{C}$ inkubiert und anschließend die Bakterien $20 \mathrm{~min}$ bei $4000 \mathrm{Upm}$ und $4^{\circ} \mathrm{C}$ abzentrifugiert. Das Bakterienpellet wurde in etwa 10 $\mathrm{ml}$ Waschpuffer (20 mM Tris $\mathrm{pH} 7,4,500 \mathrm{mM} \mathrm{NaCl}, 8 \mathrm{mM}$ Imidazol) pro Liter Bakterienkultur resuspendiert und bei $-20^{\circ} \mathrm{C}$ gelagert. Erfolgte die Induktion bei $25^{\circ} \mathrm{C}$, wurde die Bakterienkultur über Nacht bei $25^{\circ} \mathrm{C}$ inkubiert.

Die Reinigung der Proteine umfasste eine $\mathrm{Ni}^{2+}-\mathrm{NTA}$-Agarose-Reinigung und anschließende Ionenaustauschchromatographie. Um die Proteine aus den Bakterien zu extrahieren, wurden zu den resuspendierten Bakterien $1 \mathrm{mg} / \mathrm{ml}$ Lysozym zum Aufösen der Zellwand, $1 \mathrm{mM}$ PMSF als Proteaseinhibitor, $5 \mathrm{mg}$ DNase sowie $1 \mathrm{mM} \mathrm{MgCl}$ gegeben. Nach etwa 20 min auf Eis wurden zusätzlich $1 \%$ (v/v) Triton X-100 zum Zerstören der Zellmembran addiert und 10 min in- 
kubiert. Nun wurde 6 M Harnstoff in der Bakteriensuspension gelöst und weitere 30 min auf Eis inkubiert. Anschließend erfolgte die Ultraschallbehandlung $3 \times 40$ s. Die Zelltrümmer wurden 45 min bei $4^{\circ} \mathrm{C}$ mit $14500 \mathrm{Upm}$ abzentrifugiert. Der Überstand wurde nun mit etwa $1 \mathrm{ml}$ pro Kolben $\mathrm{Ni}^{2+}$-NTA-Agarose versetzt. Es folgte eine Inkubation auf einem Drehrad bei $4^{\circ} \mathrm{C}$ für die Dauer von mindestens 1-2 h. Die Agarose wurde mittels Filtration gesammelt und mit etwa 250 $\mathrm{ml}$ Waschpuffer (20 mM Tris $\mathrm{pH} 7,4,500 \mathrm{mM} \mathrm{NaCl}, 8 \mathrm{mM}$ Imidazol) mit $4 \mathrm{M}$ Harnstoff) gewaschen. Die Elution erfolgte mit Hilfe des folgenden Puffers (20 mM Tris pH 7,4, $500 \mathrm{mM} \mathrm{NaCl}, 400 \mathrm{mM}$ Imidazol, $2 \mathrm{M}$ Harnstoff). Es wurden 2 $\mathrm{ml}$ Elutionspuffer pro ml zugegebener Ni2+-NTA-Agarose eingesetzt und in zwei Schritten eluiert.

Um den Erfolg der Reinigung zu kontrollieren, wurden 5-10 $\mu$ l des Eluats mittels SDS-PAGE analysiert. Um den Hexa-His-Tag des expremierten Proteins abzuschneiden, wurden etwa 100 Units Thrombin zu dem Eluat gegeben. Anschließend wurde das Eluat in einen Dialyseschlauch (Ausschlussgröße, molecular weight cut off (MWCO): 6-8.000 kDa oder 12-14.000 kDa) gegeben und gegen den Standardpuffer (20 mM Tris pH 7,4, 100-200 mM NaCl, 1 mM EDTA, 1 mM DTT) bei $4^{\circ} \mathrm{C}$ mindestens $3 \mathrm{~h}$ dialysiert.

Die Ionenaustauschchromatographie erfolgte mit dem ÄKTA-System von Pharmacia. Die Proteine wurden an die entsprechende Ionenaustauschmatrix gebunden, durch einen linear steigenden Salzgradienten das Protein in Fraktionen eluiert und dies bei den Absorptionen $280 \mathrm{~nm}$ und $230 \mathrm{~nm}$ verfolgt. Die Reinheit der peak-Fraktionen wurde mittels SDS-PAGE und Coomassie Blue-Färbung festgestellt, anschließend die saubersten Fraktionen vereinigt und bei $-20^{\circ} \mathrm{C}$ gelagert.

Die folgenden Proteine sind von Mitarbeitern der Abteilung Neurobiologie gereinigt worden und wurden mir freundlicherweise zur Verfügung gestellt: SaCeSec22 wurde von Nikolai Mischerikow gereinigt, Tomosyn 1031-1116 und $\Delta$ N-Komplex Syb49-96 C79A488 von Ajaybabu V. Pobbati. Außerdem wurde Synaptobrevin 1-96 ${ }^{C 28 A 488}$ von Alexander Stein gereinigt und markiert. 


\subsubsection{Biochemische Standardmethoden}

\section{Proteinkonzentrationsbestimmung}

Die Konzentration der hier verwendeten Proteine wurde mittels UV-Absorption bei $280 \mathrm{~nm}$ und der Bradford-Methode bestimmt [10]. Für die Standardreihe wurden $0,1,2,3,4$ und $6 \mu \mathrm{g}$ BSA (bovine serum albumin) sowie die zu bestimmenden Proteine mit destilliertem Wasser auf ein Volumen von $200 \mu \mathrm{l}$ aufgefüllt und anschließend $800 \mu$ l Bradford-Reagenz hinzugegeben und gut gemischt. Nach wenigen Minuten wurde die Absorption der Ansätze photometrisch bei einer Wellenlänge von $595 \mathrm{~nm}$ bestimmt. Für die Standardreihe wurden Doppelbestimmungen durchgeführt und mit diesen Werten eine Eichgerade erstellt. Die Absorption des zu bestimmenden Proteins wurde mit Dreifachbestimmung festgestellt und mit dem Mittelwert sowie der Eichgeraden die Konzentration des Proteins bestimmt.

Die Absorption der Proteine bei $280 \mathrm{~nm}$ wurde in Anwesenheit von $6 \mathrm{M}$ Guanidinhydrochlorid bestimmt. Der Extinktionskoeffizient des jeweiligen Proteins wurde mit der Aminosäurensequenz auf der Internetseite http://expasy.org/tools/protparam.html berechnet und die Konzentration mit dem Lambert-Beer-Gesetz bestimmt.

In dieser Arbeit wurden Synaptobrevinkonstrukte verwendet, welche keine aromatischen Aminosäuren enthalten. Die Konzentration dieser Proteine konnte nicht mit der Bradford-Methode oder der Absorptionsbestimmung bei $280 \mathrm{~nm}$ ermittelt werden. Die Konzentration konnte nur abgeschätzt werden, hauptsächlich anhand der Bandendicke in einem SDS-Gel oder, bei fluoreszenzmarkierten Konstrukten, anhand der Absorption des Farbstoffes.

\section{Polyacrylamidgelelektrophorese}

In dieser Arbeit wurde SDS-PAGE nach Laemmli [80] sowie nach Schägger [119] durchgeführt. Es wurde eine gebrauchsfertige, gasstabilisierte, wässrige Stammlösung mit $30 \%(\mathrm{w} / \mathrm{v})$ Acrylamid und 0,8 \% (w/v) Bisacrylamid verwendet. Zusätzlich wurden Trenngelpuffer (1,5 M Tris, pH 8,8, 0,4 \% (w/v) SDS) und Sammelgelpuffer (0,5 M Tris, pH 6,8, 0,4 \% (w/v) SDS) benötigt. Verwendet 
wurde das Mini-ProteanII-Gelsystem (Biorad).

Die Vorgehensweise für Nativ-PAGE war bis auf das Fehlen von SDS in Trennund Sammelgel, Laufpuffer und Probenpuffer die gleiche wie bei der SDS-PAGE nach Laemmli. Ein weiterer Unterschied bestand in der Nutzung von 8 \%igen bzw. 9 \%igen Trenngelen.

Nach der Gelelektrophorese wurde das Trenngel in der Färbelösung (50 \% (v/v) Methanol, $10 \%$ (v/v) Essigsäure und 0,2 \% (w/v) Coomassie Brilliant Blue R-250) 15-30 min auf einem Schüttler inkubiert und anschließend mit Entfärbelösung 1 (25\% (v/v) Isopropanol, $10 \%$ (v/v) Essigsäure) sowie Entfärbelösung $2(5 \%$ (v/v) Methanol, 12,5 \% Essigsäure (v/v) entfärbt. [141]

\subsubsection{Reinigung von SNARE-Komplexen}

Die in dieser Arbeit verwendeten SNARE-Komplexe wurden über Ionenaustauschchromatographie gereinigt, um die Verunreinigung durch Einzelproteine auszuschließen. Dafür wurden die Komponenten Syntaxin, SNAP-25 und Synaptobrevin in einem Verhältnis von 1: 1: 2 zusammengegeben und entweder eine Stunde bei Raumtemperatur oder bei $4^{\circ} \mathrm{C}$ über Nacht inkubiert. Ausnahmen bildeten die Komplexe, welche Syntaxin 212-262 bzw. SNAP-25 39-206 enthielten. Sie mussten zwei Wochen bei $4^{\circ} \mathrm{C}$ inkubiert werden, da durch die N-terminalen Verkürzungen dieser Proteine die Komplexbildung sehr stark verlangsamt wurde. Anschließend erfolgte die Ionenaustauschchromatographie mit dem ÄKTASystem (siehe oben).

\subsubsection{Limitierte Proteolyse}

Die Protease Thermolysin wurde im molaren Verhältnis 1:100 verwendet. Der Reaktionspuffer enthielt $20 \mathrm{mM}$ Tris $\mathrm{pH}$ 7,4, $100 \mathrm{mM} \mathrm{NaCl}, 1 \mathrm{mM}$ EDTA, 1 mM DTT, $1 \mathrm{mM} \mathrm{ZnCl}_{2}$ und $1 \mathrm{mM} \mathrm{CaCl} 2$. Die Protease wurde zum Proteinansatz hinzugegeben und nach genau $0,5,10,15,30,60$ und 120 min Inkubation bei $35^{\circ} \mathrm{C}$ bzw. $70^{\circ} \mathrm{C}$ jeweils ein Aliquot abgenommen. Dieses wurde mit SDS-Probenpuffer vermischt, welcher zusätzlich 1mM PMSF (Proteaseinhibitor) enthielt, um die Reaktion zu stoppen und die Proben auf Eis gelagert. Anschließend wurden die Proben mittels SDS-PAGE und Coomassie Blue-Färbung analysiert. 


\subsubsection{Circular Dichroismus (CD)-Spektroskopie}

In der CD-Spektroskopie macht man sich zunutze, dass Proteine chirale Verbindungen sind, das bedeutet, sie sind optisch aktiv. Die Differenz der Absorption von rechts- bzw. linksdrehendem polarisiertem Licht durch eine chirale Verbindung wird als Zirkulärer Dichroismus (Circular Dichroism, CD) bezeichnet. Die Sekundärstruktur eines Proteins ist durch ein charakteristisches Spektrum gekennzeichnet. Das Spektrum von $\alpha$-Helices besitzt zwei Minima bei den Wellenlängen $208 \mathrm{~nm}$ und $222 \mathrm{~nm}$ (Beispiel in Abb. 3.2, rechts oben).

Die Experimente wurden an folgenden Geräten vorgenommen: J 720 (Jasco) und Chirascan (Applied Photophysics). Die Denaturierungsexperimente wurden in Phosphatpuffer (20mM Natriumphosphat pH 7,4, $100 \mathrm{mM} \mathrm{NaCl}$ und 1mM DTT) und kinetische Untersuchungen in $20 \mathrm{mM}$ Tris $\mathrm{pH}$ 7.4, $100 \mathrm{mM} \mathrm{NaCl}, 1$ mM DTT durchgeführt. Um die Stabilität der verschiedenen SNARE-Komplexe zu bestimmen, wurden die gereinigten Komplexe bei einer Proteinkonzentration zwischen 5-10 $\mu \mathrm{M}$ in $1 \mathrm{~mm}$-Küvetten (Hellma) von $25^{\circ} \mathrm{C}$ bis $95^{\circ} \mathrm{C}$ erhitzt. Das CD-Signal wurde bei $222 \mathrm{~nm}$ ( in $1^{\circ} \mathrm{C}$-Schritten bei einer Geschwindigkeit von $0,5^{\circ} \mathrm{C} / \mathrm{h}$ ) aufgezeichnet. Zusätzlich soll hier erwähnt werden, dass es aufgrund der Verwendung verschiedener Geräte Unterschiede hinsichtlich der gemessenen Schmelztemperaturen gab.

Für die kinetischen Untersuchungen wurde das CD-Signal bei $222 \mathrm{~nm}$ in 1 s-Intervallen aufgezeichnet. Vom Zeitpunkt der Zugabe der Probe in die Küvette, also dem Reaktionsstart, bis zur Aufnahme der Meßwerte durch das Gerät vergingen ca. $3 \mathrm{~s}$.

\subsubsection{Fluoreszenzspektroskopie}

\section{Protein-Fluoreszenz-Markierung}

Die hier verwendeten Fluoreszenzfarbstoffe waren Alexa 488 maleimide (A488), Oregon Green 488 iodoacetamide (OG) und Texas Red C5 bromoacetamide (TR) (Molecular Probes). Die Farbstoffe wurden an ein Cystein der jeweiligen Einzelcysteinmutante gekoppelt.

Zu etwa $1 \mathrm{ml}$ Proteinlösung (1-4 mg/ml) wurde $10 \mathrm{mM}$ DTT gegeben und 
über Nacht bei $4^{\circ} \mathrm{C}$ gegen entgasten PBS-Puffer dialysiert. Anschließend wurde der Farbstoff, gelöst in DMF (N,N-Dimethylformamid), in 10-20fachen molaren Überschuss hinzugegeben und auf einem Drehrad $2 \mathrm{~h}$ bei RT inkubiert. Danach wurde erneut $10 \mathrm{mM}$ DTT addiert und 30-60 min bei RT inkubiert. Der überschüssige Farbstoff wurde mittels Gelfiltration (Säulenmaterial: G-25 Sepharose superfine (Sephadex) für alle Proteine; G-10 Sepharose (Sephadex) für Peptide) abgetrennt.

Die Kopplung des Farbstoffs A488 wurde wie folgt vorgenommen. Etwa $1 \mathrm{ml}$ Proteinlösung (1-4 mg/ml) wurde über Nacht bei $4^{\circ} \mathrm{C}$ gegen entgasten PBS-Puffer dialysiert. Anschließend wurden $100 \mu \mathrm{l}$ TCEP hinzugegeben und 30 min auf Eis inkubiert. Anschließend wurde der Farbstoff in PBS-Puffer gelöst und etwa 0,25 mg pro Proteinlösung hinzugegeben. Nach 2-3 h Inkubation auf einem Drehrad bei $4^{\circ} \mathrm{C}$ wurde der überschüssige Farbstoff mittels Gelfiltration (Säulenmaterial: G-25 bzw. G-10 Sepharose (siehe oben)) abgetrennt.

Die Konzentration des effektiv markierten Proteins konnte durch das Messen der UV-Absorption bei dem jeweiligen Absorptionsmaximum des Farbstoffs bestimmt und mit Hilfe des Lambert-Beer-Gesetzes berechnet werden. Die Markierungseffizienz ergab sich aus dem Verhältnis dieser Konzentration und der mit der Bradford-Methode bestimmten Konzentration.

\section{Fluoreszenz-Anisotropie-Messungen}

Die Anisotropie-Messungen wurden am Spektrofluorometer FluoroLog-3 (HORIBA Jobin Yvon) in T-Konfiguration durchgeführt. Dabei wird das emitierte Licht simultan in der parallelen und der senkrechten Polarisationsebene mit zwei verschiedenen Detektoren gemessen. Um die polarisationsabhängigen Einflüsse des Gerätes zu korregieren, wurde der G-Faktor nach folgender Gleichung bestimmt:

$$
G=\frac{I_{H V}}{I_{H H}}
$$

Darin bezeichnet $I$ wiederum die Intensität und die Indices die Orientierung des Anregungs- und Emissionspolarisators (H: horizontal, V: vertikal). Die Anisotropie berechnet sich dann wie folgt:

$$
r=\frac{I_{V V}-G I_{V H}}{I_{V V}+2 G I_{V H}}
$$


Für die Anisotropie-Experimente wurden die Fluorophore AlexaFluor488 oder Oregon Green genutzt. Die Anregungswellenlänge dieser Farbstoffe beträgt $490 \mathrm{~nm}$ und das Emissionsmaximum liegt bei $520 \mathrm{~nm}$. Das markierte Protein wurde in einer Konzentration von 50-200 nM eingesetzt. Es wurden 10mmQuarzglasküvetten (Hellma) und als Reaktionspuffer PBS pH 7,4, 1mM DTT verwendet. Während der Messungen wurde der Reaktionsansatz mit Hilfe eines Magnetrührers durchmischt. Die Spaltbreiten betrugen für die Anregung 3-5 nm und für die Emission 5-8 nm. Die Emission des jeweiligen Farbstoffs wurde in 1 s-Intervallen aufgezeichnet. Die Daten wurden für einzelne Experimente auf den Anfangswert der jeweiligen Messung normalisiert und sind in dieser Arbeit als $F / F_{0}$ abgekürzt.

\section{Fluoreszenz-Messungen}

Fluoreszenz-Messungen wurden mit dem Fluorophor Texas Red durchgeführt. Texas Red hat eine Anregungswellenlänge von $590 \mathrm{~nm}$ und emitiert bei $610 \mathrm{~nm}$. Die Änderung der Fluoreszenz ergab sich aus dem so genannten quenching, welches ein Hinweis auf die Interaktion eines markierten Peptids mit einem anderen Protein ist. Die Änderung der Mikroumgebung des Fluoreszenzfarbstoffes kann zu einer Reduzierung der Fluoreszenz-Quantenausbeute und dadurch zum quenching des Farbstoffs führen.

\subsubsection{Isothermale Titrationskalorimetrie (ITC)}

Bei der Isothermalen Titrationskalorimetrie wird bei einer konstanten Temperatur die Wärmemenge $q$ ( $\mu \mathrm{cal})$ gemessen, welche während einer chemischen Reaktion aufgenommen oder abgegeben wird. Auf diese Weise kann man die Assoziationskonstante $K_{a}$, die Reaktionsenthalpie $\Delta_{r} H$ und die Stöchiometrie der Bindung $N$ bestimmen.

Bei konstanter Temperatur und konstantem Druck kann man für eine ablaufende Reaktion die Änderung der Freien Enthalpie $(\Delta G)$ pro Formelumsatz in Enthalpie- und Entropieänderungen aufteilen. Dies wird anhand der GibbsHelmholtz-Gleichung dargestellt:

$$
\Delta G=\Delta_{r} H-T \Delta_{r} S=-R T \ln K_{a},
$$


wobei $\Delta_{r} H$ die Reaktionsenthalpie, $\Delta_{r} S$ die Reaktionsentropie und $R$ die Gaskonstante definiert. Durch Umstellen der Formel erhält man folgende Gleichung, welche es ermöglicht, zusätzlich zu den bestimmten Parametern, sowohl $\Delta G$ als auch $\Delta S \mathrm{zu}$ berechnen:

$$
\Delta_{r} S=\frac{\Delta_{r} H}{T}+R \ln K_{a}
$$

Die Experimente dieser Arbeit wurden mit dem VP-ITC Instrument (MicroCal) bei $25^{\circ} \mathrm{C}$ durchgeführt. Die verwendeten Proteine wurden gegen ITCPuffer (20mM Natriumphosphat pH7.4, $200 \mathrm{mM} \mathrm{NaCl}, 1 \mathrm{mM}$ DTT) dialysiert. Die Titrationen wurden in $10 \mu \mathrm{l}$-, $15 \mu \mathrm{l}$ - oder $20 \mu \mathrm{l}$-Injektionen ausgeführt. Die Änderung der Wärmemenge während der Proteininteraktionen wurde integriert und mit MicroCal Origin 7.0 analysiert. Dabei wurde das single site Bindungsmodell verwendet. 


\section{$3 \quad$ Ergebnisse}

Die SNARE-Proteine Syntaxin, SNAP-25 und Synaptobrevin liegen als Einzelproteine hauptsächlich unstrukturiert vor und formen durch die Interaktion miteinander einen stabilen $\alpha$-helikalen Komplex, den so genannten SNARE-Komplex aus [36]. Bisher konnten die molekularen Schritte der Komplexbildung noch nicht vollständig aufgeklärt werden. Um den Komplexbildungsprozess ausführlicher zu charakterisieren, wurde in dieser Arbeit die Formierung des SNARE-Komplexes anhand verschiedener spektroskopischer (CD-Spektroskopie und Fluoreszenzanisotropie) und biophysikalischer Methoden, wie der Isothermalen Titrationskalorimetrie verfolgt. Des Weiteren wurde mit thermalen Denaturierungsexperimenten untersucht, wie stabil SNARE-Komplexe mit verschiedenen Zusammensetzungen sind.

Zur genaueren Analyse der einzelnen Komplexbildungsschritte, wurden die Proteine teilweise verkürzt oder verschiedene zielgerichtete Mutationen in die SNARE-Motive der jeweiligen Proteine eingeführt. In Abbildung 3.1 ist die Struktur des SNARE-Komplex schematisch dargestellt. Um die SNAREKomplexbildung verfolgen zu können, wurden Proteinkonstrukte ohne Membranverankerung verwendet, die es erlauben die Messungen in Lösung durchzuführen. Zusätzlich wurden die Cysteine im Linkerbereich von SNAP-25, die der Membranverankerung durch Palmitoylierung dienen, gegen Serine ausgetauscht, da Cysteine reaktiv sind und zu Quervernetzungen führen können. Des Weiteren enthielt das hier verwendete Syntaxinkonstrukt keine N-terminale Habc-Domäne, da diese die Geschwindigkeit der Komplexbildung durch den vorgelagerten Wechsel zwischen offener und geschlossener Konformation verringert [105, 91]. Das SNAREMotiv von Syntaxin wird als H3-Domäne bezeichnet (SyxH3). Viele der in dieser Arbeit verwendeten Mutationen in den SNARE-Proteinen wurden in die hydroho- 
ben Layer eingeführt. Zur Verdeutlichung der unterschiedlichen Positionen und Längen der verwendeten Konstrukte sind verschiedene Synaptobrevinvarianten als Linien dargestellt.

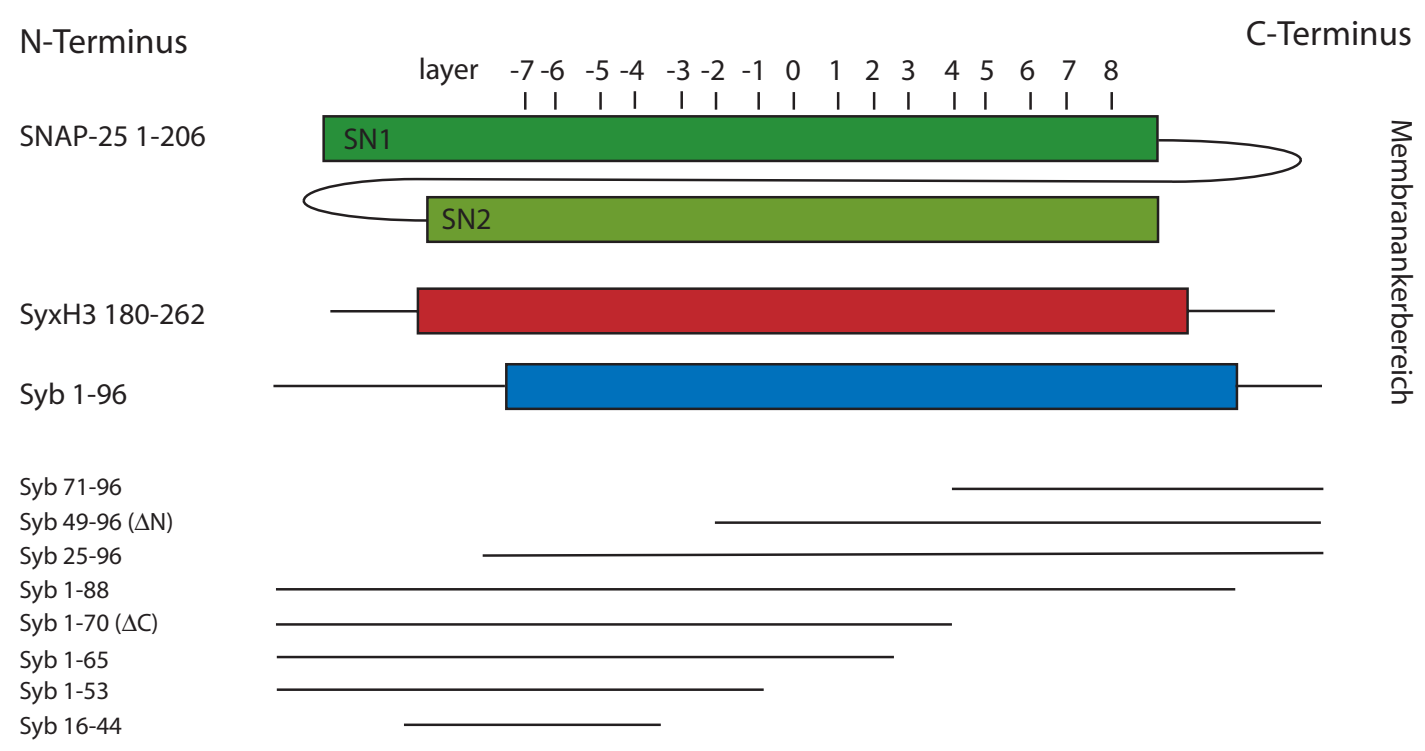

Abbildung 3.1: Schematische Darstellung des SNARE-Komplexes. Die $\alpha$-helikalen SNARE-Motive der drei Proteine sind schematisch als Boxen dargestellt. Die hydrophoben Kontakte innerhalb des $\alpha$-helikalen Bündels, die so genannten layer, sind hervorgehoben. Unterhalb des Beispielkomplexes sind verschiedene Synaptobrevinkonstrukte zur Verdeutlichung der unterschiedlichen Positionen und Längen als Linien dargestellt.

Die SNARE-Komplexbildung umfasst mindestens drei Reaktionschritte: zunächst bilden Syntaxin und SNAP-25 einen Komplex (1), welcher anschließend als Bindungstelle für Synaptobrevin dient (2). Nach diesem Bindungsschritt erfolgt die vollständige Strukturierung des SNARE-Komplexes (3).

Im ersten Teil der Ergebnisse werde ich auf die N-terminale Initiationsreaktion der beiden Q-SNARE-Proteine Syntaxin und SNAP-25 eingehen und die Minimalregion für die Initiationsreaktion charakterisieren. Auf die nachfolgende Bindung von Synaptobrevin wird im zweiten Teil näher eingegangen. Im letzten Abschnitt werde ich Ergebnisse zum finalen Schritt der SNARE-Komplexbildung, der Strukturierung der C-terminalen Region, präsentieren. 


\subsection{Die N-terminale Initiationsreaktion der Q- SNARE-Proteine}

\subsubsection{Die Integrität der N-terminalen Region der beiden SNARE-Motive von SNAP-25 ist essenziell für den Initiationsschritt der Komplexbildungsreaktion}

Das bereits in Kapitel 1 erwähnte Zipper-Modell postuliert einen Reaktionsbeginn der SNARE-Komplexbildung am N-Terminus [58]. Die Ausbildung des $\alpha$ helikalen coiled coil-Bündels soll im weiteren Verlauf reißverschlussartig in Richtung des C-Terminus erfolgen, an dem die Transmembranregionen lokalisiert sind. Auf diese Weise könnten die Membranen in eine räumliche Nähe zueinander gebracht werden und somit die Abstoßungskräfte zwischen den Lipidschichten überwunden werden. Diese These wurde bisher von einigen Arbeitsgruppen getestet und viele Indizien deuten auf diesen Reaktionsverlauf hin [66, 148, 40, 19, 5, 35]. Zum Beispiel konnte anhand der löslichen Proteinfragmente gezeigt werden, dass die SNARE-Komplexbildung deutlich inhibiert ist, wenn der N-Terminus von SyxH3 oder der N-Terminus jeweils einer der beiden SNAP-25-Helices verkürzt sind [35].

Um diesen für die Interaktion der Q-SNARE-Proteine wichtigen Bereich ausführlicher zu analysieren, wurden SNAP-25 Layer-Mutanten hergestellt. Die Layer-Positionen in Helices, d. h. die nach innen weisenden Seitenketten der aund d-Positionen, eignen sich aufgrund ihrer Bedeutung für die Stabilität des Komplexes besonders gut für Mutationen und dementsprechend wurden die korrespondierenden Layer-Positionen beider SNAP-25-Helices zu Alanin mutiert. Dabei wurde Alanin verwendet, da dies eine kleine hydrophobe Aminosäure ist, welche den Komplex lokal destabilisieren kann, jedoch die Bildung von Helices nicht unterbindet und keine zusätzlichen Oberflächenladungen erzeugt. Es sollten die Auswirkungen der Mutationen auf die Kinetik der Komplexbildung sowie die Stabilität dieser Komplexe untersucht werden. Die Verwendung von LayerMutationen in den einzelnen Proteinen ermöglicht einen genaueren Einblick in den Ablauf der Reaktion, da sie weniger invasiv als Verkürzungen sind. Eine 
Übersicht über die verwendeten Doppelalaninkonstrukte und deren Abkürzungen sind in Abschnitt $2.1 \mathrm{zu}$ finden. Der Einfachheit halber werde ich SNAP-25 Doppellayermutanten, nur nach der Position der Doppelmutation bezeichnen.

Im folgenden Abschnitt stelle ich zunächst die Experimente zur Interaktion der Q-SNARE-Proteine vor. Um diese Initiationsreaktion zu charakterisieren, wurde die Bildung des binären $\mathrm{Syx}_{2} / \mathrm{SN} 25_{1}$-Komplexes zunächst CDspektroskopisch untersucht (Abb. 3.2). Diese Methode erlaubt es, die Induktion der Sekundärstruktur während der SNARE-Komplexformierung zu verfolgen. Der Übergang vom ungefalteten zum $\alpha$-helikalen Zustand kann am besten bei einer Wellenlänge von $222 \mathrm{~nm}$ beobachtet werden, welche für $\alpha$-Helices spezifisch ist.

So bilden SyxH3 und SNAP-25 einen binären Syx $2 /$ SN251-Komplex, ein Vier-Helixbündel, in dem die Position des Synaptobrevins durch ein zweites Syntaxin besetzt ist. Für diese Messungen wurden rekombinant hergestelltes SyxH3 und SNAP-25 wt in eine Küvette gegeben und die Geschwindigkeit der Proteininteraktion als Anstieg des $\alpha$-helikalen Anteils bei $222 \mathrm{~nm}$ gemessen. Wurden SyxH3 und SNAP-25 bei einer Konzentration von $2 \mu \mathrm{M}$ gemischt, ist die Reaktion nach etwa $600 \mathrm{~s}$ abgeschlossen (Abb. 3.2).

Es wird angenommen, dass der Initiationsschritt der geschwindigkeitsbestimmende Schritt der gesamten SNARE-Komplexbildungsreaktion ist [35]. Um die Frage zu beantworten, welcher Bereich der Q-SNARE-Proteine für die Initiationsreaktion bedeutend ist, wurde anschließend die Q-SNARE-Komplexbildung mit den SNAP-25-Mutanten [-7], [-6], [-5] und [-4] untersucht. Eine deutlich langsamere Komplexbildung erfolgte, wenn SNAP-25 [-7], [-6] und [-5] eingesetzt wurden (Abb. 3.2A). Die Verwendung von SNAP-25 [-4] hatte keinen Einfluss auf die Komplexbildungsgeschwindigkeit (Abb. 3.2A). Im Vergleich zum wt erfolgt die Komplexbildung mit Syntaxin um so langsamer, je näher sich die Layer-Mutation am N-Terminus befindet. Ab dem Layer -4 haben die Mutationen keinen messbaren Effekt auf den Initiationsschritt. Folglich weist dieses Experiment auf die Bedeutung der Q-SNARE-Layer -7 bis -5 für die Initiationsreaktion der SNAREKomplexbildung hin.

Die Elliptizität der Interaktion von Syntaxin und einiger SNAP-25Mutanten erreichte, auch nach Abschluss der Reaktion, nicht den Wert des 

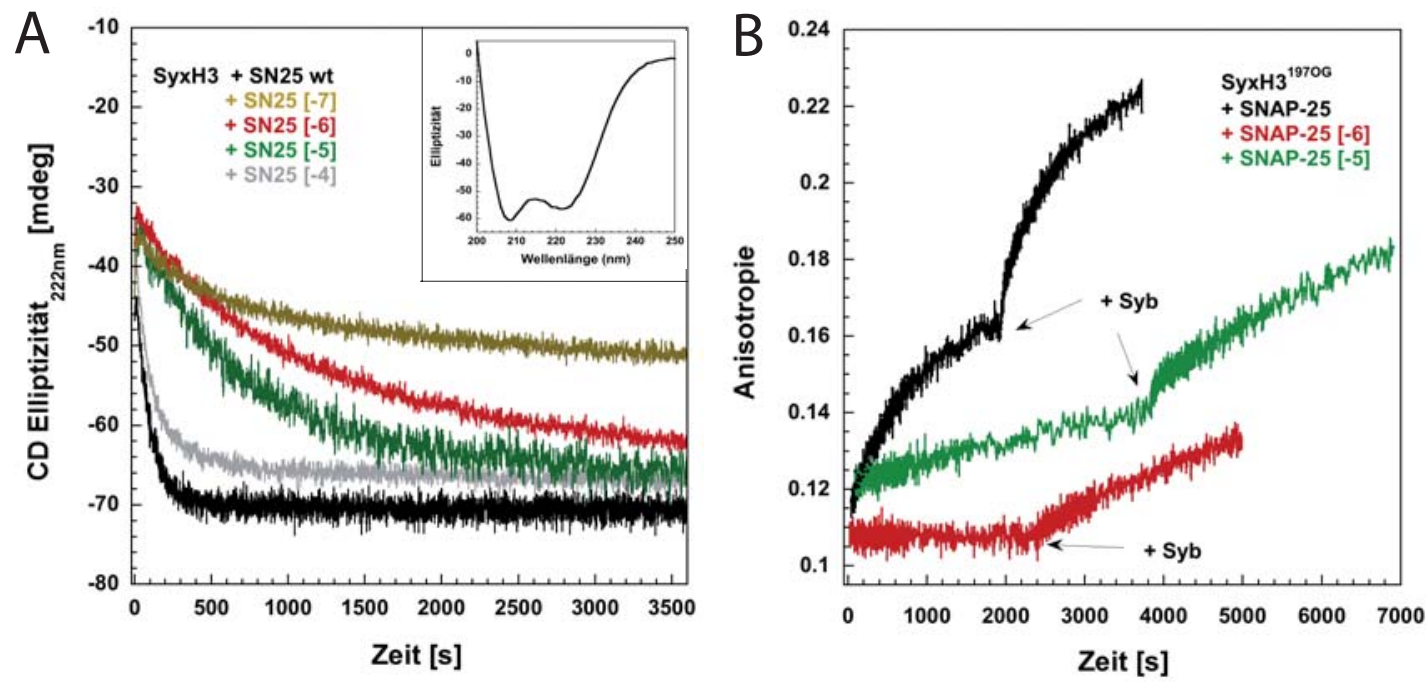

Abbildung 3.2: Die SNARE-Komplexbildung ist mit N-terminalen SNAP-25 Mutanten beeinträchtigt. (A)Die Interaktion der SNARE-Proteine Syntaxin und SNAP-25 wurde mit CD-Spektroskopie untersucht und hat einen Anstieg des $\alpha$-helikalen Anteils zur Folge. Ein CD-Spektrum mit den für $\alpha$-Helices spezifischen Minima bei $222 \mathrm{~nm}$ und $208 \mathrm{~nm}$ ist rechts oben dargestellt. Das SNARE-Motiv von Syntaxin (SyxH3) und die jeweilige SNAP-25Mutante wurden bei einer Konzentration von je $2 \mu \mathrm{M}$ in Tris-Puffer (20mM Tris pH 7,4, $100 \mathrm{mM}$ $\mathrm{NaCl}, 1 \mathrm{mM}$ DTT) gemischt und der Anstieg des $\alpha$-helikalen Anteils mittels CD-Spektroskopie bei $222 \mathrm{~nm}$ verfolgt. Die Mutationen im SNAP-25-Layer -7 bis -5 verlangsamen die Bildung des $\mathrm{Syx}_{2} / \mathrm{SN}_{25}$-Komplexes. (B) Die Bindung von $200 \mathrm{nM}$ an der Position 197 mit Oregon Green markiertem Synaptobrevin (SyxH3 ${ }^{197 O G}$ ) an $1 \mu \mathrm{M}$ SNAP-25 wt bzw. SNAP-25-Mutante wurde mittels Fluoreszenzanisotropie verfolgt. Die Bildung des SNARE-Komplexes wurde anschließend nach der Zugabe von $1 \mu \mathrm{M}$ Synaptobrevin verfolgt. Der Zeitpunkt der Syb-Zugabe ist mit einem Pfeil gekennzeichnet. Die Proteininteraktion hat einen Anstieg der Anisotropie zur Folge. Die Bildung des binären $\mathrm{Syx}_{2} / \mathrm{SN} 25_{1}$-Komplexes sowie des ternären SNARE-Komplexes ist mit N-terminalen SNAP-25-Mutanten erheblich behindert.

SyxH3/SNAP-25 wt-Komplexes (Abb. 3.2A). Es gibt verschiedene Erklärungen für diese Beobachtung. So könnte zum Beispiel sein, dass die unterschiedlichen SNAP-25-Mutanten zwar Komplexe mit Syntaxin bilden können, aber diese Komplexe nicht vergleichbar gefaltet sind wie der wt-Komplex. Vielleicht verursachen die Mutationen im SNAP-25 eine lokale Entfaltung der Komplexe, welche sich in einer reduzierten Elliptizität ausdrückt. Eine weitere Möglichkeit wäre, dass sich die Komplexe mit einer anderen Stöchiometrie ausbilden, was ebenfalls eine geringere Elliptizität zur Folge hätte.

Zusätzlich wurde der Einfluss der N-terminalen SNAP-25-Mutanten auf die SNARE-Komplexbildung mittels Fluoreszenzanisotropie untersucht. Dafür wurde 
zunächst eine Cysteinvariante des Syntaxin-SNARE-Motivs an der Position 197 mit dem Fluoreszenzfarbstoff Oregon Green markiert (SyxH3 $\left.{ }^{197 O G}\right)$. Anschließend wurden SyxH3 ${ }^{197 O G}$ und SNAP-25 in einer Küvette vermischt und der Anstieg der Anisotropie als Folge der Bildung des binären Komplexes beobachtet (Abb. 3.2B). Danach wurde zu diesem Ansatz Synaptobrevin zugegeben und ein weiterer Anstieg der Fluoreszenzanisotropie verfolgt (Abb. 3.2B). Dies wird durch die Bildung des ternären SNARE-Komplexes verursacht. Dieser Versuch wurde beispielhaft mit SNAP-25 [-6] und [-5] durchgeführt. In Übereinstimmung mit den oben gezeigten CD-Experimenten war die binäre Interaktion von SyxH3 mit den SNAP-25-Mutanten beeinträchtigt (Abb. 3.2B). Beim Mischen mit SNAP-25 [-6] wurde kein Anstieg der Anisotropie beobachtet und die Bindung von SNAP25 [-5] an SyxH3 fand nur sehr langsam statt (Abb. 3.2B). Jedoch erfolgte bei vergleichbaren CD-Experimenten ein Anstieg der Elliptizität. Dieser Unterschied der Bindungskinetik von SNAP-25-Mutanten mit SyxH3 kann wahrscheinlich mit den unterschiedlichen Proteinkonzentrationen erklärt werden, bei denen die Reaktionen durchgeführt wurden. Da die SNAP-25-Mutanten eine offensichtlich niedrigere Affinität zu SyxH3 besitzen, kann die Reaktionsgeschwindigkeit in CDExperimenten aufgrund der höheren Proteinkonzentration (jeweils $2 \mu \mathrm{M}$ anstelle von $200 \mathrm{nM}$ und $1 \mu \mathrm{M}$ bei Anistropiemessungen) beschleunigt werden.

Die anschließende Zugabe von Synaptobrevin hatte nur einen langsamen Anstieg der Anisotropie zur Folge (Abb. 3.2B), was darauf schließen lässt, dass sich der ternäre SNARE-Komplex mit den N-terminalen SNAP-25-Mutanten ebenfalls nur langsam bilden kann.

\subsubsection{Die zentrale Region von SNAP-25 hat einen Einfluss auf die SNARE-Komplexbildung}

Verschiedene genetische Studien in der Hefe, in denen hauptsächlich der 0-Layer des SNARE-Komplexes mutiert wurde, konnten zeigen, dass die 3Q:1R-Regel, also die Anwesenheit von drei Glutaminen und einem Arginin im 0-Layer, für die Funktionalität der SNARE-Komplexe eine wichtige Rolle spielt [102, 50,42]. In einer weiteren Versuchsreihe wurde von mir untersucht, welchen Einfluss SNAP25-Layermutationen auf die Entstehung des SNARE-Komplexes haben, die sich 
neben dem 0-Layer befinden.

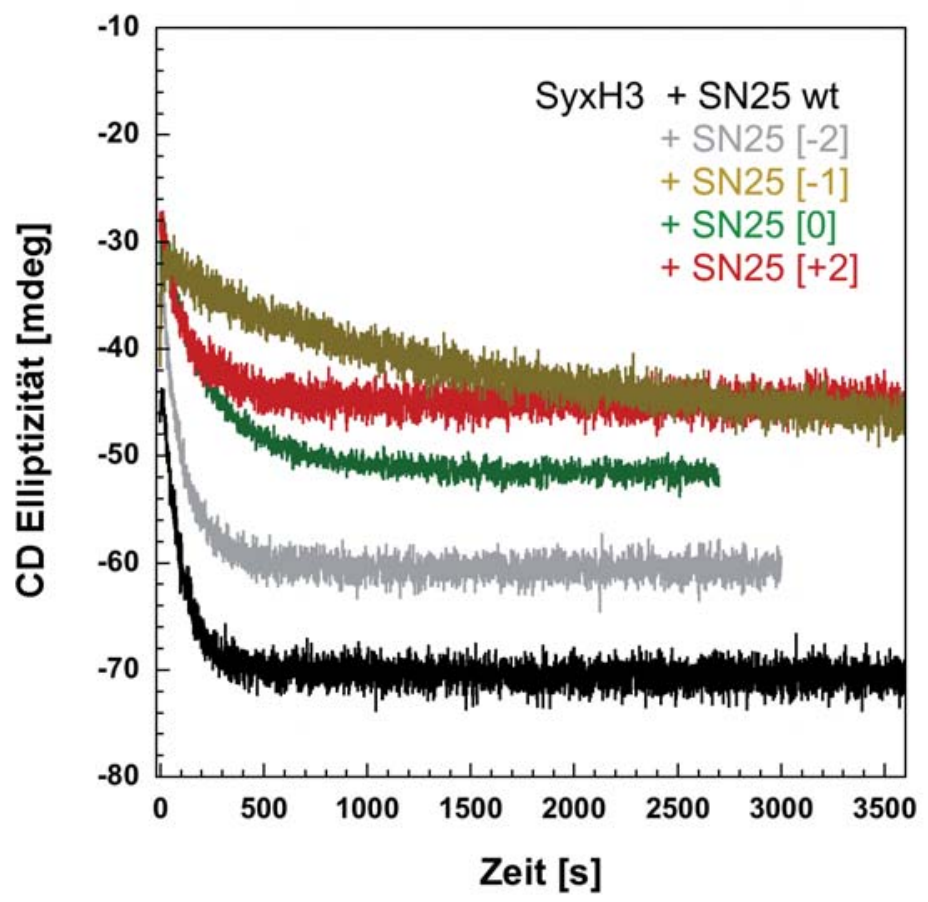

Abbildung 3.3: Die Q-SNARE-Komplexbildung ist mit zentralen SNAP-25 Mutanten teilweise beeinträchtigt. Das SNARE-Motiv von Syntaxin (SyxH3) und die jeweilige SNAP-25-Mutante wurden bei einer Konzentration von je $2 \mu \mathrm{M}$ in Tris-Puffer (20mM Tris pH 7,4, $100 \mathrm{mM} \mathrm{NaCl}, 1 \mathrm{mM}$ DTT) gemischt und der Anstieg des $\alpha$-helikalen Anteils mittels CDSpektroskopie bei $222 \mathrm{~nm}$ verfolgt. Die Interaktion von SyxH3 mit SNAP-25 [-2] und [+2] ist vergleichbar schnell wie mit SNAP-25 wt. Die Mutationen im SNAP-25-Layer -1 und 0 bewirken eine langsamere Bindung an SyxH3.

Wie oben beschrieben wurde die Q-SNARE-Komplexbildung mit den jeweiligen SNAP-25-Mutanten CD-spektroskopisch verfolgt (Abb. 3.3). Die Geschwindigkeit der Komplexbildung von Syntaxin und SNAP-25 [-2] bzw. $[+2]$ war vergleichbar mit der von SNAP-25 wt. Die Interaktion von SNAP-25 [-1] und SNAP-25 [0] mit Syntaxin war allerdings deutlich verlangsamt (Abb. 3.3).

Insgesamt unterstützen diese Ergebnisse die Annahme, dass die Region um den 0-Layer wichtig für die SNARE-Komplexbildung ist. 


\subsubsection{Veränderung der Stabilität der Komplexe mit N- terminalen und zentralen Mutationen in SNAP-25}

Allgemein zeichnen sich SNARE-Komplexe durch eine ungewöhnliche Stabilität aus [63,34]. Der SNARE-Komplex ist SDS-resistent und muss sehr stark erhitzt werden, bevor er in seine Einzelproteine zerfällt. So zeigten thermale Denaturierungsexperimente, bei denen die Entfaltung des SNARE-Komplexes mittels CDSpektroskopie verfolgt wurde, dass sich der Komplex bei $82^{\circ} \mathrm{C}$ entfaltet [34]. Um $\mathrm{zu}$ testen, ob die einzelnen N-terminalen und zentralen Mutationen in SNAP$25 \mathrm{zu}$ einer erhöhten Destabilisierung des SNARE-Komplexes führen, habe ich die jeweiligen Komplexe gereinigt. Um Verunreinigungen in Form von Einzelproteinen und des binären $\mathrm{Syx}_{2} / \mathrm{SN} 25_{1}$-Komplexes auszuschließen, wurden zunächst die ternären Komplexe, bestehend aus Syntaxin, Synaptobrevin und den jeweiligen SNAP-25-Mutanten, chromatographisch gereinigt. Anschließend wurde die Schmelztemperatur CD-spektroskopisch bestimmt. Dafür wurde der SNAREKomplex in einer Küvette erhitzt und der Zerfall der Sekundärstruktur bei der spezifischen Wellenlänge von $222 \mathrm{~nm}$ verfolgt.

Der Verlust von $\alpha$-helikaler Struktur erfolgte in einem einzigen, relativ steilen Übergang. Der wt-Komplex zerfiel bei circa $89^{\circ} \mathrm{C}$ (Abb. 3.4). Dieser Unterschied zum zuvor publizierten Schmelzpunkt $\left(82^{\circ} \mathrm{C}\right.$, [34]) resultiert wahrscheinlich aus der Verwendung unterschiedlicher CD-Geräte. Die Komplexe mit Nterminalen Mutationen ([-7],[-6]) zerfallen bei niedrigerer Temperatur als der wt-Komplex, ebenfalls in einem Übergang. Die Schmelztemperatur beträgt für beide ungefähr $83^{\circ} \mathrm{C}$ (Abb. 3.4). SNARE-Komplexe mit zentralen SNAP-25Mutationen weisen eine erhöhte Instabilität auf, im Vergleich zum wt-Komplex und der Komplexe mit N-terminalen Mutationen. Besonders instabil sind die Komplexe, welche Doppelmutationen in den SNAP-25-Layern 0 und -1 enthalten. Ersterer zeigt eine Tendenz zu einem zweiphasigen Zerfall und eine reduzierte Schmelztemperatur von circa $79^{\circ} \mathrm{C}$. Der SNAP-25 [-1]-Komplex zerfällt bei einer Temperatur von $70^{\circ} \mathrm{C}$. Die Gesamtstabilität der Komplexe ist folglich durch die beiden Mutationen stark beeinflusst (Abb. 3.4). 


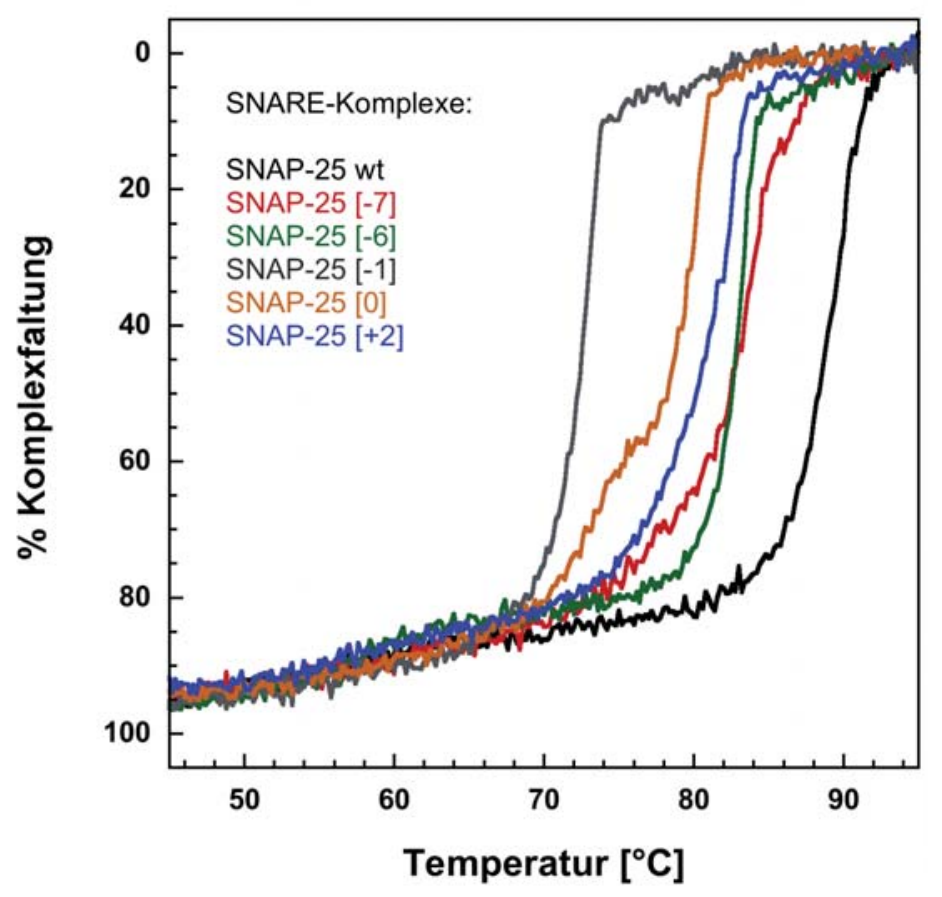

Abbildung 3.4: Die Stabilität der SNARE-Komplexe mit N-terminalen und zentralen SNAP-25 Mutanten ist reduziert. Die gereinigten SNARE-Komplexe, welche SNAP-25 wt oder SNAP-25-Layermutanten enthielten, wurden bei einer Konzentration von 10 $\mu \mathrm{M}$ in Natriumphosphat-Puffer (20 mM Natriumphosphat pH 7,4, $100 \mathrm{mM} \mathrm{NaCl}, 1 \mathrm{mM}$ DTT) von $25^{\circ} \mathrm{C}-95^{\circ} \mathrm{C}\left(30^{\circ} \mathrm{C} / \mathrm{h}\right)$ erhitzt. Die Abnahme der Elliptizität wurde CD-spektroskopisch bei $222 \mathrm{~nm}$ gemessen. Der wt-Komplex zerfällt bei etwa $89^{\circ} \mathrm{C}$. Komplexe mit N-terminalen SNAP25-Mutationen (SNAP-25 [-7], [-6]) zerfallen bei ca. $83^{\circ}$ C. Der Komplex mit SNAP-25 [0] weist einen leichten zweiphasigen Zerfall auf, der SNAP-25 [-1]-Komplex hat eine deutlich reduzierte Schmelztemperatur von ca. $70^{\circ} \mathrm{C}$.

\subsection{Die Bindung von Synaptobrevin an den Qabc-Akzeptorkomplex}

Nachdem im vorherigen Abschnitt die Interaktion von Syntaxin und SNAP-25 als Initiationsreaktion charakterisiert wurde, wende ich mich nun der Bindung von Synaptobrevin an den Akzeptorkomplex zu.

Wie bereits erläutert (Abschnitt 1.5), geht unser kinetisches Modell davon aus, dass sich zunächst ein kurzlebiger Komplex aus einem Molekül Syntaxin und einem SNAP-25 bildet. Dieser SyxH3 1 /SN251-Komplex dient sowohl als Bindungstelle für Synaptobrevin als auch für ein zweites Syntaxin. Aufgrund dieser Kompetition ist es nicht direkt möglich, die Synaptobrevinbindung zu messen, 


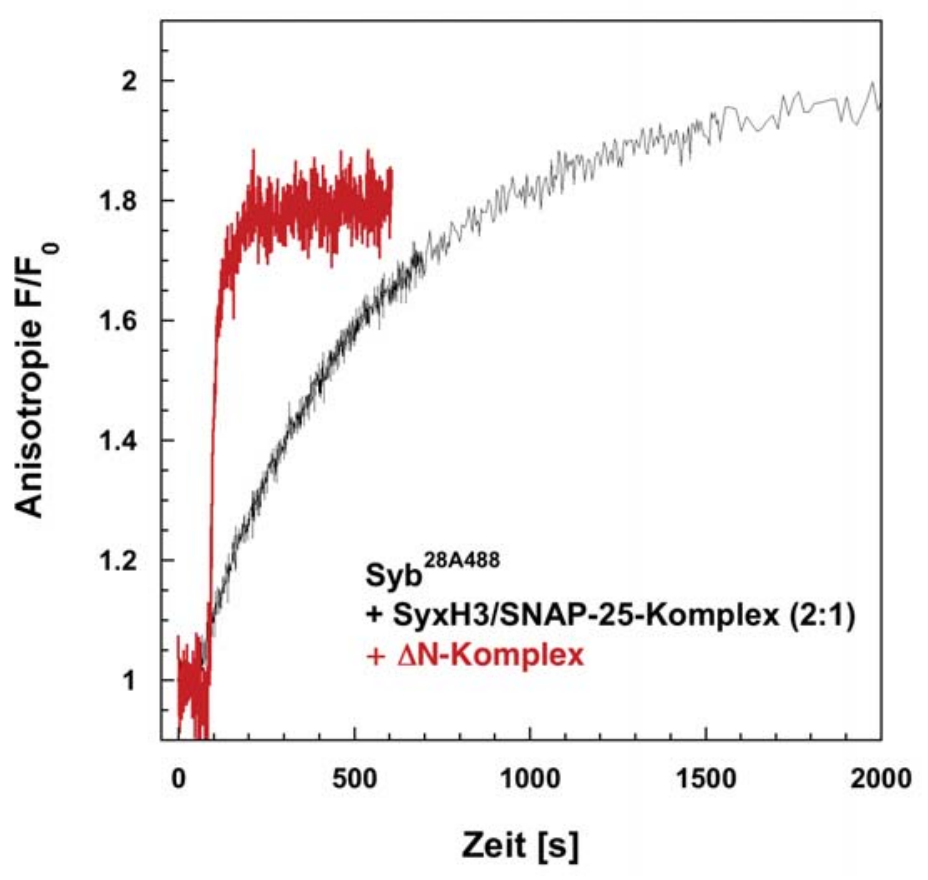

Abbildung 3.5: Ein stabilisierter Akzeptorkomplex erlaubt eine schnelle Synaptobrevinbindung. Die Bindung von $100 \mathrm{nM}$ an der Position 28 mit Alexa488 markiertem Synaptobrevin $\left(\mathrm{Syb}^{28 A 488}\right)$ an $500 \mathrm{nM}$ gereinigten $\Delta$ N-Komplex bzw. vorinkubierten $\mathrm{SyxH} 3_{2} / \mathrm{SN}_{2} 5_{1}$ Komplex wurde fluoreszenzspektroskopisch verfolgt. Die Proteininteraktion hat einen Anstieg der Anisotropie zur Folge. Die Bindung von $\mathrm{Syb}^{28 A 488}$ an den $\Delta$ N-Komplex erfolgt viel schneller, als an den $\mathrm{SyxH}_{2} / \mathrm{SN} 25_{1}$-Komplex.

da sich bei etwa stöchiometrischen Anteilen der beiden Q-SNARE-Proteine immer vorwiegend der wesentlich stabilere Komplex aus Syntaxin und SNAP-25 in 2:1-Stöchiometrie ausbildet ( $\mathrm{SyxH}_{2} / \mathrm{SN} 25_{1}$-Komplex). Synaptobrevin kann nur binden, wenn zuvor das zweite Syntaxin dissoziiert (Abb. 3.5). Dieses experimentelle Problem gilt auch für die SNARE-vermittelte Liposomenfusion, bei der diese Kompetitionsreaktion die eigentliche, topologisch schwierigere, SNAREInteraktion zwischen den Membranen verzögern könnte [142].

In der Arbeit von Fasshauer und Margittai wurde gezeigt, dass ein deutlicher Überschuss von SNAP-25 gegenüber Syntaxin die Synaptobrevinbindung beschleunigen kann [35]. Dies deutet darauf hin, dass das chemische Gleichgewicht von einem SyxH3 $2 /$ SN25 - Komplex in die Richtung eines SyxH3 $1 / \mathrm{SN}_{2} 5_{1}$ Komplexes verschoben wurde. Ein solcher Reaktionsansatz benötigt immer einen großen Überschuss von SNAP-25, was möglicherweise zu Nebenreaktionen führen kann. Um einen definierten und stabilen Akzeptorkomplex zu erhalten, wurde ein 
andere Strategie entwickelt: es wurde ein C-terminales Synaptobrevinpeptid (Syb 49-96) eingesetzt, was mit Syntaxin und SNAP-25 einen stabilen ternären Komplex bilden kann und in dem die N-terminalen Bereiche der Q-SNARE-Helices frei, d. h. nicht im Komplex mit Synaptobrevin vorliegen ( $\Delta$ N-Komplex) [109]. Ein zweites Syntaxin kann an diesen stabilisierten Akzeptorkomplex nicht binden. Ausschließlich Synaptobrevin ist in der Lage, mit den freiliegenden N-Termini der Q-SNARE-Proteine sehr schnell zu interagieren, anschließend das Peptid aus dem Komplex zu verdrängen und einen vollständig gefalteten ternären SNAREKomplex zu bilden (Abb. 3.5). Durch die Verwendung des $\Delta$ N-Komplexes wird der geschwindigkeitsbestimmende Initiationsschritt der SNARE-Komplexbildung übergangen, um ausschließlich den Synaptobrevinbindungsschritt untersuchen zu können.

Der stabilisierte Akzeptorkomplex wurde in den folgenden Experimenten zur Charakterisierung der Synaptobrevinbindungsreaktion verwendet. Zur Herstellung des $\Delta$ N-Komplexes wurden die löslichen Fragmente SyxH3, SNAP-25 und das Synaptobrevinpeptid 49-96 miteinander inkubiert und der entstehende Komplex anschließend chromatographisch gereinigt.

\subsubsection{Kinetische Charakterisierung der Synaptobrevin- bindung}

Der stabilisierte Akzeptorkomplexes ermöglicht es, die Bindungsgeschwindigkeit von Synaptobrevin direkt zu bestimmen. Die Messung mittels CD-Spektroskopie ist hier nicht möglich, da durch diese Interaktion keine nennenswerten Strukturänderungen induziert werden.

Um die Bindungsreaktion verfolgen zu können, wurde Synaptobrevin an der Position 28, in die ein einzelnes Cystein eingeführt wurde, mit dem Fluoreszenzfarbstoff Alexa488 (A488) markiert. Zu einer konstanten Konzentration von markiertem Synaptobrevin wurden jeweils unterschiedliche Konzentrationen des $\Delta \mathrm{N}$-Komplexes hinzugegeben und die Bindung an den $\Delta \mathrm{N}$-Komplex über den Anstieg der Fluoreszenzanisotropie verfolgt (Abb. 3.6A). Je mehr $\Delta$ N-Komplex eingesetzt wurde, desto schneller lief die Reaktion ab. Bei einem hinreichenden Überschuss an unmarkiertem Bindungspartner verläuft die Reaktion exponen- 

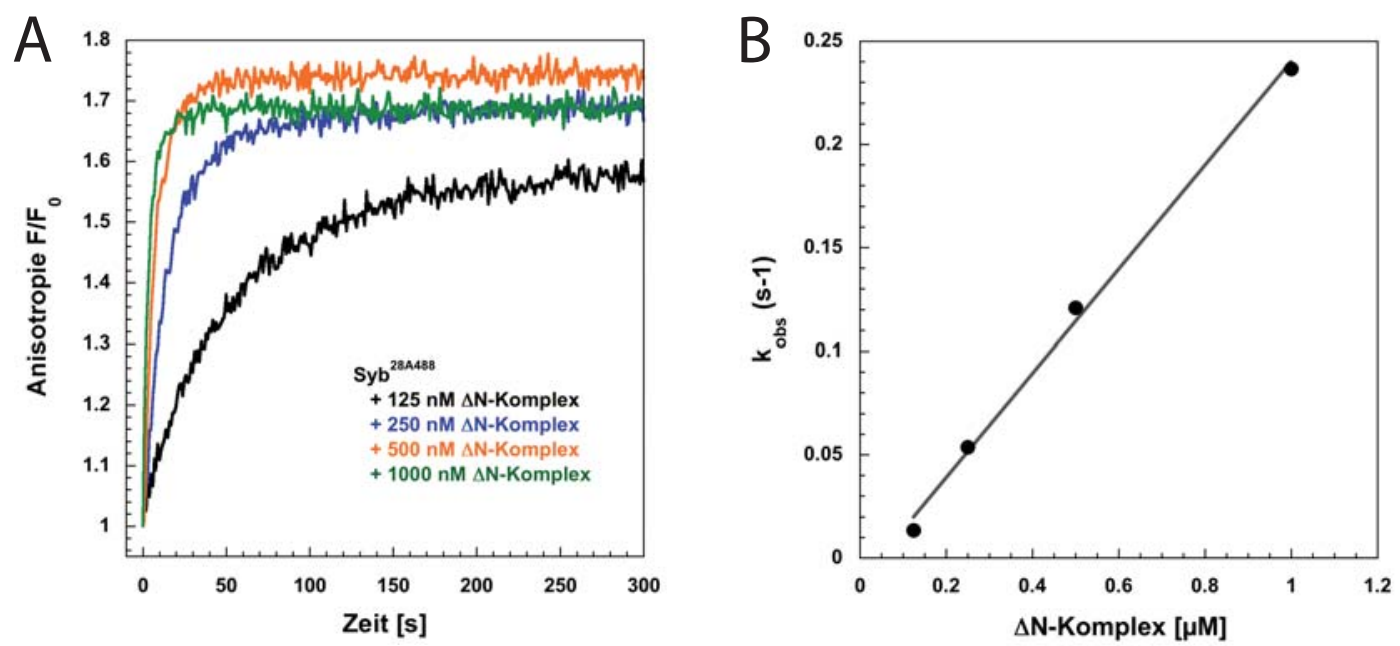

Abbildung 3.6: Bestimmung der Bindungsgeschwindigkeit von Synaptobrevin an den Akzeptor-Komplex. (A) An der Position 28 mit Alexa488 markiertes Synaptobrevin $\left(\mathrm{Syb}^{28 A 488}, 50 \mathrm{nM}\right)$ wurde mit steigenden Konzentrationen gereinigten $\Delta \mathrm{N}$-Komplexes gemischt und die Proteininteraktion als Anstieg der Fluoreszenzanisotropie verfolgt. (B) Die Zeitkonstanten der einzelnen Reaktionen wurde gegen die jeweilige $\Delta \mathrm{N}$-Komplex-Konzentration aufgetragen und die Bindungsgeschwindigkeit als Anstieg der linearen Auftragung bestimmt. Sie beträgt $2,5 \times 10^{5} M^{-1} s^{-1}$.

tiell. Daher kann sie mit einem exponentiellen fit beschrieben werden. Jede Zeitkonstante kann gegen die jeweilige $\Delta \mathrm{N}$-Komplex-Konzentration aufgetragen werden(Abb. 3.6B). Der Anstieg der linearen Anpassung dieser Datenpunkte ergibt die Bindungsgeschwindigkeit. Sie beträgt 2,5 x $10^{5} \mathrm{M}^{-1} \mathrm{~s}^{-1}$, ist vergleichbar mit der zuvor bestimmten Bindungsgeschwindigkeit [109] und dient nachfolgend als Vergleichswert.

\subsubsection{Thermodynamische Charakterisierung der Synap- tobrevinbindung}

Bis heute konnte nicht hinreichend geklärt werden, wieviel Energie während der SNARE-Komplexbildung freigesetzt wird. Dies ist jedoch wichtig, um zu überprüfen, ob diese Reaktionsenergie mechanisch zur Überwindung der Abstoßungskräfte zwischen den Membranen verwendet werden kann. Bisher unveröffentlichte Experimente von Dr. D. Fasshauer zur Thermodynamik der SNAREProteininteraktion haben ergeben, dass die binäre und ternäre Komplexbildung 
aus SyxH3 und SNAP-25 bzw. SyxH3, SNAP-25 und Synaptobrevin exotherme Reaktionen sind. Die Reaktionsenthalpien beider Reaktionen sind sehr hoch; die der binären Interaktion beträgt etwa $-60 \mathrm{kcal} / \mathrm{mol}$ und die der ternären Komplexbildung etwa -115 kcal/mol. Dies hängt wahrscheinlich mit den großen strukturellen Umlagerungen während der Komplexbildung zusammen. Die Enthalpie der ternären Komplexbildung beinhaltet die Interaktion von SyxH3 und SNAP25 , sowie die Bindung von Synaptobrevin. Der $\Delta \mathrm{N}$-Komplex erlaubte nun, die Bindung von Synaptobrevin ohne die vorhergehende Interaktion von SyxH3 und SNAP-25 zu messen.

Um die thermodynamischen Parameter der Synaptobrevinbindung $\Delta \mathrm{N}$ Komplex zu bestimmen, wurde Isothermale Titrationskalorimetrie (ITC) verwendet. Dabei wird in einem adiabaten System die Wärmemenge bestimmt, welche bei einer Proteininteraktion aufgenommen oder abgegeben wird. Daraus können die Bindungskonstante, die -enthalpie, die -entropie sowie die Stöchiometrie der jeweiligen Reaktion bestimmt werden. Im ITC-Experiment wurde der gereinigte $\Delta \mathrm{N}$-Komplex in die Reaktionszelle gegeben und Synaptobrevin 1-96 in $15 \mu \mathrm{l}$ Schritten hinzutitriert (Abb. 3.7). Die Änderung der Wärmemenge während der Proteininteraktionen wurde gegen das Molare Verhältnis von $\Delta$ N-Komplex und Synaptobrevin aufgetragen. Anschließend wurde diese Auftragung mit MicroCal Origin 7.0 unter Verwendung des single site Bindungsmodells analysiert.

Die Affinität der Interaktion von Synaptobrevin und dem $\Delta$ N-Komplex ist mit einer $\mathrm{K}_{d}$ von $1.4+/-0.5 \mathrm{nM}$ sehr hoch. Diese Werte liegen am Rande dessen, was ein ITC-Gerät messen kann. Die Stöchiometrie der Interaktion ist erwartungsgemäß im Bereich von $1(0,92)$ und die Reaktionsenthalpie beträgt $30,2 \mathrm{kcal} / \mathrm{mol}$. Wie von den Vorversuchen von Dr. D. Fasshauer zu erwarten war, ist die Reaktion exotherm, es wird also Energie während der Proteininteraktion freigesetzt. Es sollte jedoch erwähnt werden, dass die Messung zwei Reaktionen beinhaltet, erstens die Bindung des Synaptobrevins an den freien N-Terminus des $\Delta$ N-Komplexes und zweitens das Verdrängen des Synaptobrevinpeptids durch Synaptobrevin 1-96. Es konnte bisher nicht geklärt werden, ob die Verdrängungsreaktion passiv oder aktiv stattfindet. Eine passive Verdrängung würde bedeuten, dass der C-terminale Bereich von Synaptobrevin 1-96 einfach den Platz des Peptids einnimmt und dieses dementsprechend den Komplex verlässt, ohne dass ein 


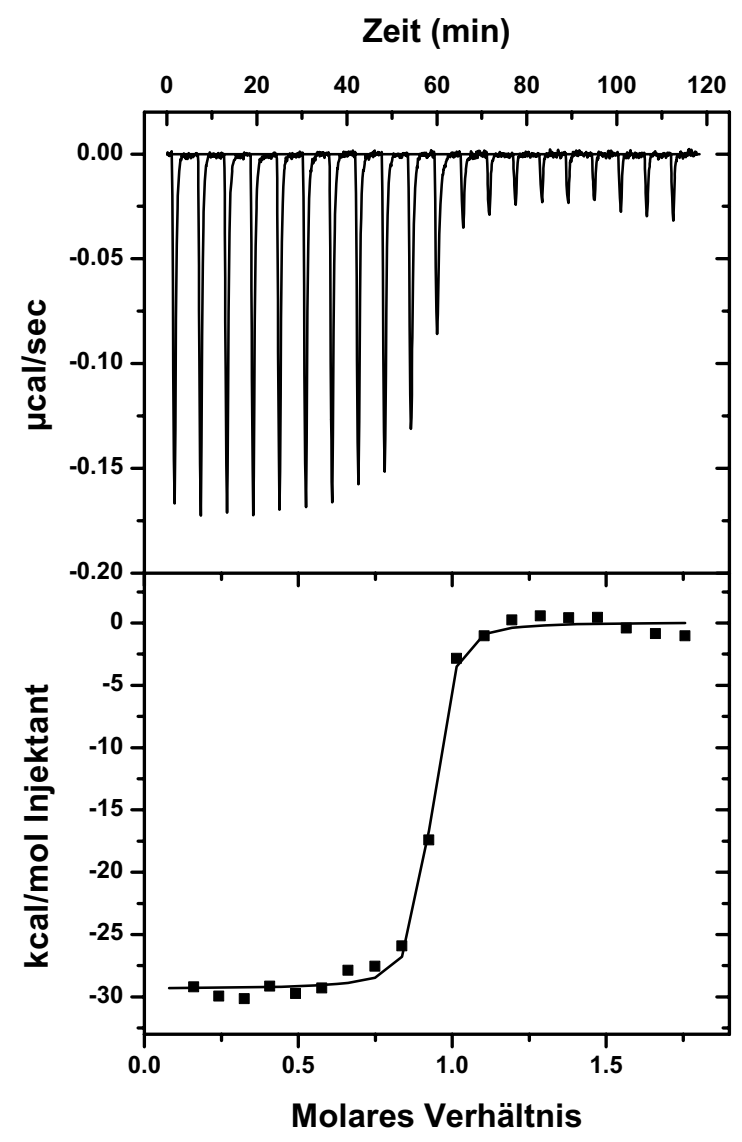

Abbildung 3.7: Der Akzeptor-Komplex bietet eine hochaffine Bindungstelle für Synaptobrevin an. Kalorimetrische Titrationen von Synaptobrevin in $\Delta$ N-Komplex. 2,5 $\mu \mathrm{M}$ gereinigter $\Delta$ N-Komplex befand sich in der Reaktionszelle und $20 \mu \mathrm{M}$ Synaptobrevin 1-96 wurde in $15 \mu \mathrm{l}$-Schritten hinzutitriert (oben). Die integrierte Fläche der Wärmeänderung wurde auf die Menge des Synaptobrevins normalisiert und dies gegen das Molare Verhältnis von Synaptobrevin zu $\Delta \mathrm{N}$-Komplex aufgetragen (unten). Die Linie repräsentiert die beste Anpassung nach Nutzung des single site-Bindungsmodells. Die Affinität der Bindung beträgt 1,4 nM, die Reaktionsenthalpie -30,2 kcal/mol, die Stöchiometrie 0,92 und die Reaktionsentropie -60,8.

zusätzlicher Energieaufwand vonnöten ist. Bei einem aktiven Verdrängungsmechanismus müsste zusätzlich Energie aufgewendet werden, um das Peptid aus dem Komplex zu drängen. Es ist aber auch möglich, dass Energie während der Verdrängung freigesetzt wird. Diese letztere Konstellation würde die tatsächlich freigesetzte Energie in die Komponenten „Bindungsenergie“ und „Verdrängungsenergie" aufteilen. 


\subsubsection{Charakterisierung der Synaptobrevinbindungsstelle des $\Delta \mathrm{N}$-Komplexes}

Im vorherigen Abschnitt wurde gezeigt, dass die Bindung von Synaptobrevin an den $\Delta \mathrm{N}$-Komplex mit hoher Affinität erfolgt. Doch wie muss der N-Terminus des Akzeptorkomplexes aufgebaut sein, um eine hochaffine Bindungsstelle für Synaptobrevin anzubieten? Wiederum bot sich die Verwendung des $\Delta$ N-Komplexes an, um dies näher zu klären. In den nachfolgenden Versuchen habe ich für die Herstellung des $\Delta$ N-Komplexes Q-SNARE-Proteine verwendet, welche N-terminale $\mathrm{Mu}$ tationen oder Verkürzungen enthielten. Zu diesen Konstrukten gehört SNAP-25 [-6], d. h. in beiden SNAP-25-Helices wurden die Aminosäuren im Layer -6 gegen Alanine ausgetauscht. Außerdem wurden SNAP-25 mit N-terminal verkürzter SN1-Helix (SN25 39-206) und N-terminal verkürztes Syntaxin (Syx 212-262) für diese Experimente verwendet. Bei diesen beiden Konstrukten wurde das jeweilige SNARE-Motiv N-terminal bis zum Layer -4 verkürzt (Abb. 3.8A).

Mit diesen Konstrukten wurden die jeweiligen $\Delta \mathrm{N}-$ Komplexe hergestellt und gereinigt, sowie die Bindung Synaptobrevins an diese Komplexe mit Anisotropie verfolgt (Abb. 3.8B). Hierbei kam eine Cysteinvariante von Synaptobrevin zum Einsatz (Syb 1-96 C79), und wurde an der C-terminalen Position 79 mit Alexa488 markiert (Syb 1-96 $\left.{ }^{79 A 488}\right)$.

Die Versuche zeigten, dass Syb 1-96 $6^{79 A 488}$ sehr schnell an den $\Delta$ N-Komplex binden kann, bei dem die N-terminalen Bereiche der Q-SNARE-Proteine unverändert sind (Abb. 3.8B). Die Bindung von Synaptobrevin an den Syx 212$262 / \Delta$ N-Komplex erfolgte etwas langsamer. Verwendete man den SN25 39206/ $\Delta$ N-Komplex, fand fast keine Bindung von Synaptobrevin statt (Abb. 3.8B). Durch die Verkürzungen scheinen wichtige Bereiche der Synaptobrevinbindungsstelle zu fehlen.

Die Bindung von Synaptobrevin an den SNAP-25 [-6]/ $\Delta$ N-Komplex hatte einen schnellen Anstieg der Anisotropie zur Folge. Dies bedeutet, dass Synaptobrevin trotz der Mutation im Layer -6 von SNAP-25 ungehindert an den $\Delta \mathrm{N}$ Komplex binden konnte (Abb. 3.8B). In den vorherigen Experimenten hatte ich gezeigt, dass N-terminale Mutationen in SNAP-25 die Bildung des Syx/SNAP25-Komplexes und des ternären Komplexes inhibieren (Abb. 3.2B). Wird dieser 

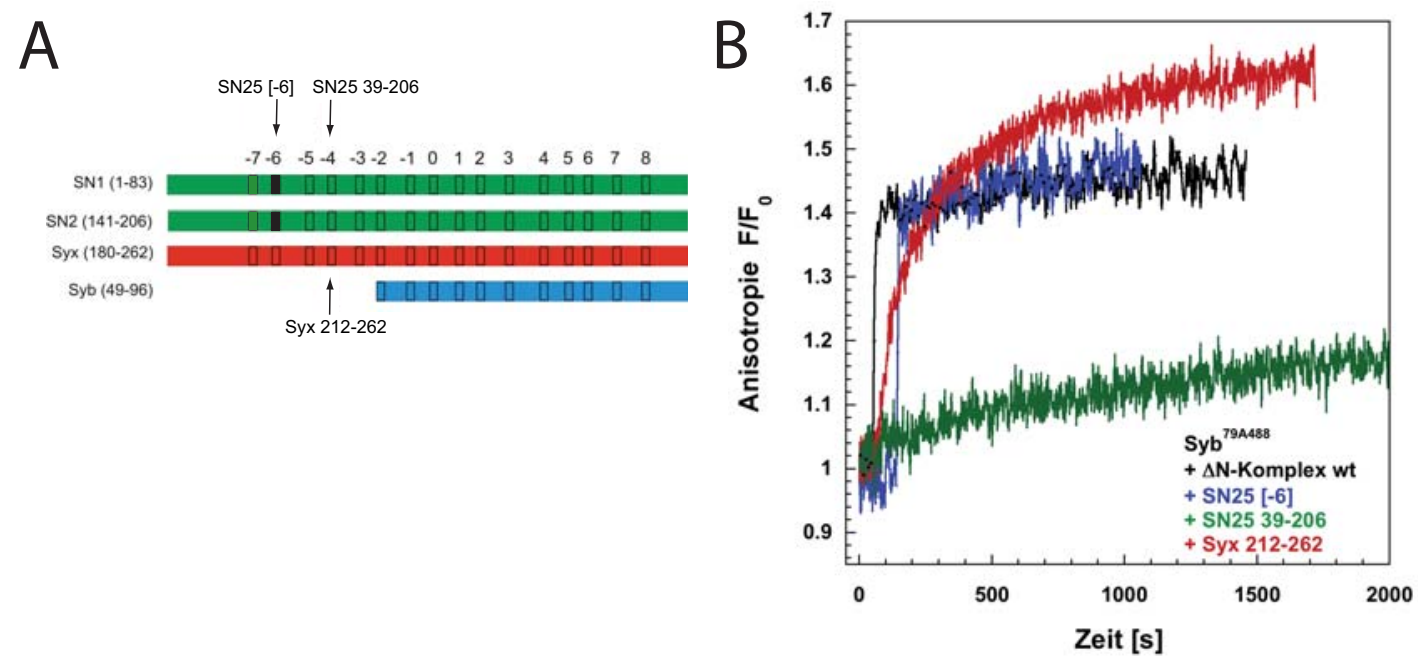

Abbildung 3.8: Charakterisierung der Synaptobrevinbindungsstelle des $\Delta \mathrm{N}$ Komplexes. (A) Graphische Darstellung der verwendeten $\Delta$ N-Komplexe mit N-terminalen SNAP-25-Mutationen bzw. -Verkürzungen. $\Delta$ N-Komplexe enthalten entweder in beiden Helices des SNAP-25 im Layer -6 ein Alanin (SN25 [-6]), ein SNAP-25 mit N-terminal verkürzter SN1Helix (SN25 39-206) oder ein N-terminal verkürztes Syntaxin (Syx 212-262). Die Positionen der Mutation bzw. der Verkürzung im jeweiligen Komplex sind mit Pfeilen markiert. (B) Bestimmung der Bindungskinetik von an der Position 79 mit Alexa488 markiertem Synaptobrevin (Syb 1-96 ${ }^{79 A 488}$ ) mit N-terminal veränderten $\Delta$ N-Komplexen. $100 \mathrm{nM}$ Syb 1-96 $6^{79 A 488}$ wurden mit jeweils $500 \mathrm{nM} \Delta \mathrm{N}$-Komplex vermischt und die Bindung mittels Anisotropie verfolgt. Syb 1-96 ${ }^{79 A 488}$ kann vergleichbar gut an den $\Delta$ N-Komplex und den SN25 [-6]/ $\Delta$ N-Komplex bin-

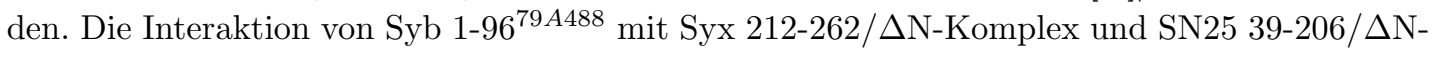
Komplex ist beeinträchtigt.

Schritt umgangen, die $\Delta$ N-Komplexbildung erfolgt bei hohen Proteinkonzentrationen und langer Inkubationszeit $(16 \mathrm{~h})$, stellt die Mutation keine Hürde für die Synaptobrevinbindung dar.

Um die Bindungsstelle für Synaptobrevin im $\Delta$ N-Komplex noch ausführlicher charakterisieren zu können, sollte die Struktur des $\Delta \mathrm{N}-$ Komplexes anhand von Röntgenstrukturanalyse bestimmt werden. Dafür wurden die SNARE-Motive von Syntaxin und SNAP-25 ohne Linkerregion, sowie das Synaptobrevinpeptid 49-96 miteinander inkubiert und der entstandene Komplex anschließend chromatographisch gereinigt. In der Abteilung von Dr. Markus Wahl (MPI für biophysikalische Chemie, Arbeitsgruppe Röntgenkristallographie) wurden verschiedene Bedingungen zur Proteinkristallisation untersucht. Es bildeten sich einige Kristalle, welche der Röntgenstrukturanalyse unterzogen wurden (in Zusammenarbeit 
mit Gert Weber und Simon Trowitzsch). Die folgende Strukturbestimmung ergab jedoch, dass diese Kristalle einen Komplex, bestehend aus jeweils zwei Syntaxin und SNAP-25 SN1-Helices enthielten. Anscheinend waren die Kristallisationsbedingungen zu harsch, weshalb der gereinigte $\Delta \mathrm{N}$-Komplex währenddessen zerfiel und der stabilere 2:2 Syx/SN1-Komplex entstand. Da der SNARE-Komplex kristallisiert werden konnte [135], könnte das darin begründet sein, dass der $\Delta \mathrm{N}$ Komplex instabiler ist als der SNARE-Komplex.

\subsubsection{Bindung von N-terminalen Synaptobrevinmutanten an den $\Delta \mathrm{N}$-Komplex}

Im vorhergehenden Kapitel wurde dargestellt, dass bereits geringe Veränderungen des Bindungsbereiches von Synaptobrevin zu Änderungen im Bindungsverhaltens von Synaptobrevin führen.

Um den Bereich von Synaptobrevin zu charakterisieren, welcher wichtig für die Bindung an den Akzeptorkomplex ist, habe ich eine Reihe von Synaptobrevinvarianten getestet. In den folgenden Experimenten wurde ein N-terminal verkürztes Synaptobrevin verwendet, sowie Mutanten, die je zwei Alanine in Layer -7 und -6 (Syb L32A, T35A; Syb [-7/-6]), bzw. in Layer -5 und -4 (Syb V39A, V42A; Syb [-5/-4]) enthielten. Diese Synaptobrevinkonstrukte wurden für Anisotropiemessungen zur Bestimmung der Bindungskinetik eingesetzt. Für die Messungen wurde ein markierter $\Delta \mathrm{N}$-Komplex verwendet. Dazu wurde ein $\Delta \mathrm{N}$-Komplex hergestellt, welcher Syntaxin, SNAP-25 und eine Cysteinvariante des Synaptobrevinpeptids (Syb 49-96 C79) enthielt. Anschließend wurde dieser $\Delta$ N-Komplex an der Position 79 des Synaptobrevinpeptids mit dem Farbstoff Alexa488 markiert. Bindet Synaptobrevin an den $\Delta \mathrm{N}$-Komplex und wird damit das markierte Peptid aus dem Komplex verdrängt, verringert sich die Anisotropie (Abb. 3.9). Mit diesem Experiment misst man demnach nicht die eigentliche Bindung von Synaptobrevin an den Komplex, sondern den darauf folgenden Verdrängungsschritt.

Wt Synaptobrevin 1-96 kann sehr schnell das markierte Peptid aus dem Komplex verdrängen $\left(\mathrm{t}_{1 / 2} \approx 11,5 \mathrm{~s}\right.$ ) (Abb. 3.9). Das N-terminal verkürzte Synaptobrevin (25-96) verdrängte das Peptid mit ähnlicher Kinetik $\left(\mathrm{t}_{1 / 2} \approx 13 \mathrm{~s}\right)$ (Abb. 


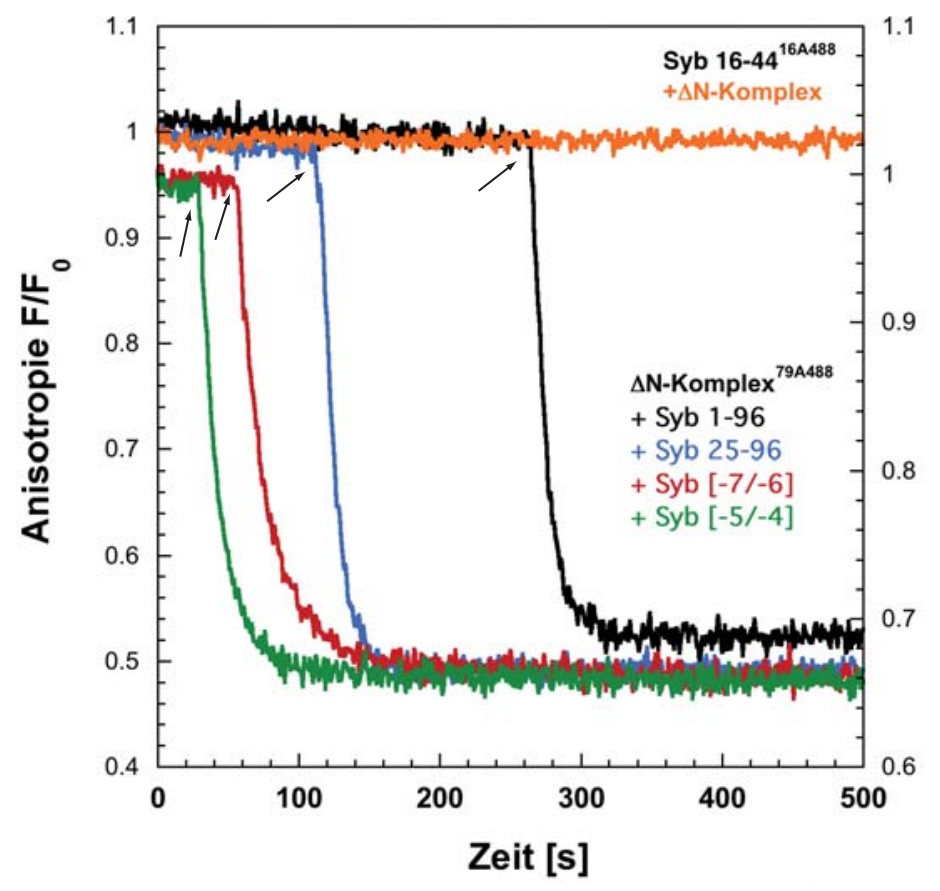

Abbildung 3.9: Der N-Terminus von Synaptobrevin ist nicht essenziell für die Bindung an den Akzeptorkomplex. $100 \mathrm{nM} \Delta \mathrm{N}$-Komplex mit einem an der Position 79 mit Alexa488 markiertem Synaptobrevinpeptid $\left(\Delta \mathrm{N}-K_{\text {Komplex }}{ }^{79 A 488}\right)$ wurde mit jeweils 500 nM N-terminal veränderten Synaptobrevinen gemischt und mittels Anisotropie verfolgt. Es wurden Synaptobrevinmutanten mit Alaninen in den Layern -7/-6 (Syb [-7/-6]) und -5/-4 (Syb [-5/-4]) sowie Synaptobrevin 25-96 (Syb 25-96) verwendet. Nach der Aufnahme einer Basislinie mit $\Delta$ N-Komplex ${ }^{79 A 488}$ wurde Synaptobrevin hinzugegeben. Der Zeitpunkt der Zugabe ist mit einem Pfeil markiert. Die Bindung von Synaptobrevin an den $\Delta$ N-Komplex wurde aufgrund der Verdrängung des markierten Peptids aus dem $\Delta$ N-Komplex als Abfall der Anisotropie bestimmt. Die Verdrängung des Peptids mit Syb [-7/-6], Syb [-5/-4], Syb 25-96 und Syb 1-96 findet vergleichbar schnell statt, wobei Syb $[-7 /-6]$ etwas langsamer zu verdrängen scheint.

In einem weiteren Experiment wurde ca. $100 \mathrm{nM}$ N-terminal markiertes Synaptobrevinpeptid 16-44 (Syb 16-44 ${ }^{C 16 A 488}$ ) mit $500 \mathrm{nM} \Delta$ N-Komplex gemischt und mittels Anisotropie untersucht. Es konnte keine Änderung der Anisotropie beobachtet werden, das Peptid Syb 16$44^{16 A 488}$ scheint nicht an den $\Delta \mathrm{N}-$ Komplex zu binden.

3.9). Die ersten 24 Aminosäuren scheinen nicht entscheidend zur Verdrängungsgeschwindigkeit beizutragen. Dies lässt darauf schließen, dass der Bereich (Syb 1-24), der sich N-terminal vom Synaptobrevin-SNARE-Motiv (Syb 32-94) befindet, nicht an der Bindungsreaktion beteiligt ist. Noch kürzere Synaptobrevinkonstrukte wurden nicht getestet, da schon gezeigt wurde, dass Synaptobrevin 35-96 und 42-96 das markierte Peptid nicht aus dem $\Delta$ N-Komplex verdrängen können und der eigentliche Bindungsbereich scheinbar auf wenige Aminosäuren 
beschränkt ist [109].

Im Vergleich zur Verdrängung mit Synaptobrevin 1-96, fand die Verdrängung des markierten Peptids durch Syb [-7/-6] und Syb [-5/-4] etwas langsamer statt $\left(\mathrm{t}_{1 / 2} \approx 23 \mathrm{~s}\right.$ bzw. $\left.\mathrm{t}_{1 / 2} \approx 16 \mathrm{~s}\right)($ Abb. 3.9).

Um die genaue Bindungsgeschwindigkeit für diese beiden Mutanten zu bestimmen, wurde ein an der Position 28 eingeführtes Cystein in beiden Mutanten mit Alexa488 markiert und in einem weiteren Experiment die Bindung an den $\Delta \mathrm{N}-$ Komplex mit Anisotropie verfolgt. Die Bindungsgeschwindigkeiten wurden, wie bereits in Abschnitt 3.2.1 beschrieben, bestimmt und sind in der Tabelle 3.1 zusammengefasst. Die Bindungsgeschwindigkeit von Syb [-5/-4] an den $\Delta \mathrm{N}$ Komplex beträgt $3,3 \times 10^{5} M^{-1} s^{-1}$, ist also vergleichbar mit der Bindung des wt, während die Bindung von Syb $[-7 /-6]$ an den $\Delta$ N-Komplex etwa sechs mal langsamer ist $\left(4,4 \times 10^{4} M^{-1} s^{-1}\right)$.

Tabelle 3.1: Zusammenfassung der ermittelten Bindungsgeschwindigkeiten

\begin{tabular}{l|r} 
Interaktion von & Bindungsgeschwindigkeit $\left[M^{-1} s^{-1}\right]$ \\
\hline \hline Syb $1-96^{28 A 488}+\Delta \mathrm{N}-\operatorname{Komplex}(\Delta \mathrm{N})$ & $2,5 \times 10^{5}$ \\
\hline Syb $[-7 /-6]^{28 A 488}+\Delta \mathrm{N}$ & $4,4 \times 10^{4}$ \\
\hline Syb $[-5 /-4]^{28 A 488}+\Delta \mathrm{N}$ & $3,3 \times 10^{5}$ \\
\hline Syb $1-52^{53 A 488}+\Delta \mathrm{N}$ & $8,0 \times 10^{4}$ \\
\hline Syb $[-3]^{28 A 488}+\Delta \mathrm{N}$ & 860 \\
\hline Syb 71-96 ${ }^{97 T R}+\Delta \mathrm{C}-$ Komplex (Syb 1-70) & 350 \\
\hline
\end{tabular}

Zusätzlich zur kinetischen Charakterisierung wurden mittels ITC die thermodynamischen Parameter der Bindungsreaktion der N-terminal veränderten Synaptobrevine an den $\Delta \mathrm{N}$-Komplex bestimmt (Zusammenfassung in Tab. 3.2). Die Bindungsaffinität von Syb 25-96 an den $\Delta$ N-Komplex ist vergleichbar mit der von Syb 1-96, jedoch ist die Enthalpie dabei etwas reduziert. In Übereinstimmung mit den zuvor dargestellten Experimenten, die zeigten, dass Syb [-7/-6] etwas schlechter an den $\Delta$ N-Komplex binden kann, beträgt die Reaktionsenthalpie der Bindung von Syb [-7/-6] -17,6 kcal/mol und die Affinität der Bindung ist 
etwa 36 mal geringer (54,3 nM) als die des Syb wt. Obwohl die vorherigen Experimente ergaben, dass Syb [-5/-4] gut an den $\Delta \mathrm{N}-\mathrm{Komplex}$ binden kann, konnte eine leicht verringerte Enthalpie von $-24,2 \mathrm{kcal} / \mathrm{mol}$ bei der Bindung von Syb [-5/-4] an den $\Delta$ N-Komplex und eine Affinität von 11,2 nM festgestellt werden. Jedoch scheinen die Synaptobrevin-Layer -7 und -6 wichtiger für die Bindung an den $\Delta$ N-Komplex zu sein.

Wie ich bereits zuvor angemerkt habe, sollte nicht außer Acht gelassen werden, dass mit Hilfe des $\Delta$ N-Komplexes zwar die direkte Bindung Synaptobrevins an den Akzeptorkomplex gemessen werden kann, aber zusätzlich eine weitere Reaktion, die Verdrängung des Peptids, stattfindet. Um diese beiden Reaktionen zu trennen und sich auf den Bindungsschritt konzentrieren zu können, wurde ein N-terminales Synaptobrevinpeptid (Syb 16-44) synthetisiert. Nach den bisherigen Befunden, die darauf hindeuten, dass der N-terminale Bereich des stabilisierten Akzeptorkomplexes eine freie und strukturierte Bindungstelle für den N-terminalen Bereich von Synaptobrevin anbieten, sollte ein Peptid Syb 16-44 in der Lage sein, an den $\Delta \mathrm{N}-$ Komplex zu binden, jedoch nicht das stabilisierende C-terminale Peptid (Syb 49-96) zu verdrängen. Dies ist in Abbildung 3.1 schematisch dargestellt. Syb 16-44 enthält an der Position 16 ein Cystein und wurde an dieser Stelle mit Alexa488 markiert, sowie anschließend die Bindung an den $\Delta \mathrm{N}$-Komplex mittels Anisotropie bestimmt. Interessanterweise konnte keine Änderung in der Anisotropie festgestellt werden (Abb. 3.9). Überraschenderweise deuten diese Fluoreszenzmessungen darauf hin, dass Syb 16-44 nicht an den $\Delta \mathrm{N}-$ Komplex bindet.

\subsubsection{Die Region zwischen -4 und -1-Layer von Synap- tobrevin ist wichtig für die Bindung an den $\Delta \mathrm{N}$ - Komplex}

Warum kann das N-terminale Synaptobrevinfragment (16-44) nicht an den $\Delta \mathrm{N}$ Komplex binden, obwohl eine frei zugängliche Bindungsstelle vorhanden ist? Gibt es einen Bereich im Synaptobrevin im Anschluss an Aminosäure 44, welcher essentiell für die Bindung an den Akzeptorkomplex ist? Um den für die Bindung notwendigen Bereich im Protein zusätzlich einzugrenzen, verwendete ich C-terminal 
Tabelle 3.2: Zusammenfassung aller ITC-Experimente.

Die mit einem * gekennzeichneten Daten wurden von Dr. Dirk Fasshauer zur Verfügung gestellt.

\begin{tabular}{|c|c|c|c|c|}
\hline Interaktion von & $K_{d}[\mathrm{nM}]$ & $\Delta H[\mathrm{kcal} / \mathrm{mole}]$ & $\Delta S$ & $N$ \\
\hline$\Delta \mathrm{N}-\mathrm{Komplex}(\Delta \mathrm{N})+$ Syb 1-96 & $1.4+/-0.5$ & $-30.2+/-0.3$ & -60.8 & 0.92 \\
\hline$\Delta \mathrm{N}+$ Syb 25-96 & $4.1+/-1.1$ & $-25.8+/-0.4$ & -48.2 & 0.91 \\
\hline$\Delta \mathrm{N}+\mathrm{Syb}[-7 /-6]$ & $54.3+/-14.1$ & $-17.6+/-0.4$ & -25.8 & 0.96 \\
\hline$\Delta \mathrm{N}+\operatorname{Syb}[-5 /-4]$ & $11.2+/-3.6$ & $-24.2+/-0.4$ & -44.8 & 1.00 \\
\hline$\Delta \mathrm{N}+$ Syb 1-88 & $7.1+/-1.5$ & $-16.7+/-0.2$ & -18.6 & 1.00 \\
\hline$\Delta \mathrm{N}+$ Syb 1-65 & $5.7+/-1.2$ & $-18.1+/-0.2$ & -23.1 & 0.97 \\
\hline$\Delta \mathrm{N}+$ Syb $1-52$ & $23.6+/-3.3$ & $-23.0+/-0.3$ & 42.0 & 1.02 \\
\hline$\Delta \mathrm{N}+$ Syb $22-44$ & keine Bindung & & & \\
\hline$\Delta \mathrm{N}+\mathrm{Eb} 1-74$ & $1.1+/-0.8$ & $-16.9+/-0.2$ & -15.8 & 0.97 \\
\hline$\Delta \mathrm{N}+\operatorname{Vamp} 447-117$ & $3.6+/-1.1$ & $-14.8+/-0.2$ & -10.5 & 0.83 \\
\hline$\Delta \mathrm{N}+\mathrm{SaCe} \operatorname{Sec} 22$ 126-196 & $63.5+/-15.8$ & $-7.3+/-0.2$ & 8.5 & 0.89 \\
\hline$\Delta \mathrm{N}+$ Tomosyn 1031-1116 & keine Bindung & & & \\
\hline$\Delta \mathrm{N}+\mathrm{Syb}[-3]$ & $364.7+/-43.4$ & $-16.0+/-0.4$ & -24.3 & 0.96 \\
\hline$\Delta \mathrm{N}+\operatorname{Syb}[-2]$ & $7.5+/-2.0$ & $-22.9+/-0.3$ & -39.6 & 0.96 \\
\hline$\Delta$ C-Komplex + Syb 71-96 & $1368.0+/-293.1$ & $-6.0+/-0.3$ & 6.9 & 0.89 \\
\hline *SNAP-25 + SyxH3 & 103 & -65 & -185 & 0.49 \\
\hline *SNAP25/SyxH3-Komplex + Syb & 30 & -53 & -143 & 0.87 \\
\hline${ }^{*}$ SyxH3/Syb + SNAP-25 & 89 & -125 & -386 & 0.81 \\
\hline
\end{tabular}


verkürzte Synaptobrevine (Übersicht in Abb. 3.1). Hierbei enthält Syb 1-88 das komplette SNARE-Motiv ohne die 'linker'-Region zwischen SNARE-Motiv und Transmembrandomäne. Syb 1-65 ist C-terminal bis Layer 3 und Syb 1-52 bis Layer -1 verkürzt. Das Synaptobrevinkonstrukt 1-52 enthielt zusätzlich ein Cystein am C-Terminus (Syb 1-52 C53). Die Anisotropiemessungen wurden mit dem bereits in Abschnitt 3.2.4 verwendeten $\Delta \mathrm{N}$-Komplex durchgeführt, welcher ein markiertes Synaptobrevinpeptid enthält. In Abbildung 3.10 sind die Kinetiken der Verdrängung des markierten Synaptobrevinpeptids dargestellt. Die Verdrängung des markierten Peptids durch Syb 1-88 erfolgte etwas langsamer $\left(\mathrm{t}_{1 / 2} \approx\right.$ $60 \mathrm{~s})$ als mit Syb 1-96 ( $\left.\mathrm{t}_{1 / 2} \approx 11,5 \mathrm{~s}\right)$. Auch mit Syb 1-65 ließ sich eine langsame Verdrängung beobachten $\left(\mathrm{t}_{1 / 2} \approx 145 \mathrm{~s}\right)$. Am langsamsten war die Reaktion mit Syb 1-52. Dieser Versuch wurde zusätzlich mit dem etwas längeren Syb 1-59 durchgeführt und ebenfalls eine sehr langsame Verdrängungsreaktion festgestellt (nicht gezeigt). Mit Syb 1-59 war nach etwa 16 Stunden das markierte Synaptobrevinfragment nicht vollständig aus dem Komplex verdrängt. Es ist demnach wahrscheinlich, dass die Verdrängungsreaktion mit dem noch kürzeren Syb 1-52 genauso langsam, wenn nicht sogar langsamer abläuft.

Diese Versuche zeigen, dass je mehr Synaptobrevin C-terminal verkürzt wurde, desto langsamer wurde das Synaptobrevinpeptid 49-96 aus dem Komplex gedrängt.

Es gibt zwei mögliche Erklärungen für die sehr langsame Verdrängung des markierten Peptids aus dem $\Delta$ N-Komplex durch Syb 1-52 C53. Erstens, Syb 1-52 C53 konnte nur schlecht an den Komplex binden und deshalb konnte eine sehr langsame Verdrängung beobachtet werden. Zweitens, Syb 1-52 C53 konnte zwar gut binden, aber das Peptid schlecht aus dem Komplex verdrängen, da Syb 1-52 C53 nur wenige Aminosäuren mit dem Peptid 49-96 im $\Delta \mathrm{N}-$ Komplex überlagert. Um eine eindeutige Aussage darüber zu erhalten, wurde das Syb 1-52 C53 an der Position 53 mit Alexa488 markiert und die Bindung an den $\Delta \mathrm{N}-$ Komplex anhand von Fluoreszenzspektroskopie verfolgt. Hierbei war zu beobachten, dass die Interaktion von Syb 1-52 $2^{53 A 488}$ mit dem $\Delta \mathrm{N}-$ Komplex einen Abfall der Fluoreszenz zur Folge hatte (Abb. 3.11). Der Fluoreszenzabfall, welcher wahrscheinlich auf Bindung beruht, wird vermutlich durch quenching des Farbstoffs als Folge der Proteininteraktion verursacht. Die Ergebnisse deuten daraufhin, dass Syb 1- 


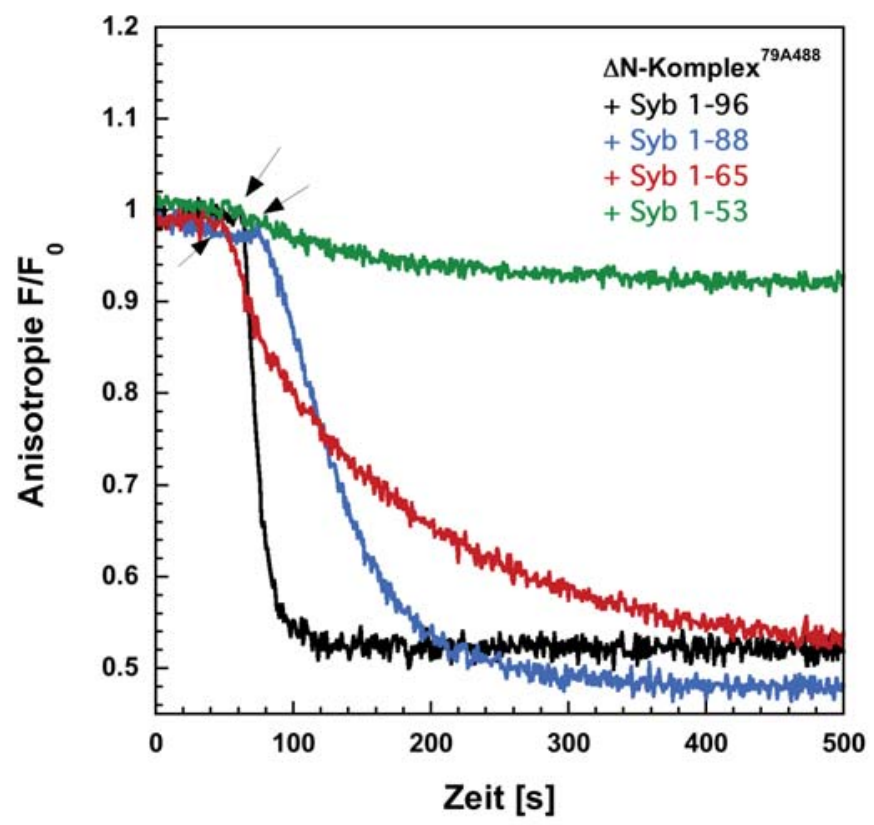

Abbildung 3.10: Bindung von C-terminal verkürzten Synaptobrevinen an den $\Delta \mathrm{N}$-Komplex. C-terminal verkürzte Synaptobrevine können das Synaptobrevinpeptid des $\Delta \mathrm{N}$-Komplexes schlechter verdrängen. Zu $100 \mathrm{nM} \Delta$ N-Komplex mit einem an der Position 79 mit Alexa488 markiertem Synaptobrevinpeptid $\left(\Delta \mathrm{N}-K_{\text {Komplex }}{ }^{79 A 488}\right)$ wurden jeweils $500 \mathrm{nM}$ der C-terminal verkürzten Synaptobrevine gegeben und die Interaktion fluoreszenzspektroskopisch verfolgt. Nach der Aufnahme einer Basislinie mit $\Delta$ N-Komplex ${ }^{79 A 488}$ wurden die Synaptobrevine hinzugegeben. Der Zeitpunkt der Zugabe ist mit einem Pfeil markiert. Die Bindung der Synaptobrevine an den $\Delta \mathrm{N}$-Komplex wurde aufgrund der Verdrängung des markierten Peptids aus dem $\Delta \mathrm{N}$-Komplex als Abfall der Anisotropie bestimmt. Je weiter der C-Terminus des Synaptobrevins verkürzt ist, desto schlechter findet die Verdrängung des markierten Peptids aus dem $\Delta \mathrm{N}$-Komplex statt.

$52^{53 A 488}$ an den $\Delta \mathrm{N}-$ Komplex binden, nicht aber das Synaptobrevinpeptid aus dem Komplex verdrängen konnte.

Anhand der Fluoreszenzänderung wurde, wie in Abschnitt 3.2.1 beschrieben, die Bindungsgeschwindigkeit von Syb $1-52^{53 A 488}$ an den $\Delta$ N-Komplex bestimmt und ist in der Tabelle 3.1 aufgeführt. Die Bindungsreaktion ist im Vergleich zum Syb 1-96 etwa drei mal langsamer. Da Syb 1-52 an den $\Delta$ N-Komplex binden kann, scheint dieses Konstrukt den entscheidenden, für die Bindung wichtigen, Bereich zu enthalten. Demnach trägt die Region zwischen den Aminosäuren 45 und 52 ( Synaptobrevin-Layer -3 bis -1) zur Bindung an den Akzeptorkomplex bei.

Wenn Syb 1-52 C53 in der Tat an den $\Delta$ N-Komplex binden kann, aber 


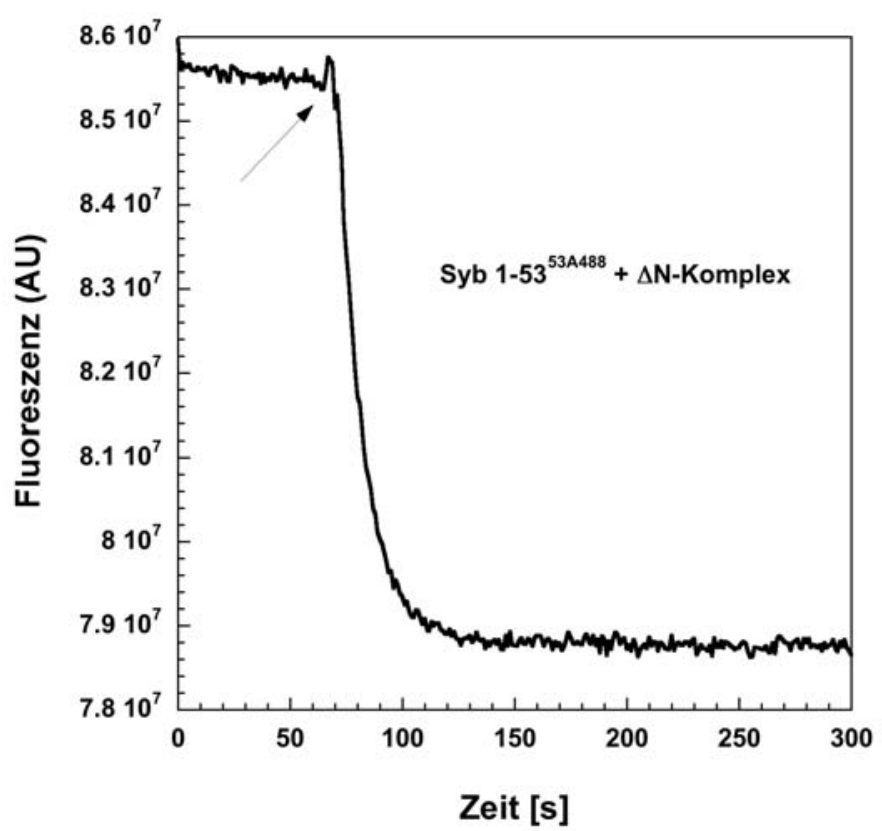

Abbildung 3.11: Bindung Syb 1-52 an $\Delta \mathrm{N}-$ Komplex. Synaptobrevin 1-52 kann an den $\Delta$ N-Komplex binden. $100-200 \mathrm{nM}$ an der Position 53 mit Alexa488 markiertes Synaptobrevin 1-52 (Syb 1-52 $2^{53 A 488}$ ) wurde mit $1 \mu \mathrm{M} \Delta$ N-Komplex gemischt und die Interaktion mittels Fluoreszenzspektroskopie verfolgt. Der Zeitpunkt der $\Delta$ N-Komplex-Zugabe ist mit einem Pfeil markiert. Die Zugabe hat einen Abfall der Fluoreszenz zur Folge. Dies wird wahrscheinlich durch ein 'quenching' des Farbstoffs aufgrund der Proteininteraktion hervorgerufen. Syb 1-52 ist demnach in der Lage an den $\Delta \mathrm{N}$-Komplex zu binden.

nicht oder nur sehr langsam die Verdrängung des Peptids unterstützt, müsste es möglich sein, die thermodynamischen Parameter des Synaptobrevinbindungsschrittes losgelöst von der nachfolgenden Verdrängung mittels ITC bestimmen zu können. Wie die Verdrängungsexperimente zeigten, benötigt diese Reaktion mehrere Stunden. Sie würde damit so langsam erfolgen, dass dies nicht signifikant in den ITC-Messungen wahrgenommen wird. Die Titration von $\Delta$ N-Komplex und Syb 1-52 C53 ergab eine Affinität von 23,6 nM und eine Enthalpie von -23,0 $\mathrm{kcal} / \mathrm{mol}$ (Tab. 3.2). Dieser Wert repräsentiert die freigesetzte Energie während der Bindung Synaptobrevins an den Akzeptorkomplex. Hingegen beträgt die Enthalpie der Bindung von Syb 1-96 an den $\Delta$ N-Komplex, welche die beiden Reaktionen Bindung und Verdrängung beinhaltet etwa $-30 \mathrm{kcal} / \mathrm{mol}$. Anscheinend wird während der Verdrängungsreaktion eine zusätzliche Wärme von circa $7 \mathrm{kcal} / \mathrm{mol}$ frei.

Zusätzlich wurden die thermodynamischen Eigenschaften der Bindung von 
Syb 1-88 und Syb 1-65 an den $\Delta$ N-Komplex bestimmt. Sie sind ebenfalls in der Tabelle 3.2 zusammengefasst. Die Bindungsaffinitäten der C-terminal verkürzten Synaptobrevine an den $\Delta \mathrm{N}-$ Komplex sind etwa viermal niedriger als mit Synaptobrevin 1-96. Auch die Reaktionsenthalpien sind mit beiden Konstrukten deutlich um fast $50 \%$ reduziert. Da die Reaktionsenthalpien dieser beiden Konstrukte der Enthalpie des Versuches mit Syb 1-52 C53 ähneln, könnte es möglich sein, dass auch mit den weniger C-terminal verkürzten Synaptobrevinkonstrukten nur die Enthalpie der Bindung bestimmt wurde. Vielleicht erfolgt die Verdrängung so langsam, dass sie in die ITC-Messungen nicht signifikant einfließt.

\subsubsection{Spezifität der R-SNARE-Bindung}

Die vesikulären Transportschritte in eukaryotischen Zellen werden durch verschiedene SNARE-Komplexe katalysiert. Obwohl ein ständiger Austausch der Membranen innerhalb der Zelle stattfindet, sind SNARE-Proteine hauptsächlich in den Membranen ihres jeweiligen Wirkungsortes konzentriert. Es ist noch ungeklärt, wie die Spezifität der SNARE-Interaktion gewährleistet wird. Wird sie primär durch Faktoren bewirkt, die für die richtige Lokalisation sorgen oder erfolgt allein die Interaktion der SNARE-Proteine spezifisch? In vivo reagieren SNARE-Proteine nur in bestimmten Zusammensetzungen. Jedoch haben in vitro-Experimente gezeigt, dass SNARE-Proteine promiskuitiv SNARE-Komplexe bilden können, d. h. SNARE-Proteine verschiedener Membrantransportschritte können, in der QabcR-Zusammensetzung, miteinander 'gemischte' Komplexe bilden [31]. Bei diesen Experimenten wurden jedoch nicht die Komplexbildungsschritte betrachtet, sondern nur, ob sich diese gemischten Komplexe bilden können, z. B. wurde der Schritt der Synaptobrevinbindung nicht isoliert betrachtet.

Wiederum bietet sich der stabilisierte Akzeptorkomplex an, um diesen Schritt detailiert zu analysieren. Um zu untersuchen, wie spezifisch die R-SNAREBindungsreaktion an den Akzeptorkomplex ist, wurden die SNARE-Motive der R-SNARE-Homologen Endobrevin/VAMP8 (Eb), VAMP4, Sec22 und Tomosyn für Bindungsexperimente verwendet. Endobrevin ist ein R-SNARE, welches $u$. a. bei der Fusion von Endosomen eine wichtige Rolle spielt, VAMP4 ist ein R- 
SNARE des Trans-Golgi-Netzwerks und Sec22 kommt im Membranverkehr des Endoplasmatischen Retikulums vor [3,130,98]. Tomosyn ist ein regulatorisches Protein, welches am C-Terminus ein R-SNARE-Motiv besitzt, jedoch keine Transmembranregion enthält [44].

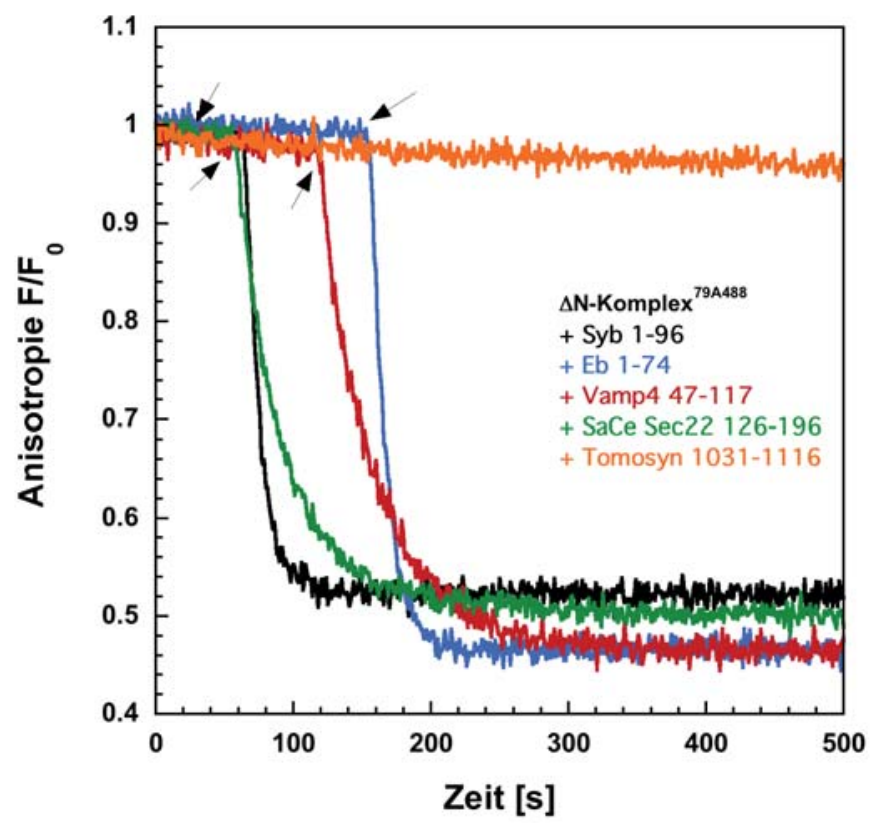

Abbildung 3.12: Bindung von homologen R-SNARE-Proteinen an den $\Delta \mathrm{N}$ Komplex. $100 \mathrm{nM} \Delta$ N-Komplex mit einem an der Position 79 mit Alexa488 markiertem Synaptobrevinpeptid $\left(\Delta \mathrm{N}-K_{\text {Komplex }}{ }^{79 A 488}\right)$ wurde mit jeweils $500 \mathrm{nM}$ Synaptobrevin-Homologen gemischt und mittels Anisotropie verfolgt. Es wurden folgende R-SNARE Homologe verwendet: Endobrevin 1-74 (Eb 1-74), VAMP4 47-117, Tomosyn 1031-1116 und Sec22 126-196 (SaCe Sec22). Die Proteinsequenzen stammen aus der Maus, wobei Sec22 eine Ausnahme bildet, da dessen Proteinsequenz aus der Bäckerhefe stammt. Nach der Aufnahme einer Basislinie mit $\Delta \mathrm{N}-$ Komplex ${ }^{79 A 488}$ wurden die Homologe hinzugegeben. Der Zeitpunkt der Zugabe ist mit einem Pfeil markiert. Die Bindung der Homologe an den $\Delta$ N-Komplex wurde aufgrund der Verdrängung des markierten Peptids aus dem $\Delta$ N-Komplex als Abfall der Anisotropie bestimmt. Eb ersetzte das Peptid mit einer vergleichbaren Geschwindigkeit wie Syb; VAMP4 und Sec22 verdrängten etwas langsamer. Interessanterweise kann Tomosyn das markierte Peptid nicht aus dem $\Delta \mathrm{N}$-Komplex verdrängen.

Zunächst sollte mit Hilfe von Fluoreszenzanisotropie überprüft werden, ob die Syb-Homologen an den $\Delta \mathrm{N}-$ Komplex binden können. Da es keine Cysteinvarianten der Homologen gab, war es nicht möglich, diese mit einem Fluoreszenzfarbstoff zu markieren. Dementsprechend wurde der markierte $\Delta$ N-Komplex für die Untersuchungen verwendet und die Verdrängung des markierten Synapto- 
brevinpeptids beobachtet. Die Zugabe von Endobrevin, VAMP4 und Sec22 zum $\Delta \mathrm{N}$-Komplex bewirkte, dass das markierte Peptid wurde von diesen Homologen aus dem Komplex verdrängt wurde (Abb. 3.12). Allerdings existierten Unterschiede in der Geschwindigkeit der Verdrängung. Endobrevin $\left(\mathrm{t}_{1 / 2} \approx 13 \mathrm{~s}\right)$ verdrängte das Peptid mit einer vergleichbaren Geschwindigkeit wie Synaptobrevin $\left(t_{1 / 2} \approx\right.$ $11,5 \mathrm{~s})$. Die Verdrängung durch VAMP4 $\left(\mathrm{t}_{1 / 2} \approx 41 \mathrm{~s}\right)$ und Sec22 $\left(\mathrm{t}_{1 / 2} \approx 57 \mathrm{~s}\right)$ lief etwas langsamer ab. Bemerkenswerterweise war Tomosyn nicht in der Lage, das Peptid aus dem Komplex zu drängen. Da man mit dieser Art Experiment nur die Verdrängung des markierten Peptids verfolgen werden kann, ist es nicht möglich, die Frage zu beantworten, ob die Bindung der homologen Proteine schlechter bzw., im Fall von Tomosyn, gar nicht erfolgt oder ob nach der Bindung an den Akzeptorkomplex nur der Verdrängungsschritt behindert ist.

Um die Bindung der R-SNARE-Homologe an den $\Delta$ N-Komplex darüber hinaus zu charakterisieren, wurden die thermodynamischen Parameter dieser Interaktionen zusätzlich mittels ITC bestimmt. Eine Zusammenfassung der Ergebnisse dieser Messungen können der Tabelle 3.2 entnommen werden. Die Bindungsaffinitäten von VAMP4 und Endobrevin an den $\Delta$ N-Komplex sind etwa gleich hoch wie die von Synaptobrevin. Die Bindungsenthalpie dieser Proteine ist niedriger (-16,9 bzw. $-14,8 \mathrm{kcal} / \mathrm{mol})$ als die der Reaktion von Synaptobrevin mit dem $\Delta \mathrm{N}$-Komplex $(-30,2 \mathrm{kcal} / \mathrm{mol})$. Auch Sec22 hat eine geringere Bindungsenthalpie (-7,3 kcal/mole) als Synaptobrevin. Des Weiteren ist die Affinität der Sec22Bindung an den Akzeptorkomplex deutlich (um den Faktor 40) reduziert. Es gibt demnach leichte Unterschiede in der Präferenz der R-SNARE-Motive von Sec22, Vamp4 und Endobrevin in der Bindung an den neuronalen Akzeptorkomplex.

Interessanterweise konnte mittels Isothermaler Titrationskalorimetrie keine Bindung Tomosyns an den Akzeptorkomplex festgestellt werden. Dies stimmt mit den Verdrängungsexperimenten überein, zeigt aber, dass schon der Bindungsschritt blockiert ist. Da die anderen R-SNARE-Homologen gut an den Akzeptorkomplex binden konnten, stellte sich die Frage nach dem Unterschied zwischen dem nicht bindenden Tomosyn und den übrigen getesteten R-SNARE-Proteinen.

Um diese Fragestellung zu beantworten, wurde auf die in unserer Abteilung durchgeführte bioinformatische Klassifikation der SNARE-Proteine zurückgegriffen [74]. Die Klassifikation unterteilt die R-SNARE-Homologen nach ih- 
ren Sequenzeigenschaften in verschiedene Gruppen (R.I, R.II, R.III, R.IV und R.Reg), welche in allen Eukaryoten vorkommen. Diese Typen lassen sich bestimmten Transportschritten bzw. Kompartimenten zuordnen [74]. Synaptobrevin ist ein R-SNARE der Gruppe R.IV, gehört also zu den sekretorischen R-SNAREProteinen. VAMP4 und Endobrevin wurden in die Gruppe R.III eingeteilt und kommen in endosomalen Kompartimenten vor. Sec22 stellt ein R-SNARE des Endoplasmatischen Retikulums dar und wird in die Gruppe R.I eingeteilt. Tomosyn wurde der R.Reg-Gruppe zugeordnet, da man davon ausgeht, dass dieses Protein regulatorische Aufgaben übernimmt (siehe auch im Abschnitt 1.6). Auf Anfrage stellte Tobias Klöpper mir die klassifizierten und alignierten SNARE-Motive der Metazoen zur Verfügung. Um einen ersten Eindruck über die Konservierung der einzelnen Positionen innerhalb der R-SNARE-Proteine, aber auch der einzelnen Gruppen zu erhalten, wurde die Software WebLogo verwendet [24]. Das Ergebnis der Analyse ist in Abbildung $3.13 \mathrm{zu}$ sehen. Zum einen fällt auf, dass die Positionen in Layer -3 und -2 in allen Gruppen außer R.Reg und R.II stark konserviert sind.

Des Weiteren ist es augenscheinlich, das die Konservierung des Nterminalen Teils des SNARE-Motivs von Tomosyn gegenüber den anderen Gruppen stark reduziert ist. Um einen detailierteren Einblick in die sequenzspezifischen Eigenschaften der Untergruppen zu erhalten, wurde eine Methode von Hannenhalli und Kollegen verwendet [57]. Diese Methode wurde eigens für die Identifizierung von spezifitätsgebenden Positionen in Untergruppen entwickelt und es konnte gezeigt werden, dass solche Positionen oft eine funktionelle Bedeutung für alle Gruppen besitzen.

Die Analyse ergab, dass die Layerpositionen -3, 0 und +6 wichtig für die Unterteilung der SNARE-Untergruppen Qa, Qb, Qc und R zu sein scheinen. Eine weiterführende Analyse der R-SNARE-Proteine ergab außerdem, dass die Layerposition -2 und die C-terminal benachbarte Position von Layer -2 spezifitätsgebende Positionen der R-SNARE-Untergruppen sind. Zwei Beispiele für solche Positionen sind zum einen das Auftreten von Glutamin (Q) und Arginin (R) im Layer 0, welche den Q-SNARE- und R-SNARE-Proteinen ihren Namen geben, und zum anderen das Auftreten von Threonin (T) im Layer -2 von Ykt6, welches in keinem anderen R-SNARE vorzukommen scheint. 
R-SNARE-Motiv

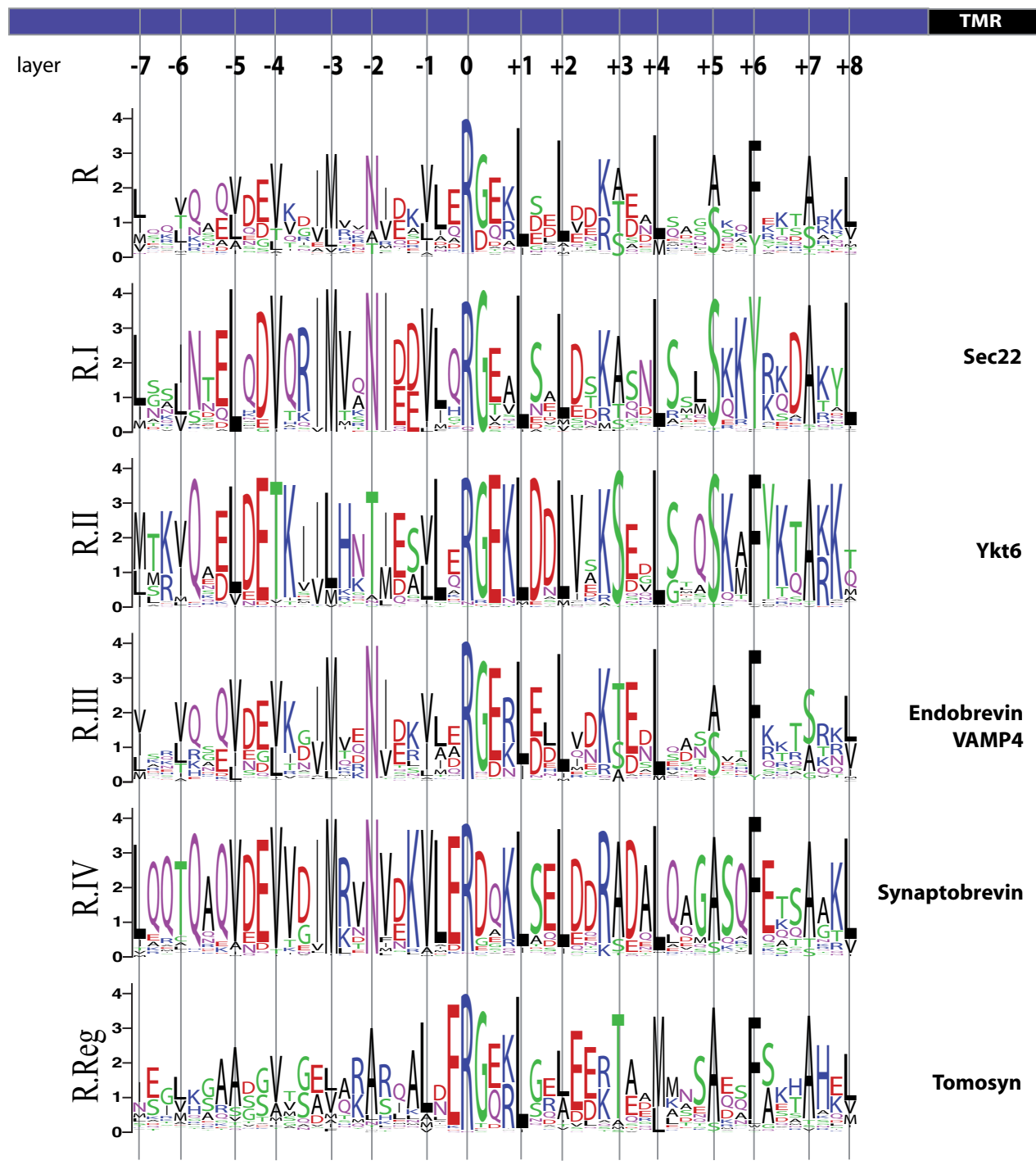

Abbildung 3.13: Konservierung der R-SNARE-Motive. Grundlage der Berechnung sind die nach [74] klassifizierten R-SNARE-Proteine von über 150 Metazoa. Für die Berechnung wurden das stark konservierte Kernstück des SNARE-Motivs mit einer Länge von 53 AS verwendet. Die Motive wurden mit Hilfe der in [74] erzeugten HMM-Modelle aligniert [28] und über das WebInterface [24] in die gewünschte graphische Form überführt. Bei den Abbildungen reflektiert die Höhe eines Buchstaben seine relative Häufigkeit im Alignment in Relation zum Vorkommen von anderen AS an der selben Position. Eine erste spezifische Mutation innerhalb aller dargestellten SNARE-Proteine ist das Arginin (R) im 0-Layer der Motive, welche ihnen auch ihren Namen gab: R-SNARE-Proteine. Des Weiteren sind die spezifischen Mutationen im -3 und -2-Layer zu erkennen, welche in 3.2.7 genauer untersucht wurden. Außerdem ist eine deutlicher Unterschied zwischen dem N-terminalen Bereich von Tomosyn Proteinen zu allen anderen Gruppen zu erkennen. Während alle anderen Gruppen in diesem Bereich stark konservierte AS besitzen (u. A. im -3 und -2-Layer), scheinen diese bei Tomosynen nicht mehr vorzukommen. 
Zusammenfassend zeigen meine Analysen, dass der N-terminale Teil des RSNARE-Motivs stark konserviert ist. Dies ist interessant, weil es dem Sequenzabschnitt entspricht, welcher von mir als entscheidend für die Bindung an den Q-SNARE Akzeptorkomplex identifiziert wurde. Bemerkenswerterweise trifft diese Konservierung nicht für den N-Terminus der Tomosyn-Gruppe (R.Reg) zu.

\subsubsection{Veränderungen in der konservierten $\mathrm{N}$-terminalen Region beeinflussen die Synaptobrevinbindung an den Akzeptorkomplex}

Für die Bindung an den Akzeptorkomplex benötigt Synaptobrevin den Bereich zwischen Layer -7 bis -4. Jedoch reicht dieser Bereich nicht für die Bindung aus. Zusätzlich ist der nachfolgende Abschnitt von Layer -4 bis -1 kritisch für die Bindung an den Akzeptorkomplex. Um diesen Bereich eingehender zu charakterisieren, wurden zwei Synaptobrevinmutanten hergestellt, in denen die besonders konservierten Layer-Positionen, sowie benachbarte Aminosäuren gegen Alanine ausgetauscht wurden (Syb I45A, M46A, kurz Syb [-3] genannt, und N49A, V50A; Syb [-2]). Des Weiteren wurde eine Tomosyn-Synaptobrevin-Chimäre konstruiert, in der die Tomosynregion AS 1100-1105 (Layer -4 bis -2) durch die des Synaptobrevins (Syb AS 44-49) ersetzt wurde (Tomo/Syb-Chimäre).

Diese Konstrukte wurden auf ihre Fähigkeit hin getestet, das markierte Synaptobrevinpeptid aus dem $\Delta$ N-Komplex verdrängen zu können. Im Gegensatz zu Tomosyn kann die Tomosyn/Synaptobrevin-Chimäre an den $\Delta$ N-Komplex binden und das markierte Peptid verdrängen, wenn auch relativ langsam (Abb. 3.14). Das bedeutet, dass der Austausch von nur fünf Aminosäuren in der LayerRegion -4 bis -2 von Tomosyns die Bindung der Chimäre und die Verdrängung des Peptids aus dem $\Delta$ N-Komplex ermöglicht.

Die Zugabe von Syb [-2] zum markierten $\Delta \mathrm{N}$-Komplex verdrängt das markierte Synaptobrevinpeptid etwas langsamer als Synaptobrevin wt (Abb. 3.14). Die Mutante Syb [-3] kann das markierte Peptid nur sehr langsam aus dem Komplex verdrängen (Abb. 3.14). Um sicherzustellen, dass diese Synaptobrevinmutante in der Tat auch zügig an den $\Delta \mathrm{N}$-Komplex bindet und nicht ausschließlich der Verdrängungsschritt blockiert ist, wurde eine Cysteinvariante hergestellt und 


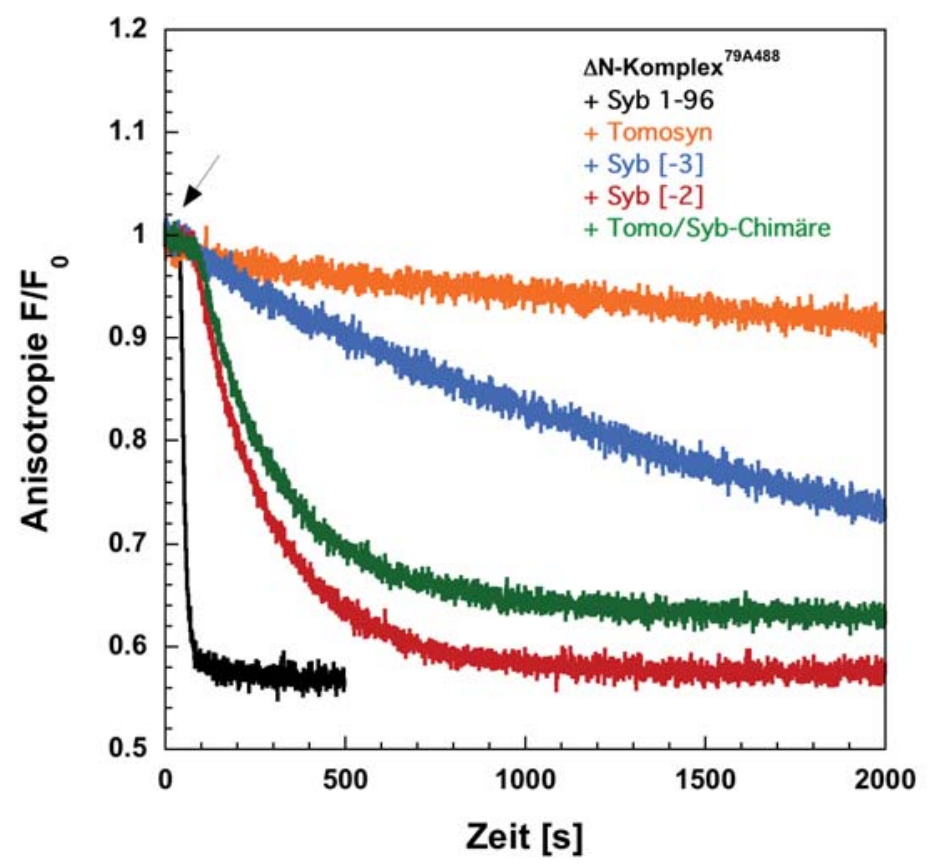

Abbildung 3.14: Mutationen der Synaptobrevinregion Layer -4 bis -2 inhibieren die Bindung an den Akzeptorkomplex. $100 \mathrm{nM} \Delta \mathrm{N}$-Komplex mit einem an der Position 79 mit Alexa488 markiertem Synaptobrevinpeptid $\left(\Delta \mathrm{N}-\mathrm{Komplex}^{79 A 488}\right)$ wurde mit jeweils 500 nM Synaptobrevin- bzw. Tomosynmutante gemischt und mittels Anisotropie verfolgt. Es wurden folgende Konstrukte verwendet: Syb wt, Tomosyn 1031-1116, Synaptobrevin I45A, M46A (Syb [-3]), Synaptobrevin N49A, V50A (Syb [-2]) und eine Tomosyn/Synaptobrevin-Chimäre (Tomo/Syb-Chimäre), in welcher der Bereich der Layer -4 bis -2 (Tomosyn AS 1100-1105 gegen Syb AS 44-49) ausgetauscht wurde. Nach der Aufnahme einer Basislinie mit $\Delta$ N-Komplex ${ }^{79 A 488}$ wurden die Konstrukte hinzugegeben. Der Zeitpunkt der Zugabe ist mit einem Pfeil markiert. Die Bindung der Mutanten an den $\Delta$ N-Komplex wurde aufgrund der Verdrängung des markierten Peptids aus dem $\Delta$ N-Komplex als Abfall der Anisotropie bestimmt. Syb [-2] und Syb [-3] können das markierte Peptid nur langsam aus dem $\Delta$ N-Komplex verdrängen. Im Gegensatz zum Tomosyn kann die Tomo/Syb-Chimäre das Peptid aus dem Komplex ersetzen, wenn auch langsamer als Syb.

diese an der Position 28 mit Alexa488 markiert. Dieses Experiment zeigte, dass Syb [-3] in der Lage ist, an den $\Delta$ N-Komplex zu binden, jedoch mussten deutlich höhere Konzentrationen der Proteine eingesetzt werden, um eine Sättigung der Reaktion zu erreichen (Abb. 3.15A). Dies spricht für eine geringe Affinität der Interaktion. Die Bindungsgeschwindigkeit dieser Interaktion beträgt $860 \mathrm{M}^{-1} \mathrm{~s}^{-1}$ und ist also deutlich langsamer als die wt-Reaktion (Abb. 3.15B).

Um die Bindung ausführlicher zu untersuchen, wurden ITC-Experimente durchgeführt. Eine Zusammenfassung der Ergebnisse dieser Messung ist der Ta- 

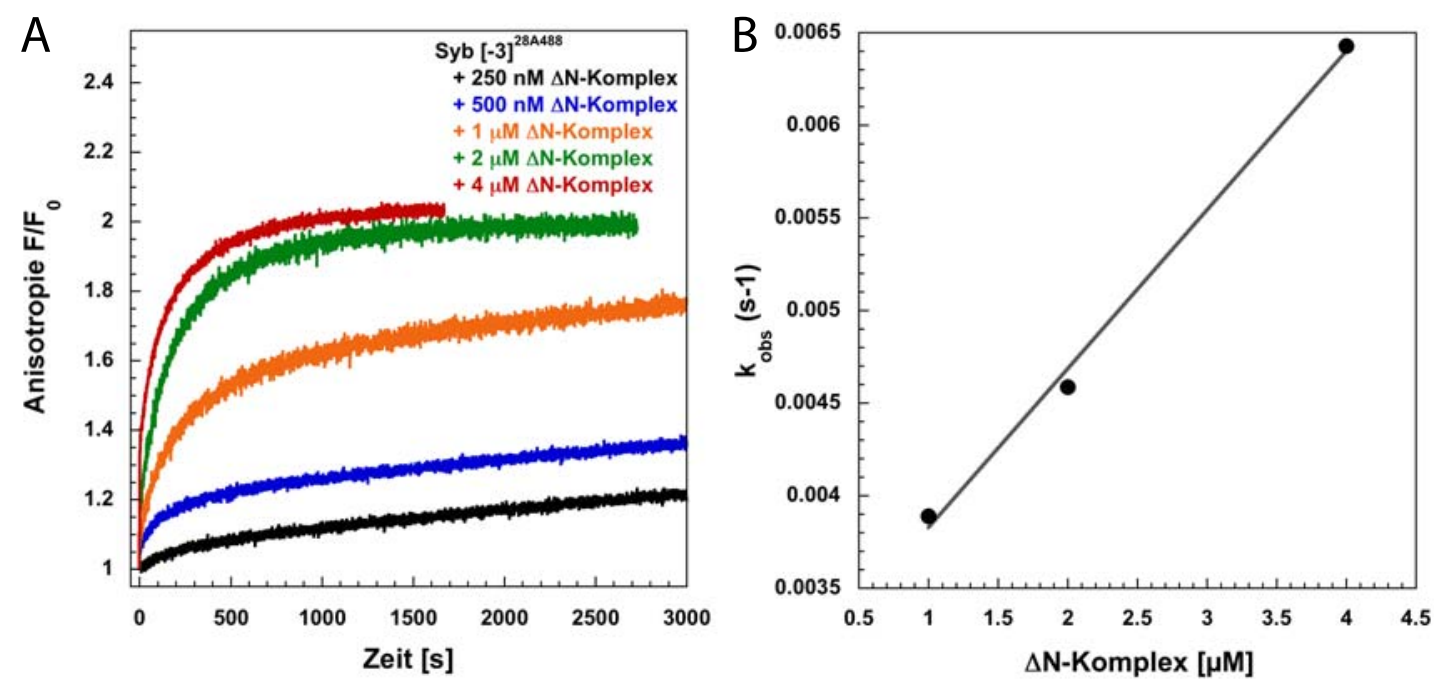

Abbildung 3.15: Bestimmung der Bindungsgeschwindigkeit von Synaptobrevin [-3] an den Akzeptor-Komplex. (A) An der Position 28 mit Alexa488 markiertes Synaptobrevin [-3] $\left(\mathrm{Syb}[-3]^{28 A 488}, 50 \mathrm{nM}\right)$ wurde mit steigenden Konzentrationen gereinigten $\Delta \mathrm{N}$ Komplexes gemischt und die Proteininteraktion als Anstieg der Fluoreszenzanisotropie verfolgt. (B) Die Zeitkonstanten der einzelnen Reaktionen wurde gegen die jeweilige $\Delta$ N-KomplexKonzentration aufgetragen und die Bindungsgeschwindigkeit als Anstieg der linearen Auftragung bestimmt. Sie beträgt $860 M^{-1} s^{-1}$.

belle $3.2 \mathrm{zu}$ entnehmen. Die Affinität der Interaktion von Syb [-3] mit dem $\Delta \mathrm{N}-$ Komplex betrug $365 \mathrm{nM}$. Diese verringerte Affinität war schon in den Fluoreszenzmessungen erkennbar. Die Interaktion ist demnach circa 200mal schwächer als die des wt; die Enthalpie der Reaktion war ebenfalls reduziert. Demzufolge haben allein die Aminosäuren 45 und 46 einen erheblichen Einfluss sowohl auf die Bindung des Synaptobrevins als auch auf das Verdrängen des Peptids aus dem $\Delta$ N-Komplex. Die Bindungsaffinität der Interaktion von Syb [-2] mit dem $\Delta \mathrm{N}$-Komplex war mit 7,5 nM etwa fünfmal schwächer und auch die Reaktionsenthalpie war mit -22.9 kcal/mol etwas niedriger als die von Synaptobrevin (Tab. 3.2). Insgesamt scheint der Effekt dieser Aminosäuren 49 und 50 deutlich weniger gravierend als mit Syb [-3] zu sein.

Zusammenfassend kann festgestellt werden, dass die Mutationen in den konservierten Layer-Regionen einen signifikanten Einfluss sowohl auf die Bindung Synaptobrevins an den Akzeptorkomplex, als auch auf die Verdrängungsreaktion haben. 


\subsection{Die C-terminale Zipper-Reaktion}

Im letzten Abschnitt dieses Kapitels werde ich auf meine Untersuchungen zur finalen C-terminalen Zipper-Reaktion eingehen, also dem Schritt, der nach der Bindung von Synaptobrevin erfolgt.

\subsubsection{Partiell unstrukturierte SNARE-Komplexe}

Es wird davon ausgegangen, dass sich, nachdem Synaptobrevin an den QabcAkzeptorkomplex gebunden hat, der C-Terminus des Vier-Helixbündels ausbildet und der so formierte SNARE-Komplex die gegenüberliegenden Membranen in eine räumliche Nähe bringt. Demnach bewirkt der Schritt letztendlich die Fusion. Verschiedene Arbeiten, welche die Auswirkungen von Antikörpern und Neurotoxinen auf die Sekretion testeten, ergaben, dass SNARE-Proteine in einem der letzten Schritte der Exozytose involviert sind. Es wurde vorgeschlagen, dass ein teilweise ausgebildeter trans-SNARE-Komplex mit einem membranproximalen unstrukturierten C-Terminus als ein Intermediat der SNARE-vermittelten Exozytose fungieren könnte $[66,148,40]$. In einer anderen Arbeit wird jedoch vorgeschlagen, dass die SNARE-Komplexbildung in einem einzelnen Schritt stattfindet, also ohne ein partiell unstrukturiertes Intermediat [92].

Kann es ein solches Intermediat geben? Und wenn ja, wieviel Energie könnte während diesem letzten Komplexbildungsschritt entstehen?

Um diese Fragestellung zu beantworten, wurden Konstrukte erstellt, welche C-terminale Layer-Mutationen oder Verkürzungen in SNAP-25 enthielten. Diese wurden mittels CD-Spektroskopie auf ihre Fähigkeit hin getestet, SNAREKomplexe mit Syntaxin und Synaptobrevin zu bilden. In Übereinstimmung mit den SNAP-25-Mutanten [+8] und [+5] konnten eine Reihe von SNAP-25Varianten, in denen die C-terminalen Layer zu Alaninen mutiert wurden, genauso schnell wie SNAP-25 wt sowohl binäre Komplexe mit Syntaxin, als auch ternäre Komplexe mit Syntaxin und Synaptobrevin bilden (Abb. 3.16A). Dies unterstützt die These, dass die SNARE-Komplexbildung vom N-Terminus in Richtung CTerminus abläuft.

Zusätzlich wurden thermale Denaturierungsexperimente durchgeführt. Die 

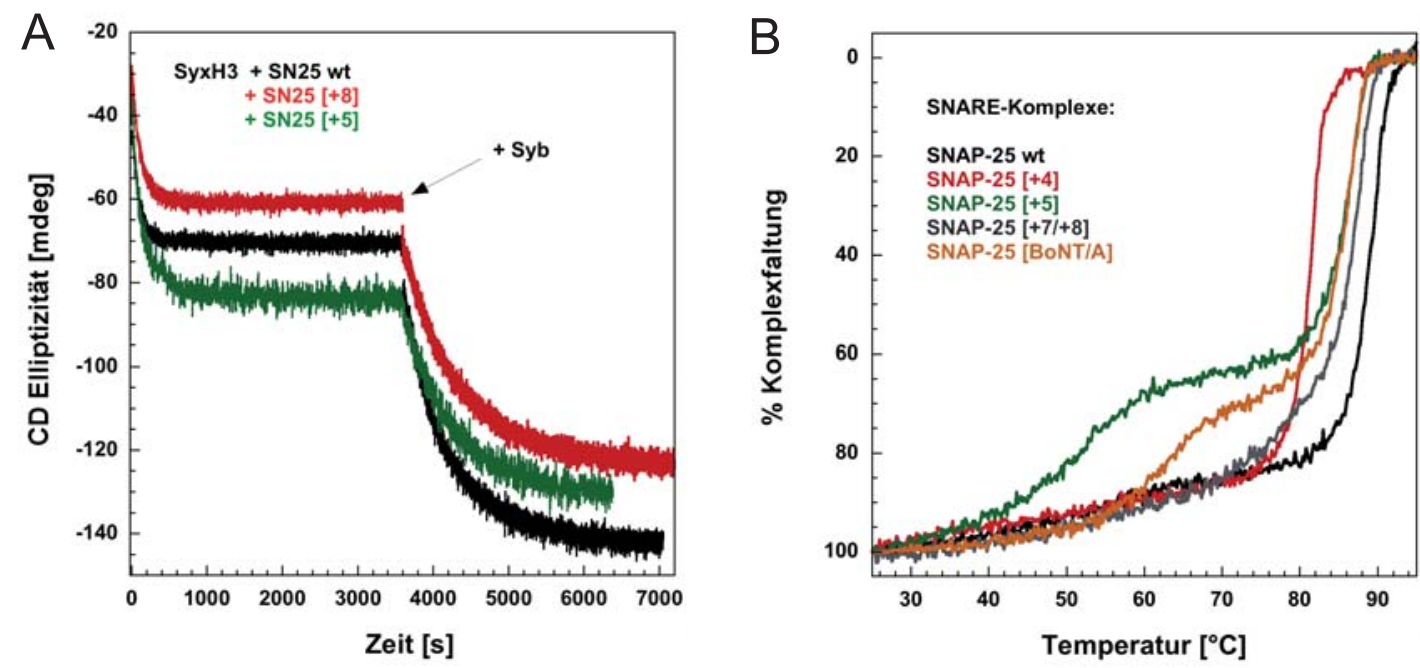

Abbildung 3.16: Bindungskinetik und Stabilität der SNARE-Komplexe mit Cterminalen SNAP-25-Mutanten. (A) Das SNARE-Motiv von Syntaxin (SyxH3) und die jeweilige SNAP-25-Mutante wurden bei einer Konzentration von je $2 \mu \mathrm{M}$ in Tris-Puffer $(20 \mathrm{mM}$ Tris pH 7,4, $100 \mathrm{mM} \mathrm{NaCl}, 1 \mathrm{mM}$ DTT) gemischt und der Anstieg des $\alpha$-helikalen Anteils mittels CD-Spektroskopie verfolgt. Die Interaktion von SyxH3 mit SNAP-25 [+5] und $[+8]$ war vergleichbar schnell wie mit SNAP-25 wt. Anschließend wurde Synaptobrevin (Syb) addiert und die ternäre Komplexbildung verfolgt (Pfeil). Auch diese Interaktionen waren etwa so schnell wie die wt-Reaktion. (B) Die gereinigten SNARE-Komplexe, welche das SNAP-25 wt oder Layermutationen enthielten, wurden bei einer Konzentration von $10 \mu \mathrm{M}$ in NatriumphosphatPuffer (20mM Natriumphosphat $\mathrm{pH} 7,4,100 \mathrm{mM} \mathrm{NaCl}, 1 \mathrm{mM}$ DTT) von $25^{\circ} \mathrm{C}-95^{\circ} \mathrm{C}$ erhitzt. Die Abnahme der Elliptizität wurde anhand von CD-Spektroskopie bei $222 \mathrm{~nm}$ gemessen. Komplexe, welche ein C-terminal verkürztes SNAP-25 [BoNT/A] oder eine Mutation in Layer +5 $($ SNAP-25 $[+5])$ enthalten, entfalteten sich in zwei Schritten. Auch der Komplex mit SNAP-25 $[+7 /+8]$ zeigte eine Tendenz zum zweiphasigen Zerfall. Der erste Zerfallsschritt repräsentiert wahrscheinlich das autonome Entfalten der C-terminalen Region des SNARE-Komplexes, der zweite Schritt könnte das Entfalten des verbliebenen SNARE-Bündels darstellen. Der Zerfall des wt SNARE-Komplexes wurde bereits in der Abb. 3.4 gezeigt.

gereinigten SNARE-Komplexe wurden erhitzt und ihr Zerfallen mittels CDSpektroskopie bei $222 \mathrm{~nm}$ verfolgt. Wie schon in Abschnitt 3.1.3 gezeigt wurde, zerfiel der wt SNARE-Komplex bei einer Temperatur von etwa $89^{\circ} \mathrm{C}$. Der SNAP-25 [+4]-Komplex zerfiel in einem Schritt und besitzt eine leicht reduzierte Schmelztemperatur (Abb. 3.16B). Die Schmelzkurve des SNARE-Komplexes mit SNAP-25 $[+7 /+8]$, wies eine Tendenz zu einem zweiphasigen Zerfall auf (Abb. 3.16B). Interessanterweise zeigten die Komplexe, welche SNAP-25 [+5] enthielten oder in denen SNAP-25 um neun Aminosäuren am C-Terminus verkürzt war (SNAP-25 [BoNT/A]), einen ausgeprägten zweiphasigen Entfaltungsprozess. Die- 
ses zweiphasige Zerfallen könnte darauf hinweisen, dass sich der C-terminale Teil des SNARE-Komplexes unabhängig vom N-terminalen Teil entfalten kann. Dies ist ein strukturelles Indiz für die Existenz von unabhängigen Bereichen im VierHelixbündel. Im Gegensatz dazu, beeinflusst die Mutation im Layer +4 wahrscheinlich eher die Gesamtstabilität des Komplexes, als ausschließlich eine bestimmte Region im Komplex.

Der Einfluss der verschiedenen SNAP-25-Mutanten auf die SNAREKomplexbildung und -stabilität wurde in Zusammenarbeit mit Dr. Jakob Sörensen (MPI für biophysikalische Chemie, Abt. Membranbiophysik) bearbeitet. Um die Effekte der verschiedenen SNAP-25-Mutanten in vivo zu untersuchen, wurde SNAP-25 wt bzw. mutiertes SNAP-25 in embryonalen chromaffinen SNAP-25 knockout-Zellen überexpremiert. Anschließend wurden Messungen der Membrankapazität durchgeführt. Die Sekretion von catecholamingefüllten Vesikeln wurde durch UV-Licht induzierte Freisetzung des Kalziums durch ein kalziumbindendes Molekül (flash photolysis of caged $\mathrm{Ca}^{2+}$ ) ausgelöst und mittels amperometrischer Detektion von freigesetzten Catecholaminen beobachtet.

In SNAP-25 knockout-Zellen ist die kalziuminduzierte Sekretion von Neurotransmitter enthaltenden Vesikeln blockiert (Abb. 3.17). Durch die Überexpression von SNAP-25 wt kann jedoch die Sekretion in diesen Zellen wieder vollständig hergestellt werden [128]. Wird jedoch SNAP-25 mit der Mutation in Layer +5 in chromaffinen knockout-Zellen überexpremiert, wird die Sekretion nicht wiederhergestellt (Abb. 3.17) [129]. Bei der Überexpression dieser Mutation in SNAP25 wt-Zellen kommt es zu einem Block der Sekretion, sie ist dominant negativ. Dies weist darauf hin, dass die Mutante zwar mit ihren SNARE-Partnern interagieren kann, aber Komplexe bildet, welche die Fusion der Membranen nicht unterstützen.

Demnach haben die Mutationen im C-terminalen Bereich des SNAREMotivs von SNAP-25 sowohl in vitro als auch in vivo drastische Auswirkungen auf den SNARE-Komplex. Diese Ergebnisse zeigen, dass es einen C-terminal destabilisierten oder unstrukturierten SNARE-Komplex geben kann.

Um diese Annahme zusätzlich zu untermauern, wurden limitierte Proteolyse-Experimente durchgeführt. Limitierte Proteolyse kann Auskunft über die Domänenstruktur eines Proteins geben. Ungefaltete Aminosäureketten 


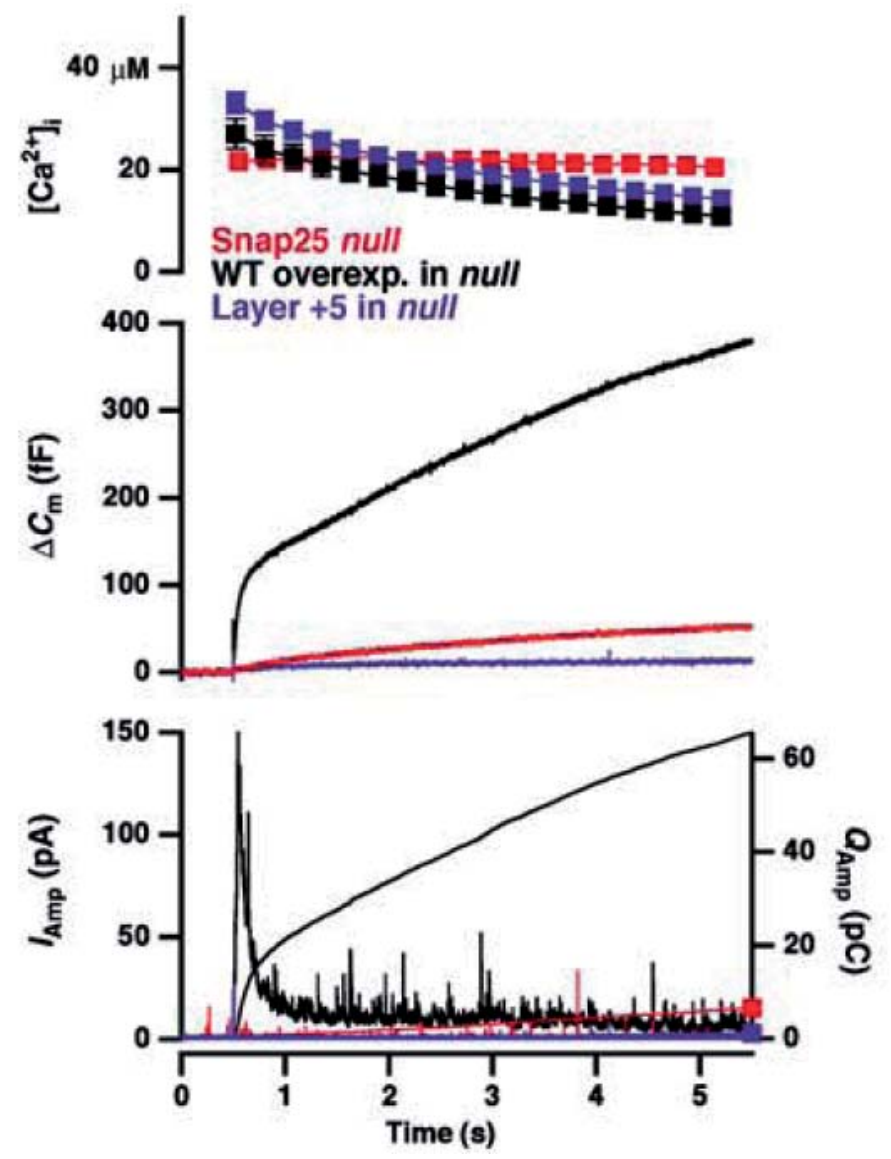

Abbildung 3.17: Die Mutation im SNAP-25 Layer +5 zeigt einen dramatischen Phänotyp in vivo. Oben: Kalziumkonzentration nach der UV-Licht induzierten Freisetzung des Kalziums durch ein kalziumbindendes Molekül nach 0,5 s. Mitte: Anstieg der Membrankapazität als Folge der Vesikelfusion mit der Plasmamembran. Unten: Amperometrische Spannung (linke Y-Achse) und die gesamte amperometrische Ladung (rechte Y-Achse).

Die Sekretion ist in SNAP-25 knockout-Zellen fast vollständig blockiert (rot). Durch Überexpression von SNAP-25 wt in SNAP-25 knockout-Zellen kann eine normale Sekretion wiederhergestellt werden (schwarz). Die SNAP-25 Layer [+5]-Mutante kann den Phänotyp des knockout nicht ausgleichen, die Sekretion ist blockiert (blau). Die Abbildung wurde der Veröffentlichung Sörensen et al., 2006 [129] entnommen und modifiziert.

können von Proteasen geschnitten werden, während gefaltete Proteinregionen nicht für Proteasen zugänglich sind. Es konnte bereits gezeigt werden, dass der Kernbereich des SNARE-Komplexes, der so genannte Minimalkomplex, proteaseresistent ist [34]. Den nachfolgenden Experimenten liegen folgende Überlegungen zu Grunde: Liegt der C-Terminus des SNAP-25 [+5]-Komplexes teilweise entfaltet vor, sollte es möglich sein, diesen proteolytisch zu spalten. Um die Reakti- 
onsbedingungen der thermalen Denaturierung nachstellen zu können, wurde die hitzestabile Protease Thermolysin verwendet, welche ihre optimale Aktivität bei etwa $70^{\circ} \mathrm{C}$ erreicht. Die Proteolyse wurde sowohl für den wt-Komplex als auch den SNAP-25 [+5]-Komplex bei $35^{\circ} \mathrm{C}$ und $70^{\circ} \mathrm{C}$ durchgeführt, also bei Temperaturen, bei denen, den CD-Experimenten zufolge, noch keine Entfaltung $\left(35^{\circ} \mathrm{C}\right)$ oder die Entfaltung eines Komplexbereiches $\left(70^{\circ} \mathrm{C}\right)$ erfolgt sein sollte (Abb. 3.18).

Der wt SNARE-Komplex ist im SDS-Gel durch eine SDS-resistente Bande bei etwa $50 \mathrm{kDa}$ gekennzeichnet Abb. 3.18A). Nach Proteolyse bei beiden Temperaturen bleibt eine definierte SDS-resistente Bande mit einem Molekulargewicht von circa $30 \mathrm{kDa}$ von der Proteolyse verschont. Dieser Minimal-Komplex enthält ausschließlich die SNARE-Motive von Syntaxin, SNAP-25 und Synaptobrevin und ist SDS- und proteaseresistent [34]. Bei $70^{\circ} \mathrm{C}$ bleibt weniger vom Ausgangsprodukt erhalten, da die Protease bei dieser Temperatur aktiver ist. Die Proteolyse des SNAP-25 [+5]-Komplexes bei $35^{\circ} \mathrm{C}$ ergab ein ähnliches $\mathrm{Ab}$ baumuster wie das des wt-Komplexes (Abb. 3.18B). Jedoch trat bei $70^{\circ} \mathrm{C}$ eine zusätzliche Bande mit einem Molekulargewicht von etwa $25 \mathrm{kDa}$ auf. Eine ähnliche Veränderung im Abbaumuster konnte für den SNAP-25 [BoNT/A]-Komplex beobachtet werden (nicht gezeigt). Dies ist ein weiteres Indiz dafür, dass diese C-terminal veränderten SNARE-Komplexe bei $70^{\circ} \mathrm{C}$ teilweise entfaltet sind und wahrscheinlich die C-terminalen Bereiche demzufolge für die Protease zugänglich sind.

\subsubsection{Thermodynamik des C-terminalen Zipper-Schrittes}

Die vorangegangenen Experimente geben deutliche Hinweise darauf, dass, aus struktureller Hinsicht, am C-terminalen Ende ein partiell unstrukturierter SNARE-Komplex existieren könnte. Wie schon vorher erwähnt, könnte sich der membranproximale Teil des SNARE-Komplexes in diesem letzten, entscheidenden Komplexbildungsschritt strukturieren. Da die Transmembrandomänen in beiden Membranen verankert sind, können sich durch weiteres Aufrollen des Cterminalen Komplexteiles die Membranen annähern und die energetische Schwelle überwunden werden, welche durch die Abstoßungskräfte der polaren Kopfgruppen der Phospholipide in den Membranen erzeugt wird. Das Ergebnis ist die 

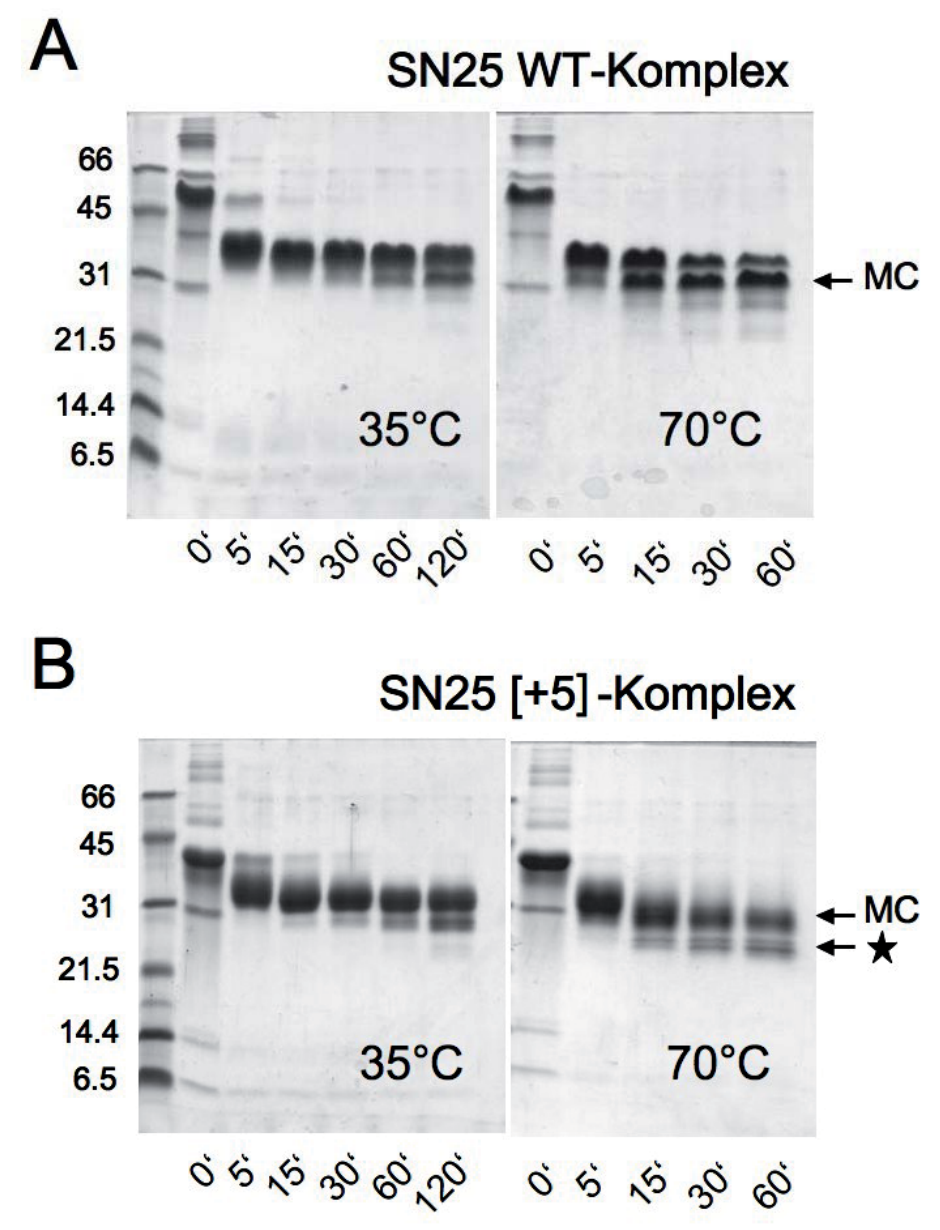

Abbildung 3.18: Limitierte Proteolyse des SNAP-25 [+5]-Komplexes. Die Komplexe mit SNAP-25 wt bzw. SNAP-25 [+5] wurden in einer Konzentration von $20 \mu \mathrm{M}$ und die Protease Thermolysin bei $200 \mathrm{nM}$ verwendet. Nach Zugabe der Protease wurde nach genau 0, 5, 10, 15, 30, 60 und 120 min Inkubation bei $35^{\circ} \mathrm{C}$ bzw. $70^{\circ} \mathrm{C}$ jeweils ein Aliquot abgenommen, dieses mit SDS-Probenpuffer $+1 \mathrm{mM}$ PMSF vermischt. Anschließend wurden die Proben mittels SDSPAGE und Coomassie Blue-Färbung analysiert. Die Komplexe zeigen bei beiden Temperaturen eine definierte SDS-resistente Bande bei ca. $30 \mathrm{kDa}$. Dies repräsentiert den Minimal-Komplex (MC) [34]. Bei $70^{\circ} \mathrm{C}$ ist die Minimal-Komplex-Bande ausgeprägter, da die Protease bei dieser Temperatur aktiver ist. Das Abbaumuster des SNAP-25 [+5]-Komplexes bei $70^{\circ} \mathrm{C}$ zeigt eine zusätzliche Bande bei ca. $25 \mathrm{kDa}$ (Stern). Dies könnte darauf hinweisen, dass der C-Terminus des Komplexes für die Protease zugänglich war und demnach weniger strukturiert ist.

Fusion der Membranen.

Ist es möglich, den letzten Schritt der SNARE-Komplexbildung - ausgehend von einem partiell gebildeten SNARE-Komplex hin zu einem vollständig ausgebildeten SNARE-Komplex - biophysikalisch zu untersuchen? Um einen Einblick in die Thermodynamik dieses letzten SNARE-Komplexbildungsschrittes zu er- 
halten, habe ich ITC-Experimente mit einem SNARE-Komplex durchgeführt, welcher SyxH3, SNAP-25 und ein C-terminal verkürztes Synaptobrevin (Syb 1-70) enthielt. Diesen Komplex bezeichne ich als $\Delta$ C-Komplex (Übersicht in Abb. 3.1). Dieser Komplex ist wahrscheinlich C-terminal unstrukturiert, d. h. die C-terminalen Abschnitte von SyxH3 und SNAP-25 sind nicht gefaltet. In CD-Experimenten konnte durch die Zugabe des ergänzenden Synaptobrevinfragmentes Syb 71-96 zum $\Delta$ C-Komplex ein Anstieg des $\alpha$-helikalen Anteils beobachtet werden, was darauf schließen läßt, dass sich der C-terminale Bereich des Komplexes nun vollständig gefaltet hat (Daten nicht gezeigt).

Dementsprechend wurden ITC-Experimente mit dem $\Delta$ C-Komplex und Syb 71-96 durchgeführt. Die Affinität der Interaktion ist mit einem Wert von 1,37 $\mu \mathrm{M}$ sehr niedrig (Abb. 3.19). Die Enthalpie der Bindung des Peptids an den $\Delta$ C-Komplex beträgt $-6,0 \mathrm{kcal} / \mathrm{mol}$ (siehe auch Tabelle 3.2 ). Diese Ergebnisse deuten darauf hin, dass die Reaktion reversibel ablaufen könnte. Es wird deutlich weniger Energie während dieser Interaktion freigesetzt, als bei der Bindung Synaptobrevins an den Akzeptorkomplex. Die Reaktionsenthalpie der SNARE-Komplexbildung aus Syntaxin, SNAP-25 und Synaptobrevin ergibt etwa $-120 \mathrm{kcal} / \mathrm{mol}$ (persönl. Kommunikation Dr. D. Fasshauer). Das würde bedeuten, dass nur rund fünf Prozent der gesamten Reaktionswärme während der SNARE-Komplexbildung in diesem letzten Schritt freigesetzt werden.

Abschließend weisen diese Ergebnisse darauf hin, dass während der finalen, C-terminalen Strukturierung des SNARE-Komplexes wenig Energie freigesetzt wird. 


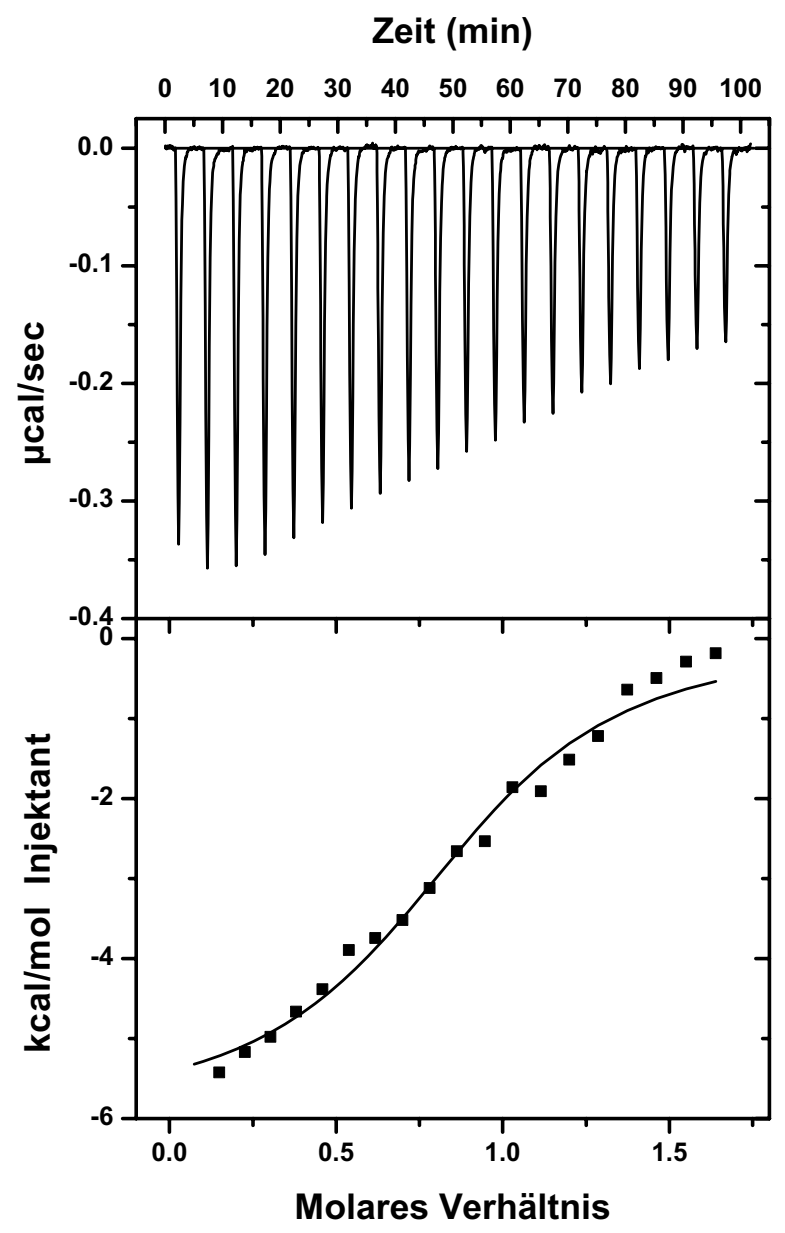

Abbildung 3.19: Thermodynamik der C-terminalen Komplexfaltung. Kalorimetrische Titrationen von Synaptobrevinpeptid 71-96 (Syb 71-96) in $\Delta$ C-Komplex. $15 \mu$ M gereinigter $\Delta \mathrm{C}$-Komplex befand sich in der Reaktionszelle und $105 \mu \mathrm{M}$ Syb 71-96 wurde in $15 \mu \mathrm{l}$-Schritten hinzutitriert (oben). Die integrierte Fläche der Wärmeänderung wurde auf die Menge des Syb 71-96 normalisiert und dies gegen das Molare Verhältnis von Syb 71-96 zu $\Delta$ C-Komplex aufgetragen (unten). Die Linie repräsentiert die beste Anpassung nach Nutzung des single siteBindungsmodells. Die thermodynamischen Parameter sind in der Tabelle 3.2 zusammengefasst. 


\section{Diskussion}

SNARE-Proteine bilden durch die Interaktion miteinander einen Komplex aus. Es wird davon ausgegangen, dass die Bildung des Komplexes die Fusion der beteiligten Membranen steuert. Da die genaue zeitliche Koordinierung dieses Prozesses sehr wichtig ist, vermutet man, dass dieser Prozess in mehreren Schritten abläuft. Jedoch sind diese Schritte noch nicht klar definiert und entsprechend existieren mehrere Modelle, welche sich in der Anzahl der Schritte und der Unterteilung des Prozesses unterscheiden. Elektrophysiologische Studien, kombiniert mit genetischen Analysen, beobachten den Fusionsprozess von außen und geben somit die Rahmenbedingungen vor, um den Prozess auf der molekularen Ebene besser verstehen zu können. Dabei zielt ein Teil der Forschung daraufhin, die Abläufe im Reagenzglas zu rekonstituieren. Es wurde z. B. gezeigt, dass SNARE-Proteine, wenn sie in unterschiedlichen Membranen verankert sind, Liposomenmembranen fusionieren können [142]. Die Untersuchungen der Aktivität von SNARE-Proteinen in künstlichen Membranen führt aber zu neuen Schwierigkeiten: Proteine können in Membranen aggregieren und die Reaktionsgeschwindigkeiten können nur bedingt kontrolliert werden, da nur ein geringer Spielraum für die Variation von Proteinkonzentrationen gegeben ist. In den letzten Jahren haben Untersuchungen an löslichen Proteinen, d.h. SNARE-Motive ohne Transmembranregionen, entscheidende Einsichten in die Funktionsweise der SNAREProteine geliefert. Diese Analysen brachten erste Hinweise auf die Unterteilung des Prozesses in distinkte Schritte während der SNARE-Komplexbildung.

In dieser Arbeit wurden erstmals die einzelnen Schritte des SNAREKomplexbildungsprozesses detailiert biophysikalisch und thermodynamisch untersucht. Als biochemisch darstellbare Schritte wurden folgende Reaktionen charakterisiert: die Bildung des transienten $\mathrm{Syx}_{1} / \mathrm{SN} 25_{1}$-Komplexes, die Bindung 
von Synaptobrevin und ein möglicherweise partiell strukturierter trans-SNAREKomplex. Dies ist einerseits wichtig, um zu verstehen, wie sich SNARE-Komplexe bilden und andererseits, zu welchen Zeitpunkten der Komplexbildung regulatorische Faktoren, thermodynamisch und strukturell gesehen, eingreifen könnten. Dies könnte entscheidend zum Verständnis der Regulation und der Rahmenbedingungen der SNARE-vermittelten Exozytose beitragen. Des Weiteren wurden diese einzelnen Schritte thermodynamisch untersucht, um die Reaktionsenergie zu bestimmen, welche während der Komplexbildungsreaktion frei wird und möglicherweise in mechanische Energie umgewandelt werden kann.

\subsection{Bildung des Akzeptorkomplexes}

\subsubsection{N-terminale Initiationsreaktion}

Dem Zipper-Modell zufolge beginnt die SNARE-Komplexbildung am N-Terminus der SNARE-Motive [59, 84,58]. Man geht davon aus, dass die Formation des SNARE-Komplexes über ein transientes Intermediat, den Syx 1 /SN25 $5_{1}$-Komplex, abläuft $[40,32,35]$. Die Bildung dieses transienten Komplexes stellt somit den ersten Reaktionsschritt dar [35].

Die Bedeutung des N-Terminus der Q-SNARE-Helices für die SNAREKomplexbildung wurde bereits in elektrophysiologischen Experimenten mit chromaffinen Zellen ersichtlich, in denen ein Antikörper die Sekretion blockierte, welcher den N-Terminus der ersten Helix des SNAP-25 (SN1) erkannte [148]. Außerdem ergaben in vitro-Experimente, dass die Verwendung von N-terminalen Peptiden der SN1-Helix bzw. Verkürzungen der SN1-, SN2- oder der Syntaxin-Helix die SNARE-Komplexbildung inhibierte [5,35]. Diese Experimente können jedoch den für die Initiation wichtigen Bereich nicht genau bestimmen, sondern nur eingrenzen, da indirekte (Antikörper) bzw. restriktive (Verkürzungen) Methoden eingesetzt wurden. Die Verwendung von weniger drastischen Alanin-Layermutationen in SNAP-25 erlaubte es, gezielt den Einfluss bestimmter Aminosäuren im SNAP25 auf die Interaktion mit Syntaxin zu untersuchen, da nur die Seitenketten der Aminosäuren verändert wurden.

In dieser Arbeit konnte der Minimalbereich für die Bildung des $\operatorname{Syx}_{1} / \mathrm{SN}_{2} 5_{1}{ }^{-}$ 
Komplexes bestimmt werden. Der N-Terminus des SNAP-25 von Layer -7 bis -5 war essentiell für die Interaktion mit Syntaxin, also der Bildung des transienten Akzeptorkomplexes. Mutationen im C-Terminus wirkten sich jedoch nicht negativ auf die Akzeptorkomplexformation aus. Folglich unterstützt dies die Hypothese des Zipper-Modells der N- zu C-terminal gerichteten Komplexbildung.

Neben der Bildung des binären Syx/SNAP-25-Komplexes, ist auch die ternäre SNARE-Komplexbildung durch die N-terminalen SNAP-25-Mutationen beeinflusst (Abb. 3.2), [129]. Der Block der Initiationsreaktion verlangsamt demnach den nachfolgenden Reaktionsschritt. Interessanterweise haben die SNAP25-Mutationen der Layer -7 bis -5 in vivo jedoch keine Auswirkungen auf die Sekretion. In begleitenden elektrophysiologischen Studien mit chromaffinen Zellen kann die blockierte Sekretion der SNAP-25 knockout-Zellen mit der Überexpression dieser SNAP-25-Mutanten vollständig wiederhergestellt werden [129]. Im Gegensatz dazu wurde die Sekretion mit einem Antikörper gegen den NTerminus der SN1-Helix blockiert [148]. Diese Unterschiede könnten mit der Existenz eines oder mehreren regulierenden Proteinen in vivo erklärt werden (priming factor). Der priming factor könnte die Organisation der N-terminalen Interaktion übernehmen und damit in vivo die Auswirkungen der N-terminalen SNAP-25-Mutationen kompensieren. Die synaptische Transmission erfordert eine schnelle Signalübertragung, jedoch bilden die Q-SNARE-Proteine Syntaxin und SNAP-25 nur sehr langsam einen Akzeptorkomplex $\left(6000 \mathrm{M}^{-1} \mathrm{~s}^{-1}\right)$ [35]. Aufgrund der langsamen Interaktion der Q-SNARE-Proteine scheint ein regulatorisches Protein unbedingt erforderlich, welches dabei hilft, den Akzeptorkomplex in einem zeitlich angemessenen Rahmen bereitzustellen und damit die schnelle Sekretion von Neurotransmittern zu ermöglichen. Die Interaktion von SNAP-25 und Syntaxin ist geschwindigkeitsbestimmend für die nachfolgenden Schritte der SNARE-Komplexbildung [35]. Die Regulation vieler biochemischer Prozesse erfolgt üblicherweise während des geschwindigkeitsbestimmenden Schrittes. Es ist wahrscheinlich, dass dies auch für die SNARE-Komplexbildung gilt.

Wie oben erwähnt, wird die Sekretion mit einem N-terminalen Antikörper blockiert [148]. Dies könnte folgende Ursache haben: Interagiert ein Antikörper mit dem N-Terminus des SNAP-25, kann der priming factor, im Gegensatz zu N- 
terminalen Mutationen, vielleicht aus sterischen Gründen, nicht mehr die korrekte Anordnung der N-Termini gewährleisten, was eine Inhibition der Komplexbildung und folglich der Sekretion nach sich zieht. Vermutlich benötigt man drastischere Mutationen in SNAP-25, um in vivo einen Effekt sehen zu können. Dies sollte zukünftig getestet werden.

Als priming factor wurden bisher verschiedene Proteine vorgeschlagen, wie z.B. Munc18, Munc13, CAPS-1/2, aber auch Synaptotagmin und Complexin [14, $154,54,145,69,138]$.

Die Hypothese konnte mit einem Experiment unterstützt werden. Wurde ein stabilisierter $\Delta \mathrm{N}$-Komplex mit der N-terminalen SNAP-25-Mutante [-6] hergestellt, erfolgte die Synaptobrevinbindung genauso schnell wie die wt-Reaktion (Abb. 3.8). Das heißt, dass die Komplexbildung normal ablaufen konnte, wenn die Initiationsreaktion übergangen wurde.

Es gibt allerdings auch Modelle, in denen die SNARE-Komplexbildung Cterminal beginnt oder keine N- bzw. C-terminale Präferenz vorliegt, also die Komplexbildung konzertiert abläuft $[79,152,56]$. In den EPR-Experimenten von Kweon und Kollegen wurde die SNARE-Komplexbildung mittels Bindung von Synaptobrevin an den $\mathrm{Syx}_{2} / \mathrm{SN} 25_{1}$-Komplex bestimmt [79]. In dem daraus resultierenden Modell beginnt die SNARE-Komplexbildung mit der Interaktion von allen drei SNARE-Proteinen, Syntaxin, SNAP-25 und Synaptobrevin, und nicht mit der Ausbildung des transienten Akzeptorkomplexes.

Die Annahmen, dass die Formation des SNARE-Komplexes C-terminal beginnt oder dass alle Helices gleichzeitig aufeinandertreffen, können mit meinen Experimenten nicht bestätigt werden, da C-terminale SNAP-25-Mutanten keinen Einfluss auf die Bildung des transienten Akzeptorkomplexes und des ternären SNARE-Komplexes hatten (Abb. 3.16A).

\subsubsection{Der Einfluss zentraler Mutationen im SNARE- Komplex}

Neben den N-terminalen SNAP-25-Mutationen in Layer -7 bis -5 beeinflussten auch Mutationen in und um den 0-Layer $(-1,0,+2)$ die Geschwindigkeit der binären Syx/SNAP-25-Komplexbildung, sowie die Stabilität des ternären Kom- 
plexes (Abb. 3.3 und 3.4). CD-Experimente mit zentralen SNAP-25-Mutanten ergaben eine langsamere Bildungsgeschwindigkeit des binären Syx/SNAP-25Komplexes. Außerdem wird eine geringere Elliptizität während der Komplexbildung im Vergleich zum wt SNAP-25 erreicht (Abb. 3.3). Weiterhin ist die Stabilität dieser SNARE-Komplexe deutlich reduziert (Abb. 3.4). Diese Ergebnisse weisen auf einen strukturellen Defekt hin.

Die begleitenden elektrophysiologischen Studien zeigten, dass die zentralen SNAP-25-Mutanten den letzten Schritt der Sekretion nicht beeinflussen, das Nachfüllen des Vesikelpools hingegen gestört ist. Dies deutet auf Probleme bei der Bildung der SNARE-Komplexe hin [129]. Ähnliche Ergebnisse wurden mit einer Mutation im 0-Layer der SN2-Helix erzielt [143].

Es ist bekannt, dass der hochkonservierte 0-Layer eine wichtige Funktion im SNARE-Komplex übernimmt und sich zumeist aus 3 Glutaminen (Q) und einem Arginin (R) zusammensetzt. Die polaren Aminosäuren des 0-Layers stellen eine Anomalie in der Struktur von coiled coils dar, da sie primär durch hydrophobe Interaktionen charakterisiert sind. Es wurde vorgeschlagen, dass diese versteckten polaren Resten besondere strukturelle und funktionale Aufgaben erfüllen. Dies umfasst zum einen die Bestimmung des oligomeren Zustands des coiled coil sowie die Ausrichtung der Helices in parallele oder antiparallele coiled coils. Zudem könnte die definierte Destabilisierung des coiled coil durch die polaren Reste die Reversibilität der coiled coil-Ausbildung ermöglichen [75]. Das definierte Destabilisieren des coiled coil könnte ebenso für den 0-Layer als Startpunkt der Dissoziationsreaktion sprechen.

Dies zeigten z.B. genetische Studien in der Bäckerhefe, bei denen die Reihenfolge oder die Anzahl der Glutamine und Arginine im 0-Layer verändert wurde. Dabei stellte man fest, dass Komplexe mit einer 2Q:2R-Zusammensetzung nicht funktional sind $[71,102]$. Elektronenmikroskopische Untersuchungen von Hefezellen, welche SNARE-Komplexe mit einer 2Q:2R-Zusammensetzung enthielten, zeigten eine Akkumulierung der Vesikel, was auf einen Defekt im letzten Schritt der Sekretion hinweist [102]. Dagegen können Komplexe mit einer 4Q:0RZusammensetzung in ihrer Funktion kaum von 3Q:1R-Komplexen unterschieden werden. Ein fehlendes Arginin kann demnach im 0-Layer toleriert werden [71,102]. Diese in vivo-Studien vermitteln einen Eindruck zur Funktionalität der Komple- 
xe, sie können aber nicht mögliche strukturelle Veränderungen verfolgen. In einer anderen Studie mit rekombinanten Proteinen ersetzte man die Glutamine der einzelnen SNAP-25-Helices mit Alaninen und untersuchte die thermale Stabilität dieser Komplexe. Man fand heraus, dass diese Mutationen nur einen geringen Einfluss auf die Stabilität hatten und daher einen geringen Effekt auf die Komplexbildung haben. Aufgrunddessen wurde vorgeschlagen, dass der 0-Layer essentiell für die Bindung von NSF/alpha-SNAP an den SNARE-Komplex ist und folglich für die Dissoziationsreaktion eine Rolle spielt [118]. Jedoch konnte gezeigt werden, dass Austausche im 0-Layer nicht die Geschwindigkeit des Dissoziationsschrittes beeinflussen [81]. In der Tat weisen die elektrophysiologischen Analysen nicht auf einen Defekt im Recycling der SNARE-Proteine hin, sondern eher auf einen Effekt in der Komplexbildung [129].

Der hydrophile 0-Layer wird von den benachbarten hydrophoben Layern gegen das Eindringen von Wassermolekülen abgeschirmt und diese tragen folglich zur Stabilität des Komplexes bei [135]. Möglicherweise wird durch einen Austausch der aliphatischen Aminosäuren Leucin und Isoleucin gegen das relativ kleine Alanin in meinen Experimenten bewirkt, dass der hydrophile 0-Layer nicht ausreichend abgeschirmt ist und somit die Struktur instabiler wird. Des Weiteren haben molecular dynamic-Simulationen ergeben, dass die den 0-Layer umgebenden hydrophoben Aminosäuren viele hydrophobe Wechselwirkungen und Salzbrücken miteinander eingehen [29]. Eine Änderung der Aminosäurezusammensetzung in der Region könnte also tatsächlich eine Verminderung der Strukturstabilität zur Folge haben.

\subsection{Synaptobrevinbindung an den Akzeptor- komplex}

\subsubsection{Die Synaptobrevinbindungsreaktion}

Wie ich bereits im obigen Abschnitt erläutert habe, zeichnet sich die erste Reaktion der SNARE-Komplexbildung durch die Bildung eines Akzeptorkomplexes bestehend aus einem Syntaxin und SNAP-25 aus. Aufgrund der Kompetition von 
Synaptobrevin und einem zweiten Syntaxin um die freie Bindungsstelle war es bislang schwierig, ausschließlich den Synaptobrevinbindungsschritt im Detail in vitro zu untersuchen. Durch die Verwendung eines stabilisierten Akzeptorkomplexes ( $\Delta$ N-Komplex) konnte dieses Problem umgangen werden, da nur Synaptobrevin an diesen Komplex binden kann [109].

Synaptobrevin kann sehr schnell mit dem $\Delta$ N-Komplex interagieren. Meine Ergebnisse zeigen auch, dass sich die Interaktion durch eine sehr hohe Bindungsaffinität auszeichnet. Des Weiteren konnte ich zeigen, dass die Synaptobrevinbindung an $\Delta \mathrm{N}$-Komplexe mit N-terminalen Verkürzungen der Syntaxin bzw. der SN1-Helix erheblich eingeschränkt ist (Abb. 3.8). In der Arbeit von Fasshauer und Margittai wurde gezeigt, dass die SNARE-Komplexbildung mit N-terminal verkürzten Q-SNARE-Proteinen blockiert ist [35]. Wie zuvor erläutert, wurde dieser Befund durch die Verwendung der 'milderen' Alanin-Mutationen in meinen Versuchen unterstützt. Diese Ergebnisse unterstützen die Annahme, dass der N-Terminus des Akzeptorkomplexes die korrekte Bindungstelle für Synaptobrevin darstellt.

Wie ich bereits in der Einleitung erläutert habe, geht man auch bei der homologen SNARE-Komplexbildung in der Bäckerhefe von einem QabcSNARE-Akzeptorkomplex aus, welcher aus einem Sso1p und einem Sec9p besteht, und als Bindungstelle für Snc1p (R-SNARE) dienen soll [40]. Da dieser 1:1-Akzeptorkomplex der Bäckerhefe strukturell charakterisiert werden konnte, scheint jedoch in der Bäckerhefe kein zweites Sso1p (Qa-SNARE) an diesen Akzeptorkomplex zu binden, verglichen mit den neuronalen SNARE-Proteinen [40]. Interessanterweise ist die Bindungsgeschwindigkeit von Snc1p an den Sso1p/Sec9Komplex langsam [99], im Vergleich zu den Ergebnissen mit Synaptobrevin, das sehr schnell an den Syx/SNAP-25-Akzeptorkomplex binden kann. Dies spricht nicht dafür, dass der Sso1p/Sec9-Komplex die ideale Bindungstelle für Snc1p anbietet. Was könnte aber der Grund dafür sein? Einerseits ist es möglich, dass eventuell doch, zumindest teilweise, 2:1-Komplexe entstehen und ein zweites Sso1p zunächst den Komplex verlassen muss, bevor Snc1p binden kann. Jedoch wird dieses Szenario nicht von den vorhandenen Daten unterstützt [99]. Auf der anderen Seite ist es auch denkbar, dass sich der Sso1p/Sec9-Komplex strukturell nicht in der bestmöglichen Konfiguration befindet, damit Snc1p schnell binden 
kann. Vielleicht gilt dies auch für den neuronalen Akzeptorkomplex, welcher nur mit Hilfe des stabilisierenden C-terminalen Synaptobrevinpeptids in die optimale Bindungskonfiguration gebracht werden kann, und zusätzlich die Bindung des zweiten Syntaxins vermieden wird.

Diese optimale strukturelle Konfiguration der Bindungsstelle für Synaptobrevin im $\Delta$ N-Komplex konnte durch die ermittelte hohe Affinität und Bindungsgeschwindigkeit dieser Reaktion bestätigt werden. Aufgrunddessen sollte im Rahmen dieser Arbeit auch die Kristallstruktur des stabilisierten Akzeptorkomplexes ermittelt werden, um einen Einblick in die strukturellen Eigenschaften der Bindungsstelle zu bekommen. In mehreren Ansätzen schien sich der gereinigte $\Delta \mathrm{N}-$ Komplex unter den harschen Bedingungen der Proteinkristallisation in den $\mathrm{Syx}_{2} / \mathrm{SN}_{2}$-Komplex umgelagert zu haben. Das deutet darauf hin, dass sich der $\Delta$ N-Komplex strukturell vom SNARE-Komplex unterscheidet. Der $\Delta$ N-Komplex ist wie der SNARE-Komplex $\alpha$-helikal gefaltet, er zerfällt aber bei thermalen Denaturierungsexperimenten bei deutlich niedrigeren Temperaturen als der SNARE-Komplex [109].

In Kapitel 3.2.1 habe ich bereits angemerkt, dass durch die Verwendung des $\Delta \mathrm{N}$ Komplexes zwar die Bindung eines zweiten Syntaxins unterbunden wird, jedoch nach der Synaptobrevinbindung eine zusätzliche Reaktion abläuft, welche in die Überlegungen einbezogen werden sollte. Das stabilisierende C-terminale Synaptobrevinpeptid des $\Delta \mathrm{N}$-Komplexes verlässt nach der Bindung des Gesamtsynaptobrevins den $\Delta \mathrm{N}$-Komplex. Bisher ist nicht geklärt, wie diese Verdrängungsreaktion abläuft.

- Erstens, wäre es möglich, dass das Peptid den Komplex verlässt, sobald die Gesamtsynaptobrevinhelix den N-Terminus des Peptids erreicht, z. B. durch eine strukturelle Umlagerung des C-terminalen Anteils. Dies stellt einen passiven Reaktionsmechanismus dar. Bei diesem Reaktionsmechanismus sollte die Länge des C-terminalen Anteils von Synaptobrevin, über die Bindungsstelle hinaus, keine Rolle für die Verdrängung des stabilisierenden Peptids spielen.

- Auf der anderen Seite könnte das stabilisierende Fragment auch so fest 
verankert sein, dass während der Gesamtsynaptobrevinbindung eine aktive Verdrängung durch strukturelle Umlagerung stattfinden muss, um das Fragment zu verdrängen und demnach das stabilisierende Synaptobrevinpeptid und der C-terminale Bereich des Gesamtsynaptobrevins kompetieren. Dieser aktive Mechanismus würde, im Hinblick auf die thermodynamische Charakterisierung der Interaktion, eine Änderung der Energiebilanz nach sich ziehen.

C-terminal verkürzte Synaptobrevinkonstrukte konnten das Synaptobrevinpeptid langsamer aus dem Komplex drängen als Gesamtsynaptobrevin (Abb. 3.10). Dabei ist auffällig, dass je kürzer der C-Terminus der Konstrukte war, desto schlechter erfolgte die Verdrängung des Synaptobrevinpeptids aus dem $\Delta$ N-Komplex. Da der C-Terminus des Gesamtsynaptobrevins eine entscheidende Rolle bei dieser Verdrängungsreaktion zu spielen scheint, spricht dies für einen aktiven Mechanismus. Möglicherweise bewirkt der C-terminale Bereich des Synaptobrevins nach der Bindung an den $\Delta$ N-Komplex eine Umstrukturierung des C-Terminus, bei der das Peptid verdrängt und die vollständige SNARE-Komplexbildung erfolgt. Allerdings ist erstaunlich, dass Synaptobrevin 1-88 das Synaptobrevinpeptid langsamer aus dem Komplex verdrängt als Syb 1-96, obwohl Syb 1-88 das vollständige SNARE-Motiv enthält und nur die Linkerregion zwischen Motiv und TMR entfernt ist. Das könnte auf eine zusätzliche, bislang unentdeckte, Aufgabe der Synaptobrevinlinkerregion während der Komplexbildung hinweisen. Bisher wurde ein Einfluss der Synaptobrevinlinkerregion auf die SNARE-Komplexbildung nur mit Synaptobrevin beobachtet, welches in artifiziellen Membranen oder synaptischen Vesikeln verankert war. Es wurde vorgeschlagen, dass die konservierten Tryptophane des Linkerbereichs (W89, W90) in die Membran eintauchen und aufgrunddessen die SNARE-Komplexbildung verhindert wird, da der Austausch der Tryptophane gegen Serine die SNARE-Komplexbildung ermöglichte [78,65]. Diese Befunde konnten jedoch von einer anderen Studie nicht bestätigt werden [124].

In weiteren Untersuchungen wurde die Region des Synaptobrevins charakterisiert, welche essentiell für die Bindung an den Akzeptorkomplex ist. Dieser Prozess kann mit zwei verschiedenen experimentellen Ansätzen untersucht werden: Erstens, 
Syntaxin, SNAP-25 und die Synaptobrevinmutante werden zusammen gemischt. Dabei bildet sich zunächst ein Akzeptorkomplex bestehend aus Syntaxin und SNAP-25, und anschließend bindet Synaptobrevin. In der Studie von Fasshauer und Margittai wurde dieser Reaktionsansatz verwendet und festgestellt, dass N-terminal oder C-terminal verkürzte Synaptobrevine SNARE-Komplexe bilden können [35]. Dieser experimentelle Ansatz ist problematisch, da vor der Synaptobrevinbindung die Akzeptorkomplexbildung als geschwindigkeitsbestimmender Schritt abläuft. Dieser Schritt könnte einen Defekt in der Synaptobrevinbindung verschleiern.

In einem zweiten Ansatz wird der stabilisierte Akzeptorkomplex, der $\Delta \mathrm{N}$ Komplex, zur Charakterisierung der Bindungsreaktion verwendet und der geschwindigkeitsbestimmende Schritt übergangen. Damit ist es möglich, die Defekte aufgrund einer Mutation während der Synaptobrevinbindung direkt zu beobachten. Der zweite Ansatz wurde in dieser Arbeit zur Beantwortung der Frage verwendet, welcher Bereich in Synaptobrevin wichtig für die Bindung an den Akzeptorkomplex ist.

Meine Experimente konnten aufzeigen, dass der N-terminale Bereich der Q-SNARE-Proteine (von Layer -7 bis -5) wichtig zur Bildung des Akzeptorkomplexes sind (Abb. 3.2). Des Weiteren wurde, wie oben bereits erwähnt, festgestellt, dass die N-terminalen Regionen der Syntaxin- und der SN1-Helix von Layer -7 bis -4 wichtige Bestandteile der Bindungstelle für Synaptobrevin im $\Delta \mathrm{N}$-Komplex sind (Abb. 3.8). Demnach stellt die Q-SNARE-Layer-Region -7 bis -4 im $\Delta \mathrm{N}$ Komplex einen kurzen Bindungsbereich für Synaptobrevin dar.

Tatsächlich scheint dieser Bereich auch im Synaptobrevin von Bedeutung für die Bindung an den $\Delta \mathrm{N}-$ Komplex zu sein, wie zielgerichtete Mutationen in Synaptobrevin-Layer -7/-6 in dieser Arbeit zeigten (Abb. 3.9). Zusätzlich wurde zuvor gezeigt, dass N-terminale Verkürzungen von Synaptobrevin, Syb 35-96 (ab Layer -6) und Syb 42-96 (ab Layer -4) nicht an den $\Delta$ N-Komplex binden können [109]. Die Bindung eines verkürzten Synaptobrevins an den $\Delta \mathrm{N}-$ Komplex, welches das SNARE-Motiv noch immer vollständig enthält (Syb 25-96), funktionierte jedoch normal (Abb. 3.9).

Überraschenderweise bindet ein N-terminales Synaptobrevinpeptid, Syb 2244 (umfasst die Layer -7 bis -4), das dem offenen Bindungsbereich im $\Delta \mathrm{N}$ - 
Komplex entspricht, nicht an den $\Delta$ N-Komplex. Dies wurde sowohl fluoreszenzspektroskopisch, als auch anhand von ITC festgestellt (Abb. 3.9). Hingegen binden Fragmente, die auch nachfolgende Bereiche umfassen (z. B. Syb 1-52, umfasst die Layer -7 bis -1), während sie nur sehr langsam, wenn überhaupt das stabilisierende Synaptobrevinpeptid aus dem $\Delta$ N-Komplex verdrängen. Das bedeutet, der Layer -4 bis -1-Bereich von Synaptobrevin ist ebenso wichtig für die Bindung an den $\Delta \mathrm{N}$-Komplex. Dies wurde durch gezielte Punktmutationen in diesem Bereich bestätigt. Mutationen der Aminosäuren vor und im Layer -3 (I45A, M46A) zeigten einen drastischen Effekt auf die Bindung des Synaptobrevins an den $\Delta \mathrm{N}$ Komplex: die Bindungsgeschwindigkeit war fast 300-mal langsamer und die Affinität der Interaktion etwa 250-mal schwächer als die der wt-Reaktion. Auch die Verdrängungsreaktion lief deutlich langsamer ab (Abschnitt 3.2.7). Zusätzlich konnte mit Hilfe von bioinformatischen Methoden eine starke Konservierung dieses Bereiches in den R-SNARE-Proteinen festgestellt werden.

Bereits 1995 wurde gezeigt, dass die Mutation im Layer -3 (M46A) bewirkt, dass Synaptobrevin in PC12-Zellen nicht mehr über Endozytose von der Plasmamembran in neue synaptische Vesikel sortiert werden kann. Die Mutante ist jedoch in der Lage SDS-resistente SNARE-Komplexe zu bilden, was gegen einen Komplexbildungsdefekt spricht [52,53]. Eine andere Studie konnte zeigen, dass in einem GST-Bindungstest Synaptobrevin M46A eine reduzierte Bindung zu Syntaxin und SNAP-25 aufweist, jedoch sind diese Ansätze nicht mit den hier verwendeten quantitativen Ansätzen vergleichbar [60]. Die äquivalente Mutation in der Bäckerhefe (Snc1p M43A) hat einen temperatursensitiven Phänotyp zur Folge und führt unter restriktiven Bedingungen zur Akkumulation von sekretorischen Vesikeln in der Zelle [55]. Auch hier folgerte man, das die Mutation in Snc1p einen Einfluss auf die Vermittlung der Endozytose von der Plasmamembran zu frühen Endosomen hat. Die Aminosäure des SynaptobrevinLayer -3 scheint demnach eine wichtige Funktion inne zu haben.

Ein wichtiger Forschungsschwerpunkt des Gebietes der Proteinfaltung zielt auf die Beantwortung der Frage, welche molekularen Mechanismen für die Ausbildung von coiled coil-Strukturen aus mehreren Polypeptidketten verantwortlich sind. In den letzten Jahren konnten dahingehend entscheidende Fortschritte gemacht wer- 
den. Wie ich bereits kurz in der Einleitung erläutert habe (Abschnitt 1.8), wurde vorgeschlagen, dass kurze Segmente innerhalb der Polypeptidketten so genannte 'Triggersequenzen' ausbilden und diese für die Bildung von coiled coils unentbehrlich sind [131]. Man geht davon aus, das coiled coil-Triggersequenzen autonom $\alpha$-helikal gefaltete Einheiten innerhalb eines ungefalteten Monomers darstellen, und die Interaktion miteinander die Ausbildung der coiled coil-Struktur bewirken und damit die Entstehung von Oligomeren unterstützen [132]. Coiled coil-Triggersequenzen tragen möglicherweise zu einer definierten und gerichteten Ausbildung von coiled coil-Strukturen bei. Dies wurde bereits in verschiedenen Proteinen untersucht, welche coiled coil-Strukturen ausbilden, z.B. Cortexillin und GCN4 Leucinzipper und verschiedene Consensus-Sequenzen für coiled coilTriggerbereiche vorgeschlagen [132,70,41,131]. Um zu untersuchen, ob SNAREProteine vielleicht ebenfalls solche Triggersequenzen innerhalb ihrer AS-Sequenz besitzen, wurden die AS-Sequenzen der neuronalen SNARE-Proteine, sowie der verwendeten homologen R-SNARE-Proteine, unter Verwendung einer veröffentlichten Consensus-Triggersequenz bioinformatisch nach einer solchen Triggersequenz durchsucht [41] (in Zusammenarbeit mit Nickias Kienle, AG Strukturelle Biochemie). Interessanterweise konnte dabei in Synaptobrevin eine Region identifiziert werden, welche sich genau in dem Bereich der Aminosäuren zwischen Layer -4 und -2 befindet. Möglicherweise ist diese mutmaßliche coiled coilTriggerregion essentiell für die Bindung von Synaptobrevin an den Akzeptorkomplex. Wie oben bereits erwähnt, hat die Mutation der zentralen Aminosäuren in der mutmaßlichen Triggersequenz (I45A, M46A) dramatische Auswirkungen auf die Synaptobrevinbindung, die Verdrängungsreaktion und folglich die SNAREKomplexbildung.

Die Strukturuntersuchungen von monomerem Synaptobrevin mittels CDSpektroskopie und NMR-Spektroskopie ergaben, dass es hauptsächlich ungefaltet ist $[36,64]$. Der Layerbereich -4 bis -2 würde gefaltet einer $\alpha$-Helixwindung entsprechen. Aufbauend auf den Erkenntnissen zu einer möglichen Triggersequenz, könnte zukünftig mit Hilfe weiterer struktureller Untersuchungen, wie NMR- und EPR-Spektroskopie, die Synaptobrevinstruktur erneut betrachtet werden und damit eventuell kurze Bereiche mit vorhandenen Sekundärstrukturelementen detektiert werden. 
Der coiled coil-Triggerbereich konnte anhand der verwendeten ConsensusSequenz nur in Synaptobrevin identifiziert werden, nicht jedoch in VAMP4, Endobrevin oder Sec22. Sollte die Bindung der R-SNARE-Proteine an den Qabc-Akzeptorkomplex eine evolutionär konservierte Reaktion sein, dann müsste es möglich sein, auch in anderen R-SNARE-Proteinen solche coiled coil-Triggersequenzen zu identifizieren. Die bisher identifizierten ConsensusSequenzen variieren sehr stark [88]. Wahrscheinlich wird die Triggersequenz weniger durch die exakte Aminosäureabfolge, als durch die Abfolge von Aminosäuren mit speziellen chemischen Eigenschaften definiert [82]. Dazu könnten die Hydrophobizität und elektrostatische Eigenschaften gehören, welche die Stabilität der $\alpha$-Helix und deren Interaktionen fördert. In Zukunft wären Untersuchungen denkbar, bei denen man die Aminosäurenabfolge der Triggersequenzen mit Hilfe von bioinformatischen Methoden nach ihren Eigenschaften definiert und anschließend mit dem erhaltenen Modell die Sequenzen aller SNARE-Proteine nach Triggersequenzen durchsucht. Es besteht auch die Möglichkeit, dass die Interaktion von SNAP-25 und Syntaxin durch die Anwesenheit solcher Triggersequenzen in beiden Proteinen unterstützt wird. Vielleicht weisen SNARE-Proteine eine neuartige Triggersequenz auf.

\subsubsection{Spezifität der Synaptobrevinbindung}

Im Rahmen dieser Arbeit wurde überprüft, ob der R-SNARE-Bindungsschritt an den Akzeptorkomplex zur Spezifität der SNARE-Interaktionen beiträgt. Um diese Frage zu beantworten, wurde anhand von Fluoreszenzanisotropie die Geschwindigkeit bestimmt, mit der die R-SNARE-Homologen das stabilisierende Synaptobrevinpeptid aus dem $\Delta \mathrm{N}$-Komplex verdrängen kann. Außerdem wurde die Enthalpie und Affinität der Interaktion mittels ITC untersucht (Abschnitt 3.2.6). Die Verdrängungskinetiken und die Affinität der Bindung von VAMP4 und Endobrevin an den Akzeptorkomplex unterschieden sich kaum von der von Synaptobrevin. Die Verdrängung des Peptids durch VAMP4 fand etwas langsamer statt und die Enthalpie der Interaktionen beider R-SNARE-Proteine war etwas niedriger als die mit Synaptobrevin. Dies kann mit der unterschiedlichen Aminosäuresequenz der einzelnen R-SNARE-Proteine erklärt werden, wodurch 
andere Kontakte während der Bindung an den Akzeptorkomplex geknüpft werden, z.B. unterschiedliche Wasserstoffbrückenbindungen oder Salzbrücken, welche einen Einfluss auf die Reaktionsenthalpie haben. Die Interaktion von Sec22 aus der Bäckerhefe mit dem Akzeptorkomplex unterschied sich hauptsächlich in den thermodynamischen Parametern von Synaptobrevin. Die Verdrängungskinetik war nur leicht reduziert, die Affinität und die Enthalpie der Reaktion jedoch deutlich herabgesetzt. Für die Ergebnisse kann es zwei Erklärungen geben. Der Arbeit von Kloepper und Kollegen, in der die SNARE-Proteine anhand ihrer Aminosäuresequenz klassifiziert wurden, konnte entnommen werden, dass Synaptobrevin (Klasse R.IV), VAMP4 und Endobrevin (beide in Klasse R.III) bei sekretorischen Prozessen eine Rolle spielen. Es ist möglich, dass die R-SNAREProteine der Klasse R.I (Sec22) und R.II (Ykt6) eher auf die Interaktion mit den Q-SNARE-Proteinen in ER- und Golgitransportschritten spezialisiert sind [74]. Zum anderen ist es denkbar, dass es bis zu einem gewissen Grad eine Spezifität zwischen den R-SNARE-Proteinen unterschiedlicher Spezies gibt, in diesem Fall Maus und Bäckerhefe. Schlussendlich kann man anhand dieser Ergebnisse feststellen, dass der R-SNARE-Bindungsschritt nur zu einem geringen Ausmaß zur Spezifität der SNARE-Interaktion beiträgt.

Eine Ausnahme stellt jedoch das R-SNARE-Motiv von Tomosyn dar, welches interessanterweise nicht in der Lage ist, an den $\Delta \mathrm{N}$-Komplex zu binden. Tomosyn gehört zu den regulatorischen R-SNARE-Proteinen, welche mit Syntaxin und SNAP-25 einen Komplex bilden können und die Bindung Synaptobrevins damit blockieren $[61,108,49]$. Andererseits besagen elektrophysiologische Studien, dass die inhibitorische Funktion des Tomosyns nicht von der SNARE-Interaktion abhängig ist [151]. Der Tomosynkomplex ist sehr stabil und da Tomosyn nicht mehr von Synaptobrevin verdrängt werden kann, muss dieser Komplex anscheinend von der ATPase NSF und deren Cofaktor $\alpha$-SNAP unter ATP-Verbrauch dissoziiert werden, um eine spätere SNARE-Komplexbildung mit Synaptobrevin gewährleisten zu können [108].

Tomosyn kann Komplexe mit Syntaxin und SNAP-25 bilden [108], jedoch nicht an deren N-Termini binden (Abb. 3.12). Ein Vergleich der Aminosäuresequenz der unterschiedlichen R-SNARE-Gruppen ergab, dass der N-Terminus der regulatorischen R-SNARE-Motive sich deutlich von der Aminosäurekonser- 
vierung der anderen Gruppen unterscheidet (Abb. 3.13). Auch der bereits oben genannte wichtige Bereich der Layer -4 bis -2 ist in der Tomosyn-Gruppe nicht konserviert. Interessanterweise konnte ein Austausch von fünf Aminosäuren im Tomosyn gegen Aminosäuren des Synaptobrevins in der Region Layer -4 bis -2 die Bindung an den Akzeptorkomplex wiederherstellen. Dies unterstützt wiederum die Bedeutung dieser Region im SNARE-Motiv für die R-SNARE-Bindung.

Da Tomosyn im Prinzip an Syntaxin und SNAP-25 binden kann, liegt die Bindungstelle des Tomosyns vermutlich am C-Terminus des Qabc-Komplexes, welcher im $\Delta \mathrm{N}$-Komplex durch das Synaptobrevinpeptid besetzt wird. Dies könnte für eine Aufgabe von Tomosyn als Platzhalter sprechen. Als ein solcher Platzhalter könnte es eine Ähnlichkeit zur stabilisierenden Funktion des Synaptobrevinpeptids im $\Delta$ N-Komplex aufweisen. Wie oben erwähnt, bildet das SNAREMotiv Tomosyns einen stabilen Komplex mit SNAP-25 und Syntaxin aus und kann nicht durch Synaptorbrevin aus diesem Komplex verdrängt werden [108]. Womöglich entsteht dieser Tomosynkomplex nur unter in vitro-Bedingungen und in vivo könnte diese thermodynamisch günstige Struktur nicht ausgebildet werden. Es wäre denkbar, dass in vivo nur der C-Terminus des Tomosyn-SNAREMotivs an die Q-SNARE-Proteine bindet und der N-Terminus als Bindungsstelle für Synaptobrevin zugänglich bliebe. Tomosyn besitzt einen sehr großen Nterminalen Teil, der sich durch WD40-repeats auszeichnet, die wahrscheinlich eine $\beta$-Propeller-Struktur ausbilden [62]. Die Funktion dieses Bereiches ist unklar. Sie könnte als Bindungsstelle für modulatorische Faktoren dienen. Man könnte spekulieren, dass in Anwesenheit der riesigen N-terminalen Domäne die Struktur des gebildeten SNARE-Komplexes anders sein könnte.

Dies würde bedeuten, dass die Zelle keinen Energieverlust, in Form von ATP-verbrauchender Dissoziierung eines vollständig ausgebildeten Tomosynkomplexes, in Kauf nehmen muss. Die Tomosyn-ähnlichen Lgl (lethal giant larvae)Proteine, sowie Sro7p und Sro77p haben im Laufe der Evolution das vollständige SNARE-Motiv oder einen Teil ihres SNARE-Motivs verloren. In Sro7p und Sro77p ist hauptsächlich die C-terminale Region des SNARE-Motivs konserviert [108]. Dies spricht ebenfalls für eine größere Bedeutung des C-Terminus der regulatorischen R-SNARE-Gruppe und lässt sich gut mit der Platzhalterhypothese vereinen. Es sind jedoch weitere Untersuchungen notwendig, um diese 
Annahme zusätzlich zu untermauern.

\subsection{Partiell unstrukturierte trans-Komplexe}

Die bisherigen Ausführungen bestätigen, dass nach der Ausbildung des Nterminalen Qabc-Akzeptorkomplexes Synaptobrevin binden kann und, dem Zipper-Modell gemäß, eine gerichtete Bildung des SNARE-Komplexes bis zum membranproximalen C-Terminus erfolgt. Das entstehende Vier-Helixbündel könnte somit die gegenüberliegenden Membranen in eine räumliche Nähe bringen und bei vollständigem Aufrollen die Fusion herbeiführen.

In dieser Arbeit konnte gezeigt werden, dass Komplexe, welche Cterminale Mutationen bzw. Verkürzungen des SNAP-25s enthalten (SNAP-25 [+5], BoNT/A) SNARE-Komplexe mit Syntaxin und Synaptobrevin bilden konnten und bei thermalen Denaturierungsexperimenten einen zweiphasigen Zerfall aufwiesen (Abb. 3.10). Das deutet darauf hin, dass in diesen Komplexen zwei Bereiche getrennt werden können, die unterschiedliche Stabilitäten besitzen. Meine Ergebnisse legen nahe, dass die C-terminale Domäne durch die Mutationen destabilisiert worden ist und demnach früher zerfällt, als das verbleibende Helixbündel. Limitierte Proteolyse-Experimente zeigten zusätzlich, dass der Komplex, der SNAP-25 [+5] enthält, einen instabilen C-Terminus besitzt. Da man zwei Bereiche auftrennen kann, die eventuell in vivo auch getrennt vorliegen, könnte dies, strukturell gesehen, einen partiell unstrukturierten trans-Komplex möglich machen.

Die Bedeutung der C-terminalen Region des SNARE-Komplexes auf die Sekretion konnte bereits mit genetischen Untersuchungen in C. elegans belegt werden, bei denen Mutationen im Layer $+4,+5$ und +6 der drei SNARE-Proteine identifiziert wurden $[100,116]$. Auch in Drosophila hatte die Doppelmutation in den Layern $+4 /+5$ in Syntaxin deutliche Defekte der neuronalen Sekretion zur Folge [38].

Strukturelle Untersuchungen an dem homologen Hefe-SNARE-Komplex ergaben, dass ein binärer Sso1p/Sec9p-Komplex (Qabc) C-terminal unstrukturiert ist. Der ternäre Sso1p/Sec9p/Snc1p-Komplex ist jedoch vollständig strukturiert [40]. Des Weiteren wurden elektrophysiologische Experimente mit den 
clostridialen Neurotoxinen TeNT und BoNT/B durchgeführt, welche beide Synaptobrevin in der Mitte des SNARE-Motivs an der gleichen Aminosäureposition schneiden. TeNT besitzt die Erkennungsregion für Synaptobrevin am N-Terminus des Proteins, während BoNT/B den C-Terminus als Erkennungsbereich benötigt. TeNT hatte in nichtstimulierten crayfish neuromuscular junctions keinen Einfluss auf die Exozytose, jedoch blockierte BoNT/B die Exozytose [66]. Daraus wurde geschlossen, dass der N-Terminus des Synaptobrevins komplexiert und daher geschützt sein muss, während der C-Terminus weiterhin für die Protease zugänglich ist. Es wurde vorgeschlagen, dass ein SNARE-Komplex mit einem membranproximalen unstrukturierten C-Terminus als ein Intermediat der SNAREvermittelten Exocystose fungieren könnte [40,66,148]. Diese Experimente sind sehr indirekt und beruhen einzig auf der unterschiedlichen Wirkung der beiden Neurotoxine. Man kann nicht ausschließen, dass der beobachtete Effekt andere Ursachen hat.

Die begleitenden elektrophysiologischen Untersuchungen mit den oben genannten SNAP-25-Mutationen zeigten auch in vivo einen drastischen Phänotyp; die Sekretion ist vollständig blockiert [129]. Da jedoch in dieser Arbeit gezeigt wurde, dass die SNARE-Komplexbildung mit diesen Mutationen nicht gestört ist (Abb. 3.10A), muss man annehmen, dass wahrscheinlich Komplexe entstehen, welche keine Sekretion vermitteln können. Es wäre denkbar, dass diese Komplexe zwischen den Membranen in einem partiell unstrukturierten Zustand verharren. Dafür kann es verschiedene Gründe geben: Zum einen könnte es sein, dass mit diesen Mutationen der C-Terminus des SNARE-Komplexes nicht vollständig strukturiert werden kann und dementsprechend der Abstand zwischen den Membranen zu groß sein könnte, um die Fusion zu ermöglichen. Dafür sprechen Experimente mit Synaptobrevin/Cellubrevin knockout-Mäusen, bei denen die Verlängerung der Linkerregion zwischen dem SNARE-Motiv und der Transmembranregion von Synaptobrevin einen Defekt der Sekretion zur Folge hatte [72]. Wahrscheinlich erzeugt der lange Linker einen zu großen Abstand zwischen den Membranen, wodurch es nicht zur Fusion kommen kann. Zum anderen ist auch möglich, dass regulierende Faktoren wie z.B. Synaptotagmin nicht an diese modifizierten Komplexe binden können und demnach die Fusion der Membranen nicht durch das

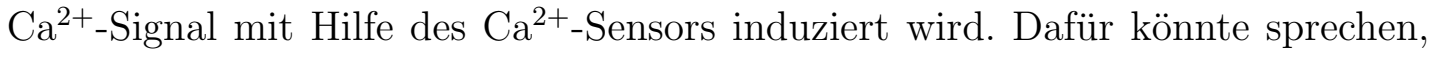


dass die Sekretion in Anwesenheit der SNAP-25 [+5]-Mutante auch mit hohen $\mathrm{Ca}^{2+}$-Mengen nicht wiederhergestellt werden konnte [129].

Interessanterweise sind die SNAP-25-Mutationen $[+4]$ und $[+5]$ dominant negativ, d.h. eine Überexpression der Mutanten blockiert die Sekretion auch in chromaffinen SNAP-25 wt-Zellen, in denen endogenes SNAP-25 vorliegt. Dies unterstützt die Annahme, dass die SNAP-25-Mutanten mit Syntaxin und Synaptobrevin nicht fusogene Komplexe bilden, welche zwischen Plasma- und Vesikelmembran verbleiben. Da NSF nur cis-Komplexe dissoziieren kann, wäre die Membran durch die nicht funktionellen trans-Komplexe versperrt und demnach kann auch die Bildung von Komplexen mit zelleigenem SNAP-25 nicht zur Sekretion führen.

C-terminal verkürztes Synaptobrevin (Syb 1-70; $\Delta \mathrm{C}$ ) kann SNAREKomplexe bilden, welche möglicherweise am C-Terminus ungefaltet sind. Solch ein $\Delta$ C-Komplex könnte einen partiell entfalteten SNARE-Komplex in Lösung nachahmen. Die Interaktion von einem C-terminalen Synaptobrevinpeptid (Syb 71-96) mit dem $\Delta$ C-Komplex könnte dann die Strukturierung des C-Terminus und somit den mutmaßlichen letzten Zipper-Schritt widerspiegeln. Meine Untersuchungen ergaben, dass diese Bindung sehr langsam ist. Des Weiteren konnte nur eine geringe Affinität und Enthalpie während der Bindung ermittelt werden. Das bedeutet, dass die Interaktion nur eine geringe Energiemenge freisetzt.

Es gibt verschiedene Möglichkeiten, wie sich ein partiell strukturierter transSNARE-Komplex zwischen den Membranen verhalten könnte. Erstens wäre es vorstellbar, dass die SNARE-Komplexbildung an einer bestimmten Stelle stoppt, um dann nach Eingang des $\mathrm{Ca}^{2+}$-Signals den C-Terminus vollständig zu strukturieren und damit die Fusion einzuleiten. Aufgrund der drastischen Strukturänderungen der SNARE-Proteine während der Komplexbildung und der dabei freigesetzten Gesamtenergie, scheint es thermodynamisch eher unwahrscheinlich, dass dieser Prozess gestoppt werden kann. Es ist auch denkbar, dass ein Protein als Bremse der Komplexbildung wirkt. Eine derartige Aufgabe wurde für Synaptotagmin vorgeschlagen, jedoch gibt es bislang keine Beweise für solch einen Mechanismus (diskutiert in $[76,16]$ ).

In einem anderen Szenario könnten die Abstoßungskräfte der Membranen stärker sein und die während der Komplexbildung freigesetzte Energie nicht aus- 
reichen, um den Komplex vollständig bis zum C-Terminus durchzustrukturieren. Damit würde der Komplex einen unstrukturierten C-Terminus besitzen und im Gleichgewicht mit den Membranabstoßungskräften stehen. Das würde einen weiteren Mechanismus erfordern, welcher die eigentliche Fusion initiiert. Auch hier könnte Synaptotagmin eine entscheidende Rolle spielen.

Da die Komplexformation am C-Terminus des $\Delta$ C-Komplexes mit Syb 7196 nur eine geringe Affinität und damit einen geringen $\Delta \mathrm{G}$-Wert aufweist, könnte dies für die letztgenannte Hypothese sprechen. Erstens zeigt es, dass nur wenig Energie während der letzten C-terminalen Strukturierung freigesetzt wird. Diese geringe Energie kann wahrscheinlich nicht die treibende Kraft sein, um die Fusion zu vermitteln. Es sollte aber bemerkt werden, dass diese Experimente mit zwei Peptidfragmenten (Syb 1-70 und 71-96) durchgeführt wurden und die freigesetzte Energie mit einem vollständigen Synaptobrevin durchaus höher liegen könnte. Zweitens würde eine geringe Affnität die Reversibilität der Reaktion unterstützen. Damit wäre es möglich, dass ein thermodynamisches Gleichgewicht zwischen C-terminaler Strukturierung und Nichtstrukturierung des transSNARE-Komplexes vorliegen kann. Die thermodynamischen Ergebnisse werden ausführlicher im nachfolgenden Abschnitt diskutiert.

Schlussendlich sollte angemerkt werden, dass die in dieser Arbeit vorstellten Experimente ausschließlich mit den löslichen SNARE-Motiven durchgeführt wurden und daher keine endgültige Aussage über die SNARE-Komplexbildung in Membranen getroffen werden kann. Jedoch zeigen die Ergebnisse von Pobbati und Kollegen, dass sich mit löslichen Proteinen erhaltene Erkenntnisse zur SNARE-Komplexbildung durchaus mit Membranfusionsexperimenten bestätigen lassen [109].

\subsection{Kinetische und Thermodynamische Aufglie- derung}

Der SNARE-Komplex ist sehr stabil, wie die hohe Schmelztemperatur und SDSResistenz belegen konnten [36]. Es wurde vorgeschlagen, dass die bei der Faltung freiwerdende Energie mechanisch an die Fusion der Membranen gekoppelt wird. 
Es konnte jedoch bisher nicht aufgeklärt werden, wieviel Energie während der Interaktion der Proteine freigesetzt wird und ob diese Energie ausreichen könnte, um zwei Membranen zu fusionieren. Insbesondere ist nicht nur die gesamte freiwerdende Energie von Interesse, sondern auch die der einzelnen Komplexbildungsschritte, um einen Eindruck von der Energetik der Zwischenreaktionen zu bekommen. Dies könnte Rückschlüsse auf die Funktionalität von regulatorischen Proteinen bei bestimmten Zwischenschritten der Komplexbildung zulassen.

Der SNARE-Komplex ist durch eine ausgeprägte Hysterese charakterisiert [32]. Das weist auf eine hohe Energiebarriere zwischen dem gefaltetem und ungefalteten Zustand der Proteine hin und bedeutet, dass sich der Komplex nicht auf dem selben Reaktionsweg entfaltet und zurückfaltet. Dies unterstützt die Hypothese, dass ein weniger stabiles Intermediat während der Komplexbildung gebildet wird. Außerdem konnte gezeigt werden, dass die Faltung der SNARE-Proteine bzw. die Entfaltung des SNARE-Komplexes keine Gleichgewichtsreaktion ist. Um den SNARE-Komplex zu entfalten, ist in vivo die ATPase NSF notwendig, welche den Komplex unter ATP-Verbrauch in die Einzelproteine dissoziiert [126]. In vitro kann der Komplex nur mit hohen Temparaturen, bzw. chaotropen Reagenzien, wie Guanidinhydrochlorid denaturiert werden [36,32]. In Anwesenheit von denaturierenden Reagenzien wurde die Dissoziationkonstante des SNAREKomplexes extrapoliert und darauf aufbauend die Dissoziationskonstante unter nativen Bedingungen abgeschätzt $\left(4,2 \times 10^{-18} s^{-} 1\right)$ [32]. Der SNARE-Komplex würde folglich mit einer Halbwertszeit von einer Milliarde Jahre zerfallen. Aufgrundddessen ist es mit biochemischen Methoden nicht möglich, die Freie Energie $(\Delta \mathrm{G})$ dieser Reaktion zu bestimmen.

Im Rahmen dieser Arbeit wurde Isothermale Titrationskalorimetrie eingesetzt, um die SNARE-Komplexbildungsschritte thermodynamisch zu charakterisieren. Obwohl es nicht möglich ist, die Freie Energie der Gesamtreaktion zu ermitteln, kann die mit ITC bestimmte Reaktionsenthalpie $(\Delta \mathrm{H})$ zumindest einen Eindruck von den energetischen Änderungen während der Komplexbildung und deren Zwischenschritte geben. Die Änderung der Enthalpie wird während der Proteininteraktion z.B. durch die Kontakte der Aminosäuren miteinander in Form von Wasserstoffbrückenbindungen und Salzbrücken hervorgerufen. Außerdem tragen Konformationsänderungen und die Verdrängung von Wassermolekülen von 
der Bindungsoberfläche zur Änderung der Enthalpie bei. Dementsprechend kann man aus Enthalpieänderungen nicht mit letzter Gewissheit Rückschlüsse auf die genauen molekularen Ereignisse treffen. In Abbildung 4.1 sind die Enthalpiewerte für die Komplexbildungszwischenschritte in einer Übersicht dargestellt.

Während der Komplexbildung mit allen drei Proteinen wird eine Enthalpie von ungefähr $-120 \mathrm{kcal} / \mathrm{mol}$ frei (Dr. D. Fasshauer). Die Bildung des binären $\mathrm{Syx}_{2} / \mathrm{SN} 25_{1}$-Komplexes setzt etwa $-60 \mathrm{kcal} / \mathrm{mol}$ frei (Dr. D. Fasshauer). Dieser Wert ist im Vergleich zu anderen binären Proteininteraktionen ungewöhnlich hoch [97, 133]. Die hohe Enthalpie lässt auf eine strukturelle Umlagerung schließen, bei der eine große Anzahl von intermolekularen Bindungen entstehen, wie z.B. Wasserstoffbrückenbindungen und van-der-Waals-Wechselwirkungen [97]. Die anschließende Bindung von Synaptobrevin an diesen Komplex hat eine Enthalpieänderung von etwa $-55 \mathrm{kcal} / \mathrm{mol}$ zur Folge (Dr. D. Fasshauer). Hierbei gilt es zu beachten, dass zuvor das zweite Syntaxin den Komplex verlassen muss. Da in dieser Arbeit die Bindungsenthalpie von Synaptobrevin an den Akzeptorkomplex mit Hilfe des stabilisierten $\Delta \mathrm{N}$-Komplexes bestimmt werden konnte $(\approx-30 \mathrm{kcal} / \mathrm{mol})$, ist es unter Umständen möglich, die Enthalpieänderung der off-pathway-Reaktion, also Bindung und Dissoziation des zweiten Syntaxins, aus der Gesamtreaktion 'herausrechnen' zu können. Außerdem wäre es denkbar, aufgrund der Enthalpiebestimmungen mit verschiedenen Synaptobrevinkonstrukten, die Synaptobrevinbindungsreaktion in 'Bindung' und 'C-terminale Faltung' aufzuteilen. Die Differenz aus der gesamten Synaptobrevinbindungsreaktion (-30 $\mathrm{kcal} / \mathrm{mol}$ ) und der Einzelreaktionen $(-22 \mathrm{kcal} / \mathrm{mol}$ (Synaptobrevinbindung) + -6 $\mathrm{kcal} / \mathrm{mol}$ (C-terminale Faltung) $=-28 \mathrm{kcal} / \mathrm{mol}$ ) könnte die Enthalpieänderung der Verdrängungsreaktion des Synaptobrevinpeptids aus dem $\Delta$ N-Komplex darstellen (-2 kcal/mol) (siehe auch Abschnitt 4.2).

Mittels ITC konnte ich die Reaktion von Synaptobrevin und dem $\Delta \mathrm{N}$ Komplex verfolgen und so die Affinität der Synaptobrevinbindung bestimmen, welche etwa 1,5 nM $\left(10^{-9}\right)$ beträgt. Auf der Grundlage der Formel $\Delta G=-R T \ln k$ entspricht dies einem $\Delta \mathrm{G}$-Wert von etwa $-12,1 \mathrm{kcal} / \mathrm{mol}$. Es ist jedoch denkbar, dass aufgrund der technischen Limitierung des ITC-Gerätes die exakte Affinitätsbestimmung nicht möglich war, sondern nur ein Näherungswert erhalten wurde und die eigentliche Affinität deutlich höher ist. Es ist fraglich, ob der erste Schritt 


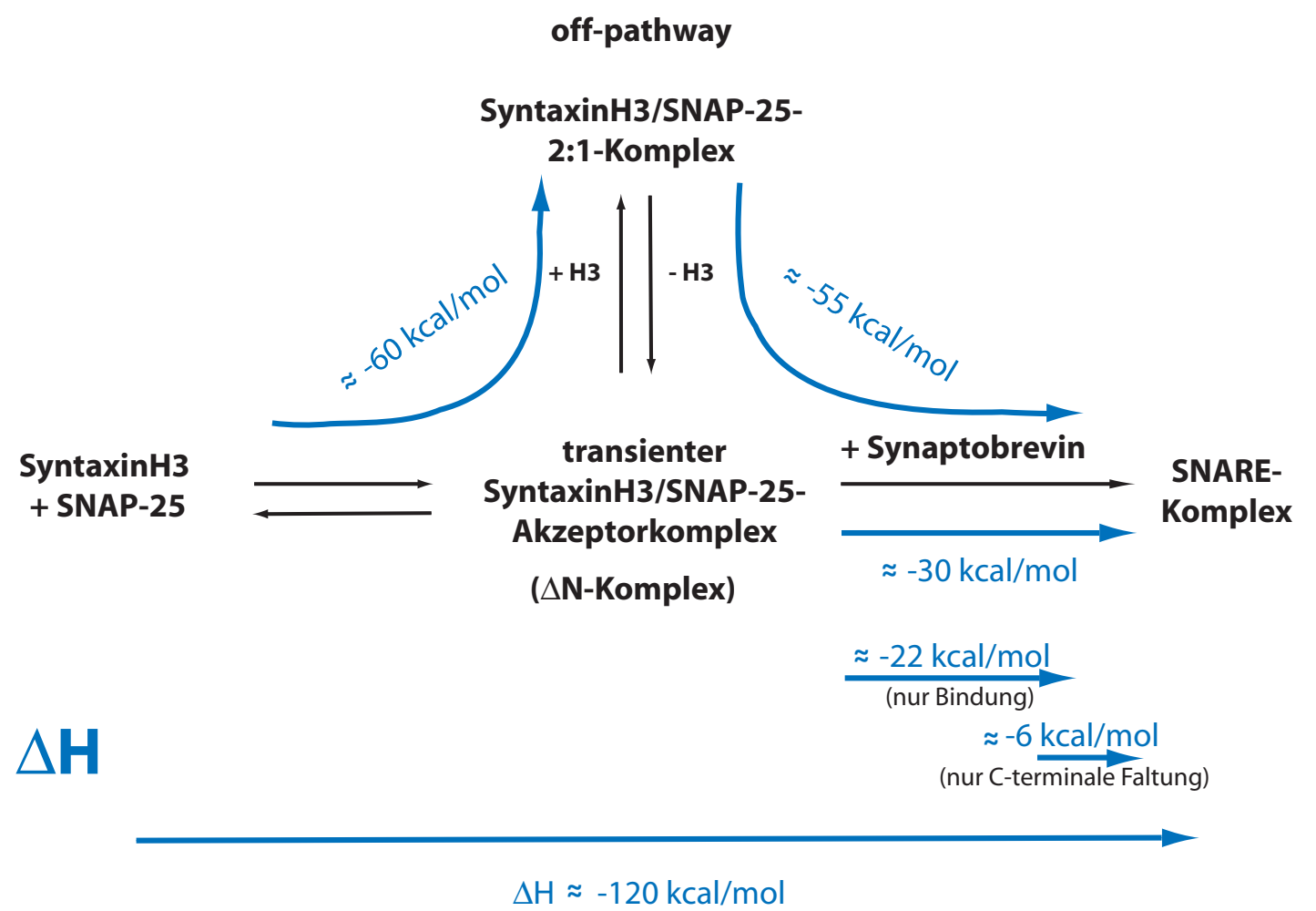

Abbildung 4.1: Thermodynamische Übersicht der SNARE-Komplexbildung. Die SNARE-Komplexbildungsschritte und die ermittelten Enthalpiewerte der jeweiligen Reaktionsschritte sind in einem Diagramm dargestellt. Die Interaktion der drei Proteine Syntaxin, SNAP-25 und Synaptobrevin hat eine Enthalpieänderung von rund $-120 \mathrm{kcal} / \mathrm{mol}$ zur Folge. Die Bildung des 2:1-Komplexes setzt eine Enthalpie von etwa $-60 \mathrm{kcal} / \mathrm{mol}$ frei. Aufgrund der Bindung von Synaptobrevin an den 2:1-Komplex gibt es eine Enthalpieänderung von etwa $55 \mathrm{kcal} / \mathrm{mol}$, wobei zuvor das zweite Syntaxin den 2:1-Komplex verlassen muss. Die Bindung von Synaptobrevin an einen stabilisierten Akzeptorkomplex ( $\Delta$ N-Komplex) setzt eine Enthalpie von etwa $-30 \mathrm{kcal} / \mathrm{mol}$ frei. Mit Hilfe unterschiedlich langer Synaptobrevinkonstrukte konnte die Synaptobrevinbindungsreaktion in die Komponenten 'Bindung' $(-22 \mathrm{kcal} / \mathrm{mol})$ und 'C-terminale Faltung' (-6 kcal/mol) zerlegt werden.

der Synaptobrevinbindungsreaktion, die N-terminale Bindung, reversibel oder irreversibel ist. Möglicherweise können die diskreten Einzelreaktionen der SNAREKomplexbildung reversibel ablaufen, die Gesamtreaktion ist jedoch irreversibel. Dann wäre es vielleicht möglich, $\Delta \mathrm{G}$ der Gesamtreaktion aus den Einzelreaktionen zu berechnen. Um die Frage zu beantworten, ob die Bindung Synaptobrevins reversibel oder irreversibel ist, wären Experimente denkbar, bei dem Syb 1-52 mit $\Delta$ N-Komplex inkubiert wird und die Bindung von Syb 1-52 an den $\Delta \mathrm{N}$ Komplex z. B. in einem Nativ-Gel überprüft wird. Anschließend könnte man zu 
diesem Ansatz Synaptobrevin 1-96 geben und über einen Zeitraum beobachten, ob sich aufgrund einer Verdrängungsreaktion SDS-resistente Komplexe mit Syb 1-96 gebildet haben. Dies könnte für eine reversible Reaktion sprechen und damit die Bestimmung des Gesamt- $\Delta$ G-Wertes anhand der Werte der Einzelreaktionen ermöglichen.

Aufgrund des nicht vorhandenen chemischen Gleichgewichts der SNAREKomplexbildungsreaktion ist es eigentlich biochemisch nicht möglich, $\Delta \mathrm{G}$ der Gesamtreaktion zu bestimmen. Deshalb haben verschiedene Arbeitsgruppen versucht, $\Delta \mathrm{G}$ über die physikalische Größe Kraft zu bestimmen. Dafür wurden folgende Methoden verwendet: AFM (Atomic Force Microscopy) und SFA (Surface Force Apparatus), sowie Einzelmolekülmessungen mit FRET [150,87,83].

In einer kürzlich veröffentlichten Studie nutzten Li und Kollegen SFA um die Freie Energie $\Delta \mathrm{G}$ zu bestimmen, welche nötig ist, um einen partiell strukturierten SNARE-Komplex auseinander zu ziehen [83]. Anschließend wurde abgeschätzt, wieviele Komplexe sich in der Reaktionsmembran befinden. Anhand dieser Werte der Komponenten, Kraft und Anzahl der Komplexe, wurde die Freie Energie für einen einzelnen Komplex berechnet, welche $-35 \mathrm{KbT}$ ( $\approx-21$ $\mathrm{kcal} / \mathrm{mol}$ ) beträgt. Ein Problem dieser Methode könnte in der Bestimmung der Anzahl der beteiligten Komplexe liegen, welche nur abgeschätzt werden konnte. Berechnet man beispielsweise die Affinität der Interaktion ausgehend von dem vorgeschlagenen $\Delta \mathrm{G}$-Wert von $-21 \mathrm{kcal} / \mathrm{mol}$, erhält man eine Affinität von etwa $1 \mathrm{fM}\left(10^{-15}\right)$. Diese Affinität wäre beeindruckend hoch. Die bisher höchste Affinität zwischen Proteinen wurde für Antikörper-Antigen-Interaktionen bestimmt, welche sich in der Größenordnung von 1 pM $\left(10^{-12}\right)$ befinden [110]. Weiterhin wurde bei diesem Ansatz nur die Energie bestimmt, welche benötigt wird, um Synaptobrevin von Syntaxin und SNAP-25 abzutrennen, nicht jedoch die der Trennung von allen drei Proteinen. Außerdem ist fraglich, ob $\Delta \mathrm{G}$ tatsächlich mit dieser Methode bestimmt werden kann, da auch hier keine Gleichgewichtsreaktion stattfindet.

Die Verwendung des stabilisierten $\Delta \mathrm{N}$-Komplexes in meiner Arbeit ermöglichte es, die Kinetik der SNARE-Komplexbildung für zwei Teilschritte zu bestimmen (Abb. 4.2A). Dabei wird deutlich, dass die Bildung des Akzeptorkomplexes aus 
Syntaxin und SNAP-25 eine sehr langsame und reversible Reaktion ist. Ist jedoch die Bindungstelle als Akzeptor vorbereitet, kann Synaptobrevin sehr schnell daran binden. Die Bildung des Akzeptorkomplexes ist folglich der geschwindigkeitsbestimmende Schritt. Dies legt die Überlegung nahe, dass es eine sehr hohe Energiebarriere geben muss, welche Syntaxin und SNAP-25 zu so einer langsamen Reaktion zwingen.

Die Abbildung 4.2B stellt in einem Energieprofil dar, wie die einzelnen Komplexbildungsreaktionen, aufgrund der in dieser Arbeit bestimmten thermodynamischen und kinetischen Ergebnisse, ablaufen könnten. Aufgrund der langsamen Bindungsgeschwindigkeit von Syntaxin und SNAP-25 nehme ich eine sehr hohe Aktivierungsenergie $\left(\Delta \mathrm{G}^{*}\right)$ an, welche zunächst überwunden werden muss. Wie bereits zuvor erläutert wurde, ist es sehr wahrscheinlich, dass diese Reaktion von einem priming factor katalysiert wird. Dies würde die Aktivierungsenergie herabsetzen, z.B. in dem die drei Helices in Kontakt gebracht werden, und damit den Ablauf der Reaktion optimieren. Außerdem kann zumindest für diese Reaktion $\Delta \mathrm{G}$ bestimmt werden, da die Bildung des binären Akzeptorkomplexes eine reversible Reaktion ist. Der $\Delta \mathrm{G}$-Wert dieser Reaktion beträgt etwa $-9,5 \mathrm{kcal} / \mathrm{mol}$. Die relativ geringe Enthalpieänderung und die sehr hohe Bindungsgeschwindigkeit von Synaptobrevin an den Akzeptorkomplex unterstützt die Vermutung, dass diese Reaktion keinen hohen Energieaufwand mehr benötigt. Die thermodynamischen Untersuchungen des letzten Komplexbildungsschrittes, in denen gezeigt wurde, dass die Strukturierung des C-Terminus nur eine geringe Enthalpieänderung zur Folge hat, legen nahe, dass der sich danach bildende partiell strukturierte SNARE-Komplex in einem Gleichgewicht mit einem vollständig strukturierten Komplex stehen könnte. Sollte diese Reaktion tatsächlich reversibel sein, könnte auch für diesen Teilschritt der SNARE-Komplexbildung der $\Delta$ G-Wert bestimmt werden. Bei der für diesen Reaktionsschritt ermittelten Affinität von 1,37 $\mu \mathrm{M}$, kann ein $\Delta \mathrm{G}$-Wert von etwa $-8,0 \mathrm{kcal} / \mathrm{mol}$ berechnet werden.

Ob die hier aus den thermodynamischen Werte ermittelte Energie ausreichen könnte, um zwei Membranen zu fusionieren, kann auch in dieser Arbeit nicht abschließend geklärt werden. Es wäre zudem möglich, dass mehrere SNAREKomplexe die Fusion der Membranen vermitteln. Es wird angenommen, dass zwischen drei und 15 SNARE-Komplexe an der Fusion eines Vesikels mit der 


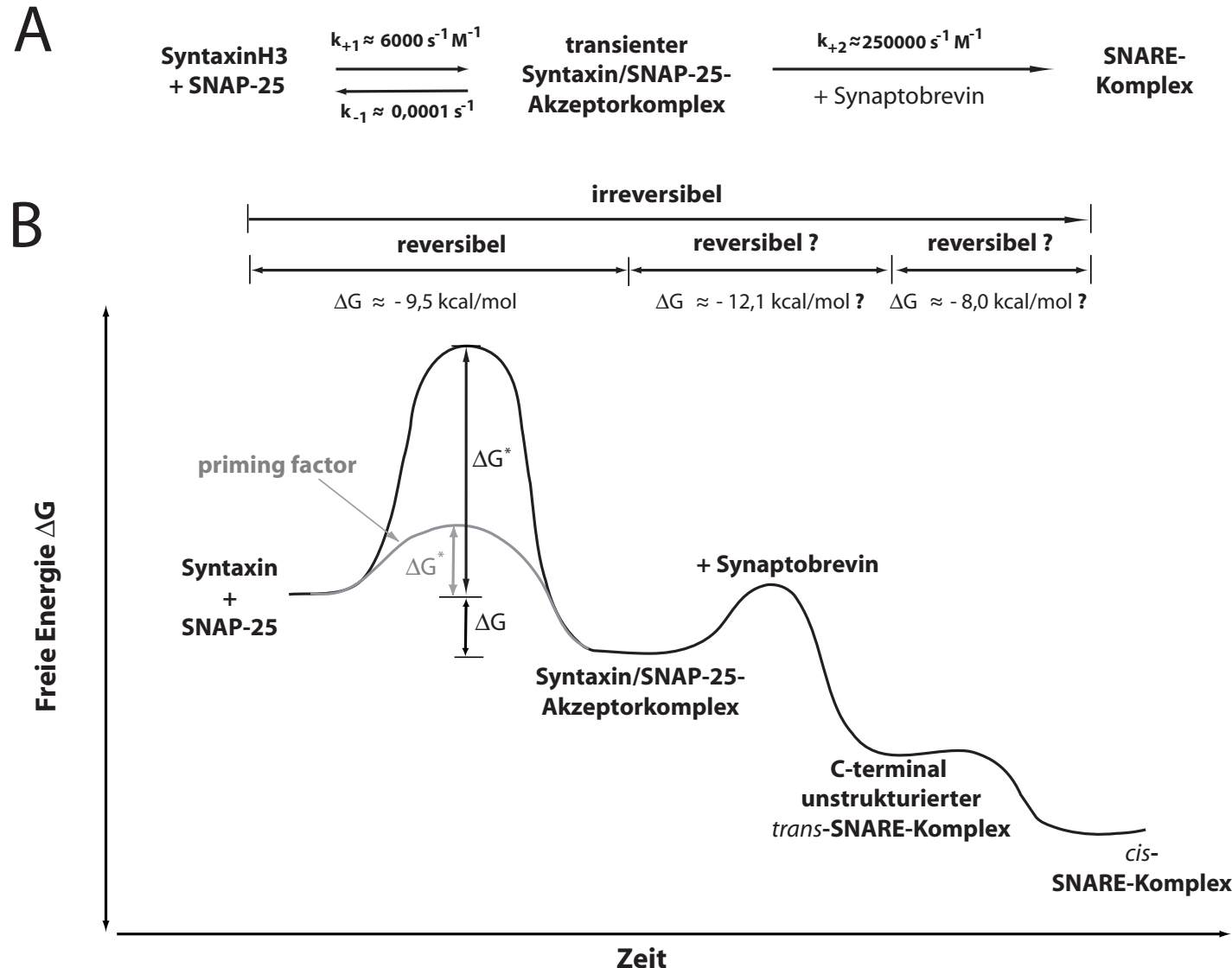

Abbildung 4.2: Kinetik und Energieprofil der SNARE-Komplexbildung. (A) Übersicht der kinetischen Ergebnisse für zwei Zwischenschritte der SNARE-Komplexbildung. Die Interaktion von Syntaxin und SNAP-25 findet mit einer Bindungsgeschwindigkeit von etwa $6000 s^{-1} M^{-1}$ und die Rückreaktion mit einer Geschwindigkeit von rund 0,0001 $s^{-1}$ statt. Die Geschwindigkeit der Bindungsreaktion von Synaptobrevin an den Akzeptorkomplex beträgt etwa $250000 s^{-1} M^{-1}$.

(B) Darstellung eines Energieprofils der einzelnen Komplexbildungsreaktionen. Die Interaktion von Syntaxin und SNAP-25 benötigt wahrscheinlich eine hohe Aktivierungsenergie $\left(\Delta \mathrm{G}^{*}\right)$, welche in vivo durch die Anwesenheit eines priming factors reduziert sein könnte (grau). Die Bindung von Synaptobrevin erfordert vermutlich keinen hohen Energieaufwand. Die anschließende Bildung eines C-terminal unstrukturierten Komplexes könnte in einem Gleichgewicht mit einem vollständig strukturierten Komplex stehen. Der vollständig gebildete cis-SNAREKomplex stellt die thermodynamisch günstigste Struktur dar. Im oberen Bereich der Abbildung wird verdeutlicht, dass die Gesamtreaktion irreversibel ist, jedoch möglicherweise die Einzelreaktionen reversibel sein könnten. Darauf aufbauend, könnte vielleicht $\Delta \mathrm{G}$ der Gesamtreaktion aus den ermittelten $\Delta \mathrm{G}$-Werten der Einzelreaktionen berechnet werden.

Plasmamembran beteiligt sind [96]. Es stehen noch weitere Experimente aus, um diese Fragen zu beantworten. 


\subsection{Modell der SNARE-Komplexbildung}

Die in dieser Arbeit präsentierten Daten erlauben es, einen detailierteren Einblick in die verschiedenen Zwischenreaktionen zur Bildung des synaptischen SNAREKomplexes und der dabei entstehenden Intermediate zu erhalten. Ich möchte an dieser Stelle ein Modell zur Bildung des SNARE-Komplexes vorschlagen, welches in Abbildung 4.3 illustriert ist. Dieses Modell basiert jedoch zumeist auf Erkenntnissen mit löslichen SNARE-Proteinen und sollten auch mit membranverankerten SNARE-Proteinen überpüft werden, wobei dies, zumindest teilweise, bereits geschehen ist [109]. Des Weiteren werde ich mich in diesem Modell primär auf den Faltungsprozess der unstrukturierten SNARE-Einzelproteine zu einer coiled coil-Struktur konzentrieren und werde die wichtigen Schritte vor und nach der Komplexbildung, wie die docking-Reaktion bzw. Fusionsporenausbildung und Dissoziation der cis-Komplexe, außen vor halten.

Die SNARE-Proteine Syntaxin und SNAP-25 liegen primär unstrukturiert an der Plasmamembran vor. Zunächst erfolgt eine N-terminale Interaktion von Syntaxin und SNAP-25 im Bereich der Layer -7 bis -5 , wodurch ein transientes N-terminal strukturiertes $\mathrm{Syx}_{1} / \mathrm{SN} 25_{1}$-Intermediat entsteht. Dieses Intermediat entsteht in vitro sehr langsam und dessen Bildung benötigt vermutlich eine hohe Aktivierungsenergie, weswegen dies als der geschwindigkeitsbestimmende Schritt der SNARE-Komplexbildung anzusehen ist. Um diese Reaktion in vivo zu beschleunigen, ist die Existenz von priming factors sehr wahrscheinlich, welcher die Anordnung der N-Termini der Q-SNARE-Proteine organisiert und die Aktivierungsenergie reduziert. Das $\mathrm{Syx}_{1} / \mathrm{SN} 25_{1}$-Intermediat entspricht einem Akzeptorkomplex, an den das vesikuläre Synaptobrevin binden kann. Synaptobrevin enthält einen Bereich von Layer -4 bis -2 , welcher vermutlich teilweise strukturiert ist und einer coiled coil-Triggersequenz entsprechen könnte. Mit Hilfe dieses Segmentes kann Synaptobrevin sehr schnell und mit hoher Affinität an den Akzeptorkomplex binden und löst damit die nachfolgende gerichtete Strukturierung der Helices aus. In diesem Schritt könnte die Ausbildung des coiled coil erfolgen, wodurch es zu einer strukturellen Umlagerung am C-Terminus kommt und ein partiell unstrukturierter Komplex entsteht. Der niedrige $\Delta \mathrm{G}$ - und Affinitätswert des letzten C-terminalen Zipper-Schrittes lassen vermuten, dass diese 


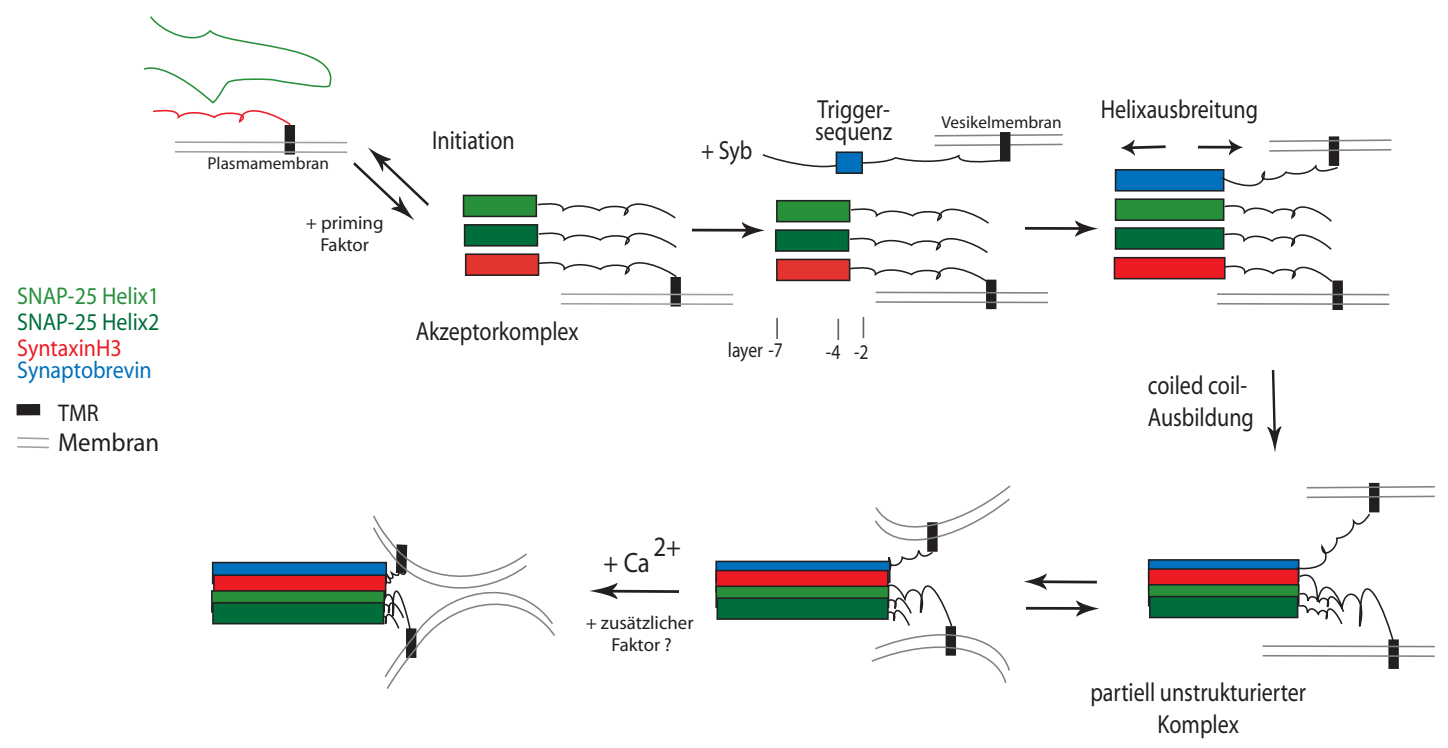

Abbildung 4.3: Zwischenschritte der SNARE-Komplexbildung. Syntaxin und SNAP25 liegen primär unstrukturiert auf der Plasmamembran vor. Die N-terminale Interaktion der beiden Proteine hat die Ausbildung eines Akzeptorkomplexes zur Folge. Dieser Schritt wird wahrscheinlich durch priming factors katalysiert. Synaptobrevin bindet mit einer kurzen strukturierten Region an den Akzeptorkomplex und initiiert die Ausbildung der Helices sowie der coiled coil-Struktur. Ein partiell unstrukturierter Komplex entsteht, dessen C-Terminus sich möglicherweise strukturieren und wieder entfalten kann. Die Fusion wird durch ein zusätzliches Protein vermittelt, welches nach Eingang des $\mathrm{Ca}^{2+}$-Signals die letzte Energiebarriere überwindet und die Vermischung der Lipidschichten einleitet.

Die $\alpha$-helikal strukturierten Regionen sind als Boxen dargestellt. Die N-terminale SyntaxinDomäne und der SNAP-25-Linkerbereich sind nicht dargestellt.

Reaktion reversibel sein kann. Vielleicht befindet sich in diesem Schritt der Komplexbildung die freiwerdende Energie und die Abstoßungskräfte der Membranen in einem Gleichgewicht, weswegen sich der C-terminale Bereich falten und wieder entfalten kann. Deshalb wären nach Eingang des $\mathrm{Ca}^{2+}$-Signals weitere Faktoren nötig, um die Fusion der Membranen zu initiieren. Einer dieser Faktoren könnte Synaptotagmin sein, das sich durch Kalzium- und Phospholipidbindungstellen auszeichnet $[107,12]$.

Um den genauen Ablauf der SNARE-Komplexbildung vollständig zu charakterisieren und dessen Stellenwert in der Exozytose zu untermauern, werden jedoch weitere Untersuchungen unentbehrlich sein. 


\section{$5 \quad$ Zusammenfassung}

Membranfusionsereignisse werden durch eine konservierte Proteinfamilie, die so genannten SNARE-Proteine, vermittelt. SNARE-Proteine bilden einen stabilen $\alpha$-helikalen Komplex zwischen zwei Membranen aus. Dabei bilden die plasmamembranständigen Proteine SNAP-25 und Syntaxin einen Akzeptorkomplex für das in der Vesikelmembran sitzende Synaptobrevin aus. Man geht davon aus, dass sich aufgrund dieser Komplexbildung die Membranen annähern und so letztendlich deren Fusion induziert wird. Der genaue Ablauf dieser Reaktionen, sowie mögliche Intermediate der Komplexbildung, konnte bisher nicht vollständig aufgeklärt werden. Um zu einem tieferen Verständnis des Ablaufs der SNAREvermittelten Membranfusion beizutragen, wurden in dieser Arbeit die einzelnen Schritte der SNARE-Komplexbildung in vitro anhand von biophysikalischen Methoden, wie CD- und Fluoreszenzspektroskopie charakterisiert. Zusätzlich wurde die SNARE-Komplexbildung thermodynamisch mittels Isothermaler Titrationskalorimetrie untersucht.

Im ersten Abschnitt dieser Arbeit wurde die Interaktion von Syntaxin und SNAP-25 untersucht, die einen Akzeptorkomplex für Synaptobrevin bilden. Frühere Arbeiten zeigten, dass die Bildung des Q-SNARE-Akzeptorkomplexes geschwindigkeitsbestimmend für die nachfolgenden Schritte ist. Mittels zielgerichteter Mutationen in SNAP-25 wurde gezeigt, dass die N-terminalen Regionen der drei Q-SNARE-Helices für die Komplexbildung entscheidend sind. Weitere thermodynamische Analysen ergaben, dass die langsame Q-SNARE-Akzeptorbildung möglicherweise in vivo durch einen priming factor beschleunigt wird.

Der zweite Teil der Arbeit beschäftigte sich mit der nachfolgenden Synaptobrevinbindungsreaktion. Im diesem Schritt bindet Synaptobrevin an den QSNARE-Akzeptorkomplex, jedoch kann in vitro ein zweites Syntaxinmolekül die 
Bindungsstelle von Syntaxin blockieren. Dieses experimentelle Problem wurde mit der Verwendung eines stabilisierten Akzeptorkomplexes umgangen, bei dem ein C-terminales Synaptobrevinpeptid einen Komplex mit Syntaxin und SNAP-25 bildet. Dieser stabilisierte Akzeptorkomplex bietet eine freie N-terminale Synaptobrevinbindungsstelle und nach der Bindung von Synaptobrevin kann das Cterminale Synaptobrevinfragment aus dem Verbund verdrängt werden. Durch Mutationen sowohl im Bindungsbereich des Akzeptorkomplexes als auch in Synaptobrevin, konnte der Bindungsschritt in dieser Dissertation erstmals in vitro detailiert analysiert werden. Der N-terminale Bereich von Synaptobrevin wurde als essenziell für die ternäre SNARE-Komplexbildung identifiziert. Zusätzlich konnte gezeigt werden, dass im Gegensatz zu anderen Synaptobrevinhomologen, das regulatorische R-SNARE-Protein Tomosyn nicht an die Bindungsstelle für Synaptobrevin im stabilisierten Akzeptorkomplex binden kann.

Auch wurde der C-terminale Aufrollschritt, der auf die Synaptobrevinbindung folgt, im dritten Teil dieser Arbeit näher charakterisiert. Dabei konnte CDspektroskopisch gezeigt werden, dass sich SNARE-Komplexe mit C-terminalen Mutationen in zwei Phasen entfalten. Dies gibt einen strukturellen Hinweis darauf, dass ein C-terminal destabilisierter SNARE-Komplex existieren kann. Anhand von thermodynamischen Untersuchungen wurde außerdem deutlich, dass die C-terminale Faltungsreaktion reversibel sein könnte und demnach nicht die treibende Kraft der Membranfusion sein kann, sondern weitere regulatorische Proteine für diesen Schritt nötig sind. 


\section{Summary}

Membrane fusion events are mediated by a set of conserved protein machinery, the SNARE proteins. SNARE proteins assemble into a very stable $\alpha$-helical complex between two membranes. The plasma membrane residing SNARE proteins, syntaxin and SNAP-25, form an acceptor complex for the vesicular SNARE protein, synaptobrevin. The formation of the SNARE complex brings the two membranes closer and thus, leads to membrane fusion. The exact process of this reaction and the possible intermediates of complex formation have yet to be described. In order to gain deeper insights into the process of SNARE mediated membrane fusion, I used biophysical methods such as circular dichroism and fluorescence spectroscopy to characterize distinct steps of complex assembly in vitro. Also, I investigated the thermodynamics of the SNARE complex assembly using isothermal titration calorimetry.

In the first section, I investigated the interaction of syntaxin and SNAP-25 and their assembly into an acceptor complex for synaptobrevin binding. Previous work has shown that the formation of this Q-SNARE acceptor complex is the ratelimiting step for subsequent steps in SNARE complex formation. Site-directed mutations in SNAP-25 revealed that the N-terminal regions of the Q-SNAREs are critical for the acceptor complex assembly. Further thermodynamic analysis showed that this slow interaction is probably catalyzed in vivo by a priming factor.

Next, I investigated the binding of synaptobrevin to the Q-SNARE acceptor complex. In the in vitro setting, a second syntaxin molecule occupies the synaptobrevin bindung site. This technical problem was solved by using a stabilized acceptor complex which consists of SNAP-25, syntaxin and a C-terminal synaptobrevin peptide. This peptide-stabilized acceptor complex provides a free 
N-terminal binding site for synaptobrevin. Upon synaptobrevin binding, the peptide is displaced and the ternary SNARE complex forms. Using this stabilized complex, I studied the synaptobrevin binding with mutations in the different hydrophobic layers as well as by truncating the single SNARE proteins. The Nterminal region of synaptobrevin proved to be essential in the formation of the ternary SNARE complex. Additionally, contrary to other R-SNARE homologs, the regulatory R-SNARE tomosyn is unable to bind to the synaptobrevin binding site in the stabilized acceptor complex.

In the third part, I attempted to study the C-terminal folding of the SNARE complex after binding of synaptobrevin. Thermal melts using circular dichroism revealed that C-terminally mutated SNARE complexes unfold in two phases. Furthermore, based on thermodynamic experiments, it seems that the C-terminal folding step is able to alternate between a folded and unfolded state. This results might indicate the existence of a partially destabilized SNARE complex. Thus, the final assembly step might not provide the driving force for membrane fusion and other regulatory proteins are necessary to fulfill this task. 


\section{Literaturverzeichnis}

[1] Antonin, W. ; Fasshauer, D. ; Becker, S. ; Jahn, R. ; Schneider, T. R.: Crystal structure of the endosomal SNARE complex reveals common structural principles of all SNAREs. In: Nat Struct Biol 9 (2002), Nr. 2, S. 107-11

[2] Antonin, W. ; Holroyd, C. ; Fasshauer, D. ; Pabst, S. ; Von Mollard, G. F. ; JAHN, R.: A SNARE complex mediating fusion of late endosomes defines conserved properties of SNARE structure and function. In: Embo $J 19$ (2000), Nr. 23, S. 6453-64

[3] Antonin, W. ; Holroyd, C. ; Tikkanen, R. ; Honing, S. ; Jahn, R.: The R-SNARE endobrevin/VAMP-8 mediates homotypic fusion of early endosomes and late endosomes. In: Mol Biol Cell 11 (2000), Nr. 10, S. 3289-98

[4] Balch, W. E. ; Dunphy, W. G. ; Braell, W. A. ; Rothman, J. E.: Reconstitution of the transport of protein between successive compartments of the Golgi measured by the coupled incorporation of N-acetylglucosamine. In: Cell 39 (1984), Nr. 2 Pt 1, S. 405-16

[5] Blanes-Mira, C. ; Merino, J. M. ; Valera, E. ; Fernandez-Ballester, G. ; Gutierrez, L. M. ; Viniegra, S. ; Perez-Paya, E. ; Ferrer-Montiel, A.: Small peptides patterned after the N-terminus domain of SNAP25 inhibit SNARE complex assembly and regulated exocytosis. In: J Neurochem 88 (2004), Nr. 1, S. 124-35

[6] Blasi, J. ; Chapman, E. R. ; Link, E. ; Binz, T. ; Yamasaki, S. ; De Camilli, P. ; Sudhof, T. C. ; Niemann, H. ; Jahn, R.: Botulinum neurotoxin A selectively cleaves the synaptic protein SNAP-25. In: Nature 365 (1993), Nr. 6442, S. 160-3 
[7] Blasi, J. ; Chapman, E. R. ; Yamasaki, S. ; Binz, T. ; Niemann, H. ; Jahn, R.: Botulinum neurotoxin $\mathrm{C} 1$ blocks neurotransmitter release by means of cleaving HPC-1/syntaxin. In: EMBO J. 12 (1993), Nr. 12, S. 4821-8

[8] Block, M. R. ; Glick, B. S. ; Wilcox, C. A. ; Wieland, F. T. ; Rothman, J. E.: Purification of an N-ethylmaleimide-sensitive protein catalyzing vesicular transport. In: Proc Natl Acad Sci U S A 85 (1988), Nr. 21, S. 7852-6

[9] Bracher, A. ; Kadlec, J. ; Betz, H. ; Weissenhorn, W.: X-ray structure of a neuronal complexin-SNARE complex from squid. In: J Biol Chem 277 (2002), Nr. 29, S. 26517-23

[10] Bradford, M. M.: A rapid and sensitive method for the quantitation of microgram quantities of protein utilizing the principle of protein-dye binding. In: Analytical Biochemistry 72 (1976), S. 248-54

[11] Brandhorst, D. ; Zwilling, D. ; Rizzoli, S. O. ; Lippert, U. ; Lang, T. ; JAHN, R.: Homotypic fusion of early endosomes: SNAREs do not determine fusion specificity. In: Proc Natl Acad Sci U S A 103 (2006), Nr. 8, S. 2701-6

[12] Brose, N. ; Petrenko, A. G. ; Sudhof, T. C. ; Jahn, R.: Synaptotagmin: a calcium sensor on the synaptic vesicle surface. In: Science 256 (1992), Nr. 5059, S. $1021-5$

[13] Burkhard, Peter ; Steinmetz, Michel O. ; Schulthess, Therese ; Landwehr, Ruth ; Aebi, Ueli ; Kammerer, Richard A.: Crystallization and Preliminary XRay Diffraction Analysis of the 190-A-Long Coiled-Coil Dimerization Domain of the Actin-Bundling Protein Cortexillin I fromDictyostelium discoideum. In: $J$ Struct Biol 122 (1998), Nr. 3, S. 293-296

[14] Burkhardt, P. ; Hattendorf, D. A. ; Weis, W. I. ; Fasshauer, D.: Munc18a controls SNARE assembly through its interaction with the syntaxin N-peptide. In: Embo J advance online publication doi: 10.1038/emboj.2008.37 (13 March 2008)

[15] Cerveny, Kara L. ; Tamura, Yasushi ; Zhang, Zhongyan ; Jensen, Robert E. ; SESAKI, Hiromi: Regulation of mitochondrial fusion and division. In: trends in Cell Biology 17 (2007), Nr. 11, S. 563-569 
[16] Chapman, Edwin R.: How Does Synaptotagmin Trigger Neurotransmitter Release? In: Annual Review of Biochemistry 77 (2008), Nr. 1

[17] Chen, Elizabeth H. ; Grote, Eric ; Mohler, William ; Vignery, Agnes: Cellcell fusion. In: FEBS Letters 581 (2007), Nr. 11, S. 2181-2193

[18] Chen, X. ; Tomchick, D. R. ; Kovrigin, E. ; Arac, D. ; Machius, M. ; Sudhof, T. C. ; RIzo, J.: Three-dimensional structure of the complexin/SNARE complex. In: Neuron 33 (2002), Nr. 3, S. 397-409

[19] Chen, Y. A. ; Scales, S. J. ; PAtel, S. M. ; Doung, Y. C. ; Scheller, R. H.: SNARE complex formation is triggered by $\mathrm{Ca} 2+$ and drives membrane fusion. In: Cell 97 (1999), Nr. 2, S. 165-74

[20] Chen, Y. A. ; Scales, S. J. ; Scheller, R. H.: Sequential SNARE assembly underlies priming and triggering of exocytosis. In: Neuron 30 (2001), Nr. 1, S. $161-70$

[21] Clary, D. O. ; Griff, I. C. ; Rothman, J. E.: SNAPs, a family of NSF attachment proteins involved in intracellular membrane fusion in animals and yeast. In: Cell 61 (1990), Nr. 4, S. 709-21

[22] Clary, D. O. ; Rothman, J. E.: Purification of three related peripheral membrane proteins needed for vesicular transport. In: J Biol Chem 265 (1990), Nr. 17, S. $10109-17$

[23] Cohen, C. ; Parry, D. A. D.: [alpha]-Helical coiled coils - a widespread motif in proteins. In: Trends in Biochemical Sciences 11 (1986), S. 245-248

[24] Crooks, Gavin E. ; Hon, Gary ; Chandonia, John-Marc ; Brenner, Steven E.: WebLogo: A Sequence Logo Generator. In: Genome Res. 14 (2004), Nr. 6, S. $1188-1190$

[25] Davis, A. F. ; Bai, J. ; Fasshauer, D. ; Wolowick, M. J. ; Lewis, J. L. ; Chapman, E. R.: Kinetics of synaptotagmin responses to Ca2+ and assembly with the core SNARE complex onto membranes. In: Neuron 24 (1999), Nr. 2, S. $363-76$

[26] DiAntonio, A. ; Parfitt, K. D. ; Schwarz, T. L.: Synaptic transmission persists in synaptotagmin mutants of Drosophila. In: Cell 73 (1993), Nr. 7, S. $1281-1290$ 
[27] Dulubova, I. ; Sugita, S. ; Hill, S. ; Hosaka, M. ; Fernandez, I. ; Sudhof, T. C. ; Rizo, J.: A conformational switch in syntaxin during exocytosis: role of munc18. In: EMBO J 18 (1999), Nr. 16, S. 4372-82

[28] Durbin, R. ; Eddy, S. ; Krogh, A. ; Mitchison, G.: Biological sequence analysis: probabilistic models of proteins and nucleic acids. In: Cambridge University Press (1998)

[29] Durrieu, M. P. ; Lavery, R. ; BaAden, M.: Interactions between neuronal fusion proteins explored by molecular dynamics. In: Biophys $J$ (2008)

[30] Eckert, D. M. ; Kim, P. S.: Mechanisms of viral membrane fusion and its inhibition. In: Annu Rev Biochem 70 (2001), S. 777-810

[31] Fasshauer, D. ; Antonin, W. ; Margittai, M. ; Pabst, S. ; Jahn, R.: Mixed and non-cognate SNARE complexes. Characterization of assembly and biophysical properties. In: J Biol Chem 274 (1999), Nr. 22, S. 15440-6

[32] Fasshauer, D. ; Antonin, W. ; Subramaniam, V. ; Jahn, R.: Snare assembly and disassembly exhibit a pronounced hysteresis. In: Nat Struct Biol 9 (2002), Nr. 2, S. 144-51

[33] Fasshauer, D. ; Bruns, D. ; Shen, B. ; Jahn, R. ; Brunger, A. T.: A structural change occurs upon binding of syntaxin to SNAP-25. In: J Biol Chem 272 (1997), Nr. 7, S. 4582-90

[34] Fasshauer, D. ; Eliason, W. K. ; Brunger, A. T. ; Jahn, R.: Identification of a minimal core of the synaptic SNARE complex sufficient for reversible assembly and disassembly. In: Biochemistry 37 (1998), Nr. 29, S. 10354-62

[35] Fasshauer, D. ; Margittai, M.: A transient N-terminal interaction of SNAP25 and syntaxin nucleates SNARE assembly. In: J Biol Chem 279 (2004), Nr. 9, S. $7613-21$

[36] Fasshauer, D. ; Otto, H. ; Eliason, W. K. ; Jahn, R. ; Brunger, A. T.: Structural changes are associated with soluble N-ethylmaleimide-sensitive fusion protein attachment protein receptor complex formation. In: J Biol Chem 272 (1997), Nr. 44, S. 28036-41 
[37] Fasshauer, D. ; Sutton, R. B. ; Brunger, A. T. ; Jahn, R.: Conserved structural features of the synaptic fusion complex: SNARE proteins reclassified as Q- and R-SNAREs. In: Proc Natl Acad Sci U S A 95 (1998), Nr. 26, S. 15781-6

[38] Fergestad, T. ; Wu, M. N. ; Schulze, K. L. ; Lloyd, T. E. ; Bellen, H. J. ; BroAdie, K.: Targeted mutations in the syntaxin H3 domain specifically disrupt SNARE complex function in synaptic transmission. In: J Neurosci 21 (2001), Nr. 23, S. $9142-50$

[39] Fernandez, I. ; Ubach, J. ; Dulubova, I. ; Zhang, X. ; Südhof, T. C. ; RIzo, J.: Three-dimensional structure of an evolutionarily conserved N-terminal domain of syntaxin 1A. In: Cell 94 (1998), Nr. 6, S. 841-9

[40] Fiebig, K. M. ; Rice, L. M. ; Pollock, E. ; Brunger, A. T.: Folding intermediates of SNARE complex assembly. In: Nat Struct Biol 6 (1999), Nr. 2, S. $117-23$

[41] Frank, S. ; Lustig, A. ; Schulthess, T. ; Engel, J. ; Kammerer, R. A.: A distinct seven-residue trigger sequence is indispensable for proper coiled-coil formation of the human macrophage scavenger receptor oligomerization domain. In: J Biol Chem 275 (2000), Nr. 16, S. 11672-7

[42] Fratti, Rutilio A. ; Collins, Kevin M. ; Hickey, Christopher M. ; Wickner, William: Stringent 3Q:1R Composition of the SNARE 0-Layer Can Be Bypassed for Fusion by Compensatory SNARE Mutation or by Lipid Bilayer Modification. In: J. Biol. Chem. 282 (2007), Nr. 20, S. 14861-14867

[43] Fries, E. ; Rothman, J. E.: Transport of vesicular stomatitis virus glycoprotein in a cell-free extract. In: Proc Natl Acad Sci U S A 77 (1980), Nr. 7, S. 3870-4

[44] Fujita, Y. ; Shirataki, H. ; Sakisaka, T. ; Asakura, T. ; Ohya, T. ; Kotani, H. ; Yokoyama, S. ; Nishioka, H. ; Matsuura, Y. ; Mizoguchi, A. ; Scheller, R. H. ; TAKAI, Y.: Tomosyn: a syntaxin-1-binding protein that forms a novel complex in the neurotransmitter release process. In: Neuron 20 (1998), Nr. 5, S. $905-15$

[45] Geppert, M. ; Goda, Y. ; Hammer, R. E. ; Li, C. ; Rosahl, T. W. ; Stevens, C. F. ; Sudhof, T. C.: Synaptotagmin I: a major Ca2+ sensor for transmitter release at a central synapse. In: Cell 79 (1994), Nr. 4, S. 717-27 
[46] Gerona, R. R. ; Larsen, E. C. ; Kowalchyk, J. A. ; Martin, T. F.: The C terminus of SNAP25 is essential for $\mathrm{Ca}(2+)$-dependent binding of synaptotagmin to SNARE complexes. In: J Biol Chem 275 (2000), Nr. 9, S. 6328-36

[47] Giraudo, Claudio G. ; Eng, William S. ; Melia, Thomas J. ; Rothman, James E.: A Clamping Mechanism Involved in SNARE-Dependent Exocytosis. In: Science 313 (2006), Nr. 5787, S. 676-680. http://dx.doi.org/10.1126/ science.1129450. - DOI 10.1126/science.1129450

[48] Glick, B. S. ; Rothman, J. E.: Possible role for fatty acyl-coenzyme A in intracellular protein transport. In: Nature 326 (1987), Nr. 6110, S. 309-12

[49] Gracheva, Elena O. ; Burdina, Anna O. ; Holgado, Andrea M. ; BerthelotGrosjean, Martine ; Ackley, Brian D. ; Hadwiger, Gayla ; Nonet, Michael L. ; Weimer, Robby M. ; RIchmond, Janet E.: Tomosyn Inhibits Synaptic Vesicle Priming in Caenorhabditis elegans. In: PLoS Biology 4 (2006), Nr. 8, S. e261

[50] Graf, Carmen T. ; Riedel, Dietmar ; Schmitt, Hans D. ; Jahn, Reinhard: Identification of Functionally Interacting SNAREs by Using Complementary Substitutions in the Conserved '0' Layer. In: Mol. Biol. Cell 16 (2005), Nr. 5, S. $2263-2274$

[51] Griffin, E. E. ; Detmer, S. A. ; Chan, D. C.: Molecular mechanism of mitochondrial membrane fusion. In: Biochim Biophys Acta 1763 (2006), Nr. 5-6, S. $482-9$

[52] Grote, E. ; HaO, J. C. ; Bennett, M. K. ; Kelly, R. B.: A targeting signal in VAMP regulating transport to synaptic vesicles. In: Cell 81 (1995), Nr. 4, S. $581-9$

[53] Grote, E. ; Kelly, R. B.: Endocytosis of VAMP is facilitated by a synaptic vesicle targeting signal. In: J Cell Biol 132 (1996), Nr. 4, S. 537-47

[54] Guan, R. ; DaI, H. ; Rizo, J.: Binding of the Munc13-1 MUN Domain to Membrane-Anchored SNARE Complexes. In: Biochemistry 47 (2008), Nr. 6, S. $1474-81$

[55] Gurunathan, S. ; Chapman-Shimshoni, D. ; Trajkovic, S. ; Gerst, J. E.: Yeast exocytic v-SNAREs confer endocytosis. In: Mol Biol Cell 11 (2000), Nr. 10, S. $3629-43$ 
[56] Han, X. ; JAckson, M. B.: Structural transitions in the synaptic SNARE complex during Ca2+-triggered exocytosis. In: J Cell Biol 172 (2006), Nr. 2, S. 281-93

[57] Hannenhalli, Sridhar ; Wang, Li-San: Enhanced position weight matrices using mixture models. In: Bioinformatics 21 (2005), S. 204-212

[58] Hanson, P. I. ; Heuser, J. E. ; Jahn, R.: Neurotransmitter release - four years of SNARE complexes. In: Curr. Opin. Neurobiol. 7 (1997), Nr. 3, S. 310-315

[59] Hanson, P. I. ; Roth, R. ; Morisaki, H. ; Jahn, R. ; Heuser, J. E.: Structure and conformational changes in NSF and its membrane receptor complexes visualized by quick-freeze/deep-etch electron microscopy. In: Cell 90 (1997), Nr. 3, S. $523-35$

[60] Hao, J. C. ; Salem, N. ; Peng, X. R. ; Kelly, R. B. ; Bennett, M. K.: Effect of mutations in vesicle-associated membrane protein (VAMP) on the assembly of multimeric protein complexes. In: J Neurosci 17 (1997), Nr. 5, S. 1596-603

[61] Hatsuzawa, K. ; Lang, T. ; Fasshauer, D. ; Bruns, D. ; Jahn, R.: The R-SNARE motif of tomosyn forms SNARE core complexes with syntaxin 1 and SNAP-25 and down-regulates exocytosis. In: J Biol Chem 278 (2003), Nr. 33, S. 31159-66

[62] Hattendorf, Douglas A. ; Andreeva, Anna ; Gangar, Akanksha ; BrennWALD, Patrick J. ; WEIS, William I.: Structure of the yeast polarity protein Sro7 reveals a SNARE regulatory mechanism. In: Nature 446 (2007), Nr. 7135, S. $567-571$

[63] Hayashi, T. ; McMahon, H. ; Yamasaki, S. ; Binz, T. ; Hata, Y. ; Südhof, T. C. ; Niemann, H.: Synaptic vesicle membrane fusion complex: action of clostridial neurotoxins on assembly. In: EMBO J. 13 (1994), Nr. 21, S. 50515061

[64] Hazzard, J. ; Sudhof, T. C. ; Rizo, J.: NMR analysis of the structure of synaptobrevin and of its interaction with syntaxin. In: J Biomol NMR 14 (1999), Nr. 3, S. 203-7 
[65] Hu, K. ; Carroll, J. ; Fedorovich, S. ; Rickman, C. ; Sukhodub, A. ; DAvletov, B.: Vesicular restriction of synaptobrevin suggests a role for calcium in membrane fusion. In: Nature 415 (2002), Nr. 6872, S. 646-50

[66] Hua, S. Y. ; Charlton, M. P.: Activity-dependent changes in partial VAMP complexes during neurotransmitter release. In: Nat Neurosci 2 (1999), Nr. 12, S. $1078-83$

[67] Jahn, R. ; Lang, T. ; Sudhof, T. C.: Membrane fusion. In: Cell 112 (2003), Nr. 4, S. $519-33$

[68] Jahn, R. ; Scheller, R. H.: SNAREs-engines for membrane fusion. In: Nat Rev Mol Cell Biol 7 (2006), Nr. 9, S. 631-43

[69] Jockusch, Wolf J. ; Speidel, Dina ; Sigler, Albrecht ; Sorensen, Jakob B. ; Varoqueaux, Frederique ; Rhee, Jeong-Seop ; Brose, Nils: CAPS-1 and CAPS-2 Are Essential Synaptic Vesicle Priming Proteins. In: Cell 131 (2007), Nr. 4, S. $796-808$

[70] Kammerer, R. A. ; Schulthess, T. ; Landwehr, R. ; Lustig, A. ; Engel, J. ; Aebi, U. ; Steinmetz, M. O.: An autonomous folding unit mediates the assembly of two-stranded coiled coils. In: Proc Natl Acad Sci U S A 95 (1998), Nr. 23, S. 13419-24

[71] Katz, L. ; Brennwald, P.: Testing the 3Q:1R rule: mutational analysis of the ionic zero layer in the yeast exocytic SNARE complex reveals no requirement for arginine. In: Mol Biol Cell 11 (2000), Nr. 11, S. 3849-58

[72] Kesavan, J. ; Borisovska, M. ; Bruns, D.: v-SNARE actions during Ca(2+)triggered exocytosis. In: Cell 131 (2007), Nr. 2, S. 351-63

[73] Kielian, M. ; Rey, F. A.: Virus membrane-fusion proteins: more than one way to make a hairpin. In: Nat Rev Microbiol 4 (2006), Nr. 1, S. 67-76

[74] Kloepper, T. H. ; Kienle, C. N. ; Fasshauer, D.: An elaborate classification of SNARE proteins sheds light on the conservation of the eukaryotic endomembrane system. In: Mol Biol Cell 18 (2007), Nr. 9, S. 3463-71

[75] Knappenberger, J. A. ; Smith, J. E. ; Thorpe, S. H. ; Zitzewitz, J. A. ; Matthews, C. R.: A buried polar residue in the hydrophobic interface of 
the coiled-coil peptide, GCN4-p1, plays a thermodynamic, not a kinetic role in folding. In: J Mol Biol 321 (2002), Nr. 1, S. 1-6

[76] Koh, T. W. ; Bellen, H. J.: Synaptotagmin I, a Ca2+ sensor for neurotransmitter release. In: Trends Neurosci 26 (2003), Nr. 8, S. 413-22

[77] Koshiba, T. ; Detmer, S. A. ; Kaiser, J. T. ; Chen, H. ; McCaffery, J. M. ; ChAn, D. C.: Structural basis of mitochondrial tethering by mitofusin complexes. In: Science 305 (2004), Nr. 5685, S. 858-62

[78] Kweon, D. H. ; Kim, C. S. ; Shin, Y. K.: Insertion of the membrane-proximal region of the neuronal SNARE coiled coil into the membrane. In: J Biol Chem 278 (2003), Nr. 14, S. 12367-73

[79] Kweon, D. H. ; Kim, C. S. ; Shin, Y. K.: Regulation of neuronal SNARE assembly by the membrane. In: Nat Struct Biol 10 (2003), Nr. 6, S. 440-7

[80] Laemml, U. K.: Cleavage of structural proteins during the assembly of the head of bacteriophage T4. In: Nature 227 (1970), Nr. 5259, S. 680-5

[81] Lauer, J. M. ; Dalal, S. ; Marz, K. E. ; Nonet, M. L. ; Hanson, P. I.: SNARE complex zero layer residues are not critical for N-ethylmaleimide-sensitive factormediated disassembly. In: J Biol Chem 281 (2006), Nr. 21, S. 14823-32

[82] Lee, D. L. ; Lavigne, P. ; Hodges, R. S.: Are trigger sequences essential in the folding of two-stranded alpha-helical coiled-coils? In: J Mol Biol 306 (2001), Nr. 3, S. 539-53

[83] Li, Feng ; Pincet, Frederic ; Perez, Eric ; Eng, William S. ; Melia, Thomas J. ; Rothman, James E. ; TAReste, David: Energetics and dynamics of SNAREpin folding across lipid bilayers. In: Nat Struct Mol Biol 14 (2007), Nr. 10, S. 890-896

[84] Lin, R. C. ; Scheller, R. H.: Structural organization of the synaptic exocytosis core complex. In: Neuron 19 (1997), Nr. 5, S. 1087-94

[85] Link, E. ; Edelmann, L. ; Chou, J. H. ; Binz, T. ; Yamasaki, S. ; Eisel, U. ; Baumert, M. ; Sudhof, T. C. ; Niemann, H. ; Jahn, R.: Tetanus toxin action: inhibition of neurotransmitter release linked to synaptobrevin proteolysis. In: Biochemical and Biophysical Research Communications 189 (1992), Nr. 2, S. $1017-23$ 
[86] Littleton, J. T. ; Stern, Michael ; Schulze, Karen ; Perin, Mark ; Bellen, Hugo J.: Mutational analysis of Drosophila synaptotagmin demonstrates its essential role in Ca2+-activated neurotransmitter release. In: Cell 74 (1993), Nr. 6, S. $1125-1134$

[87] Liu, W. ; Montana, Vedrana ; Bai, Jihong ; Chapman, Edwin R. ; Mohideen, U. ; PARPura, Vladimir: Single Molecule Mechanical Probing of the SNARE Protein Interactions. In: Biophys. J. 91 (2006), Nr. 2, S. 744-758. http://dx. doi.org/10.1529/biophysj.105.073312. - DOI 10.1529/biophysj.105.073312

[88] Lupas, A. N. ; Gruber, M.: The structure of alpha-helical coiled coils. In: Adv Protein Chem 70 (2005), S. 37-78

[89] Madigan, M. T. ; Martinko, J.M. ; Parker, J.: Mikrobiologie. Heidelberg : Spektrum Akademischer Verlag, 2002

[90] Margittai, M. ; Fasshauer, D. ; Pabst, S. ; Jahn, R. ; Langen, R.: Homoand heterooligomeric SNARE complexes studied by site-directed spin labeling. In: J Biol Chem 276 (2001), Nr. 16, S. 13169-77

[91] Margittai, M. ; Widengren, J. ; Schweinberger, E. ; Schroder, G. F. ; Felekyan, S. ; Haustein, E. ; Konig, M. ; Fasshauer, D. ; Grubmuller, H. ; JAhn, R. ; SEIdel, C. A.: Single-molecule fluorescence resonance energy transfer reveals a dynamic equilibrium between closed and open conformations of syntaxin 1. In: Proc Natl Acad Sci U S A (2003)

[92] Matos, M. F. ; Mukherjee, K. ; Chen, X. ; Rizo, J. ; Sudhof, T. C.: Evidence for SNARE zippering during Ca2+-triggered exocytosis in PC12 cells. In: Neuropharmacology 45 (2003), Nr. 6, S. 777-86

[93] Mayorga, Luis S. ; Tomes, Claudia N. ; Belmonte, Silvia A.: Acrosomal exocytosis, a special type of regulated secretion. In: IUBMB Life 59 (2007), Nr. 4, S. $286-292$

[94] Melia, T. J. ; Weber, T. ; McNew, J. A. ; Fisher, L. E. ; Johnston, R. J. ; Parlati, F. ; Mahal, L. K. ; Sollner, T. H. ; Rothman, J. E.: Regulation of membrane fusion by the membrane-proximal coil of the t-SNARE during zippering of SNAREpins. In: J Cell Biol 158 (2002), Nr. 5, S. 929-40 
[95] Misura, K. M. ; Scheller, R. H. ; Weis, W. I.: Three-dimensional structure of the neuronal-Sec1-syntaxin 1a complex. In: Nature 404 (2000), Nr. 6776, S. $355-62$

[96] Montecucco, C. ; Schiavo, G. ; Pantano, S.: SNARE complexes and neuroexocytosis: how many, how close? In: Trends Biochem Sci 30 (2005), Nr. 7, S. $367-72$

[97] Myszka, D. G. ; Sweet, R. W. ; Hensley, P. ; Brigham-Burke, M. ; Kwong, P. D. ; Hendrickson, W. A. ; Wyatt, R. ; Sodroski, J. ; Doyle, M. L.: Energetics of the HIV gp120-CD4 binding reaction. In: Proc Natl Acad Sci U S A 97 (2000), Nr. 16, S. 9026-31

[98] Newman, A P. ; Shim, J ; Ferro-Novick, S: Bet1, BOS1, and SEC22 are members of a group of interacting yeast genes required for transport from the endoplasmic reticulum to the Golgi complex. In: Mol. Cell. Biol. 10 (1990), Nr. 7, S. $3405-3414$

[99] Nicholson, K. L. ; Munson, M. ; Miller, R. B. ; Filip, T. J. ; Fairman, R. ; Hughson, F. M.: Regulation of SNARE complex assembly by an N-terminal domain of the t- SNARE Sso1p. In: Nature Struct. Biol. 5 (1998), Nr. 9, S. 793-802

[100] Nonet, M. L. ; Saifee, O. ; Zhao, H. ; Rand, J. B. ; Wei, L.: Synaptic transmission deficits in Caenorhabditis elegans synaptobrevin mutants. In: $J$ Neurosci 18 (1998), Nr. 1, S. 70-80

[101] Nonet, Michael L. ; Grundahl, Kiely ; Meyer, Barbara J. ; Rand, James B.: Synaptic function is impaired but not eliminated in C. elegans mutants lacking synaptotagmin. In: Cell 73 (1993), Nr. 7, S. $1291-1305$

[102] Ossig, R. ; Schmitt, H. D. ; Groot, B. de ; Riedel, D. ; Keranen, S. ; Ronne, H. ; Grubmuller, H. ; Jahn, R.: Exocytosis requires asymmetry in the central layer of the SNARE complex. In: EMBO J 19 (2000), Nr. 22, S. 6000-10

[103] Pabst, S. ; Margittai, M. ; Vainius, D. ; Langen, R. ; Jahn, R. ; Fasshauer, D.: Rapid and selective binding to the synaptic SNARE complex suggests a modulatory role of complexins in neuroexocytosis. In: J Biol Chem 277 (2002), Nr. 10, S. $7838-48$ 
[104] Parlati, F. ; Varlamov, O. ; Paz, K. ; McNew, J. A. ; Hurtado, D. ; SollNeR, T. H. ; Rothman, J. E.: Distinct SNARE complexes mediating membrane fusion in Golgi transport based on combinatorial specificity. In: Proc Natl Acad Sci U S A 99 (2002), Nr. 8, S. 5424-9

[105] Parlati, F. ; Weber, T. ; McNew, J. A. ; Westermann, B. ; Sollner, T. H. ; Rothman, J. E.: Rapid and efficient fusion of phospholipid vesicles by the alpha- helical core of a SNARE complex in the absence of an N-terminal regulatory domain [see comments]. In: Proc Natl Acad Sci U S A 96 (1999), Nr. 22 , S. $12565-70$

[106] Paumet, F. ; Rahimian, V. ; Rothman, J. E.: The specificity of SnAREdependent fusion is encoded in the SNARE motif. In: Proc Natl Acad Sci U SA 101 (2004), Nr. 10, S. 3376-80

[107] Perin, MS ; Brose, N ; Jahn, R ; Sudhof, TC: Domain structure of synaptotagmin (p65). In: J. Biol. Chem. 266 (1991), Nr. 1, S. 623-629

[108] Pobbati, A. V. ; Razeto, A. ; Boddener, M. ; Becker, S. ; Fasshauer, D.: Structural basis for the inhibitory role of tomosyn in exocytosis. In: $J$ Biol Chem 279 (2004), Nr. 45, S. 47192-200

[109] Pobbati, A. V. ; Stein, A. ; Fasshauer, D.: N- to C-terminal SNARE complex assembly promotes rapid membrane fusion. In: Science 313 (2006), Nr. 5787, S. 673-6

[110] Rathanaswami, Palaniswami ; Roalstad, Shelly ; Roskos, Lorin ; Su, Qiaojuan J. ; LACKIE, Steve ; BABCoOK, John: Demonstration of an in vivo generated sub-picomolar affinity fully human monoclonal antibody to interleukin-8. In: Biochemical and Biophysical Research Communications 334 (2005), Nr. 4, S. 1004-1013

[111] Reim, K. ; Mansour, M. ; Varoqueaux, F. ; McMahon, H. T. ; Sudhof, T. C. ; Brose, N. ; Rosenmund, C.: Complexins regulate a late step in Ca2+dependent neurotransmitter release. In: Cell 104 (2001), Nr. 1, S. 71-81

[112] Rickman, Colin ; Archer, Deborah A. ; Meunier, Frederic A. ; Craxton, Molly ; Fukuda, Mitsunori ; Burgoyne, Robert D. ; DAvletov, Bazbek: Synaptotagmin Interaction with the Syntaxin/SNAP-25 Dimer Is Mediated by an 
Evolutionarily Conserved Motif and Is Sensitive to Inositol Hexakisphosphate. In: J. Biol. Chem. 279 (2004), Nr. 13, S. 12574-12579

[113] Rizo, J. ; Sudhof, T. C.: Snares and Munc18 in synaptic vesicle fusion. In: Nat Rev Neurosci 3 (2002), Nr. 8, S. 641-53

[114] Roche, Stephane ; Bressaneldi, Stephane ; Rey, Felix A. ; Gaudin, Yves: Crystal Structure of the Low-pH Form of the Vesicular Stomatitis Virus Glycoprotein G. In: Science 313 (2006), Nr. 5784, S. 187-191. http://dx.doi.org/ 10.1126/science.1127683. - DOI 10.1126/science.1127683

[115] Roche, Stephane ; Rey, Felix A. ; Gaudin, Yves ; Bressanelli, Stephane: Structure of the Prefusion Form of the Vesicular Stomatitis Virus Glycoprotein G. In: Science 315 (2007), Nr. 5813, S. 843-848. http://dx.doi.org/10.1126/ science.1135710. - DOI 10.1126/science.1135710

[116] Saifee, O. ; Wei, L. ; Nonet, M. L.: The Caenorhabditis elegans unc-64 locus encodes a syntaxin that interacts genetically with synaptobrevin. In: Mol Biol Cell 9 (1998), Nr. 6, S. 1235-52

[117] SAmbrook, Joseph ; Russell, David W.: Molecular cloning : a laboratory manual. 3rd. Cold Spring Harbor, N.Y. : Cold Spring Harbor Laboratory Press, 2001

[118] Scales, S. J. ; Yoo, B. Y. ; Scheller, R. H.: The ionic layer is required for efficient dissociation of the SNARE complex by alpha-SNAP and NSF. In: Proc Natl Acad Sci U S A 98 (2001), Nr. 25, S. 14262-7

[119] Schagger, H.: Tricine-SDS-PAGE. In: Nat Protoc 1 (2006), Nr. 1, S. 16-22

[120] Schaub, Johanna R. ; Lu, Xiaobing ; Doneske, Blair ; Shin, Yeon-Kyun ; McNew, James A.: Hemifusion arrest by complexin is relieved by Ca2+synaptotagmin I. In: Nat Struct Mol Biol 13 (2006), Nr. 8, S. 748-750

[121] Schiavo, G. ; Benfenati, F. ; Poulain, B. ; Rossetto, O. ; Laureto, P. Polverino d. ; DasGupta, B. R. ; Montecucco, C.: Tetanus and botulinum-B neurotoxins block neurotransmitter release by proteolytic cleavage of synaptobrevin. In: Nature 359 (1992), Nr. 6398, S. 832-5 
[122] Schoch, S. ; Deak, F. ; Konigstorfer, A. ; Mozhayeva, M. ; Sara, Y. ; Sudhof, T. C. ; Kavalali, E. T.: SNARE function analyzed in synaptobrevin/VAMP knockout mice. In: Science 294 (2001), Nr. 5544, S. 1117-22

[123] Schulze, K. L. ; Broadie, K. ; Perin, M. S. ; Bellen, H. J.: Genetic and electrophysiological studies of Drosophila syntaxin-1A demonstrate its role in nonneuronal secretion and neurotransmission. In: Cell 80 (1995), Nr. 2, S. 31120

[124] Siddiqui, T. J. ; Vites, O. ; Stein, A. ; Heintzmann, R. ; Jahn, R. ; FassHAUER, D.: Determinants of synaptobrevin regulation in membranes. In: Mol Biol Cell 18 (2007), Nr. 6, S. 2037-46

[125] Skehel, John J. ; Wiley, Don C.: Receptor binding and membrane fusion in virus entry: The Influenza Hemagglutinin. In: Annual Review of Biochemistry 69 (2000), Nr. 1, S. 531-569

[126] Sollner, T. ; Whiteheart, S. W. ; Brunner, M. ; Erdjument-Bromage, H. ; Geromanos, S. ; Tempst, P. ; Rothman, J. E.: SNAP receptors implicated in vesicle targeting and fusion. In: Nature 362 (1993), Nr. 6418, S. 318-24

[127] Sollner, T. H.: Intracellular and viral membrane fusion: a uniting mechanism. In: Curr Opin Cell Biol 16 (2004), Nr. 4, S. 429-35

[128] Sorensen, J. B. ; Nagy, G. ; Varoqueaux, F. ; Nehring, R. B. ; Brose, N. ; Wilson, M. C. ; Neher, E.: Differential control of the releasable vesicle pools by SNAP-25 splice variants and SNAP-23. In: Cell 114 (2003), Nr. 1, S. 75-86

[129] Sorensen, J. B. ; Wiederhold, K. ; Muller, E. M. ; Milosevic, I. ; Nagy, G. ; Groot, B. L. ; Grubmuller, H. ; Fasshauer, D.: Sequential N- to C-terminal SNARE complex assembly drives priming and fusion of secretory vesicles. In: Embo J 25 (2006), Nr. 5, S. 955-66

[130] Steegmaier, Martin ; Klumperman, Judith ; Foletti, Davide L. ; Yoo, JinSan ; Scheller, Richard H.: Vesicle-associated Membrane Protein 4?is Implicated in Trans-Golgi Network Vesicle Trafficking. In: Mol. Biol. Cell 10 (1999), Nr. 6, S. 1957-1972

[131] Steinmetz, M. O. ; Jelesarov, I. ; Matousek, W. M. ; Honnappa, S. ; JahnKe, W. ; Missimer, J. H. ; Frank, S. ; Alexandrescu, A. T. ; Kammerer, 
R. A.: Molecular basis of coiled-coil formation. In: Proc Natl Acad Sci U S A 104 (2007), Nr. 17, S. 7062-7

[132] Steinmetz, M. O. ; Stock, A. ; Schulthess, T. ; Landwehr, R. ; Lustig, A. ; Faix, J. ; Gerisch, G. ; Aebi, U. ; Kammerer, R. A.: A distinct 14 residue site triggers coiled-coil formation in cortexillin I. In: Embo $J 17$ (1998), Nr. 7, S. $1883-91$

[133] Stites, W. E.: Protein - Protein Interactions: Interface Structure, Binding Thermodynamics, and Mutational Analysis. In: Chem Rev 97 (1997), Nr. 5, S. 12331250

[134] Strop, P. ; Kaiser, S. E. ; Vrluic, M. ; Brunger, A. T.: The structure of the yeast plasma membrane SNARE complex reveals destabilizing water filled cavities. 2007

[135] Sutton, R. B. ; Fasshauer, D. ; Jahn, R. ; Brunger, A. T.: Crystal structure of a SNARE complex involved in synaptic exocytosis at $2.4 \mathrm{~A}$ resolution. In: Nature 395 (1998), Nr. 6700, S. 347-53

[136] Tang, J. ; Maximov, A. ; Shin, O. H. ; Dai, H. ; Rizo, J. ; Sudhof, T. C.: A complexin/synaptotagmin 1 switch controls fast synaptic vesicle exocytosis. In: Cell 126 (2006), Nr. 6, S. 1175-87

[137] Toonen, Ruud F. G. ; Verhage, Matthijs: Munc18-1 in secretion: lonely Munc joins SNARE team and takes control. In: Trends in Neurosciences 30 (2007), Nr. 11, S. $564-572$

[138] Varoqueaux, Frederique ; Sigler, Albrecht ; Rhee, Jeong-Seop ; Brose, Nils ; Enk, Carsten ; Reim, Kerstin ; Rosenmund, Christian: Total arrest of spontaneous and evoked synaptic transmission but normal synaptogenesis in the absence of Munc13-mediated vesicle priming. In: Proceedings of the National Academy of Sciences 99 (2002), Nr. 13, S. 9037-9042

[139] Verhage, M. ; Maia, A. S. ; Plomp, J. J. ; Brussaard, A. B. ; Heeroma, J. H. ; Vermeer, H. ; Toonen, R. F. ; Hammer, R. E. ; Berg, T. K. d. ; Missler, M. ; Geuze, H. J. ; Sudhof, T. C.: Synaptic assembly of the brain in the absence of neurotransmitter secretion. In: Science 287 (2000), Nr. 5454, S. $864-9$ 
[140] Washbourne, P. ; Thompson, P. M. ; Carta, M. ; Costa, E. T. ; Mathews, J. R. ; Lopez-Bendito, G. ; Molnar, Z. ; Becher, M. W. ; Valenzuela, C. F. ; PArtridge, L. D. ; Wilson, M. C.: Genetic ablation of the t-SNARE SNAP-25 distinguishes mechanisms of neuroexocytosis. In: Nat Neurosci 5 (2002), Nr. 1, S. $19-26$

[141] Weber, K. ; Osborn, M.: The reliability of molecular weight determinations by dodecyl sulfate-polyacrylamide gel electrophoresis. In: J Biol Chem 244 (1969), Nr. 16, S. $4406-12$

[142] Weber, T. ; Zemelman, B. V. ; McNew, J. A. ; Westermann, B. ; Gmachl, M. ; Parlati, F. ; Sollner, T. H. ; Rothman, J. E.: SNAREpins: minimal machinery for membrane fusion. In: Cell 92 (1998), Nr. 6, S. 759-72

[143] Wei, S. ; Xu, T. ; Ashery, U. ; Kollewe, A. ; Matti, U. ; Antonin, W. ; Rettig, J. ; Neher, E.: Exocytotic mechanism studied by truncated and zero layer mutants of the C-terminus of SNAP-25. In: Embo $J 19$ (2000), Nr. 6, S. $1279-89$

[144] Weimbs, T. ; Mostov, K. ; Low, S. H. ; Hofmann, K.: A model for structural similarity between different SNARE complexes based on sequence relationships. In: Trends Cell Biol 8 (1998), Nr. 7, S. 260-2

[145] Weninger, Keith ; Bowen, Mark E. ; Choi, Ucheor B. ; Chu, Steven ; BrunGER, Axel T.: Accessory Proteins Stabilize the Acceptor Complex for Synaptobrevin, the 1:1 Syntaxin/SNAP-25 Complex. In: Structure 16 (2008), Nr. 2, S. 308-320

[146] Whiteheart, S. W. ; Griff, I. C. ; Brunner, M. ; Clary, D. O. ; Mayer, T. ; Buhrow, S. A. ; Rothman, J. E.: SNAP family of NSF attachment proteins includes a brain-specific isoform. In: Nature 362 (1993), Nr. 6418, S. 353-5

[147] Wu, Kenneth C. ; Bryan, Janine T. ; Morasso, Maria I. ; Jang, Shyh-Ing ; Lee, Jeung-Hoon ; Yang, Jun-Mo ; Marekov, Lyuben N. ; PARry, David A. ; Steinert, Peter M.: Coiled-Coil Trigger Motifs in the 1B and 2B Rod Domain Segments Are Required for the Stability of Keratin Intermediate Filaments. In: Mol. Biol. Cell 11 (2000), Nr. 10, S. 3539-3558 
[148] Xu, T. ; Rammner, B. ; Margittai, M. ; Artalejo, A. R. ; Neher, E. ; JAHN, R.: Inhibition of SNARE complex assembly differentially affects kinetic components of exocytosis. In: Cell 99 (1999), Nr. 7, S. 713-22

[149] Yang, B. ; Gonzalez, Jr. L. ; Prekeris, R. ; Steegmaier, M. ; Advani, R. J. ; Scheller, R. H.: SNARE interactions are not selective. Implications for membrane fusion specificity. In: J Biol Chem 274 (1999), Nr. 9, S. 5649-53

[150] Yersin, A. ; Hirling, H. ; Steiner, P. ; Magnin, S. ; Regazzi, R. ; Huni, B. ; Huguenot, P. ; De los Rios, P. ; Dietler, G. ; Catsicas, S. ; Kasas, S.: Interactions between synaptic vesicle fusion proteins explored by atomic force microscopy. In: Proceedings of the National Academy of Sciences 100 (2003), Nr. 15, S. 8736-8741. http://dx.doi.org/10.1073/pnas.1533137100. - DOI 10.1073/pnas. 1533137100

[151] Yizhar, Ofer ; Lipstein, Noa ; Gladycheva, Svetlana E. ; Matti, Ulf ; Ernst, Stephen A. ; Rettig, Jens ; Stuenkel, Edward L. ; Ashery, Uri: Multiple functional domains are involved in tomosyn regulation of exocytosis. In: Journal of Neurochemistry 103 (2007), Nr. 2, S. 604-616

[152] Zhang, F. ; Chen, Y. ; Su, Z. ; Shin, Y. K.: SNARE assembly and membrane fusion, a kinetic analysis. In: J Biol Chem 279 (2004), Nr. 37, S. 38668-72

[153] Zhang, X. ; Kim-Miller, M. J. ; Fukuda, M. ; Kowalchyk, J. A. ; Martin, T. F.: Ca2+-dependent synaptotagmin binding to SNAP-25 is essential for Ca2+triggered exocytosis. In: Neuron 34 (2002), Nr. 4, S. 599-611

[154] Zilly, Felipe E. ; Rensen, Jakob B. ; JAhn, Reinhard ; LANG, Thorsten: Munc18Bound Syntaxin Readily Forms SNARE Complexes with Synaptobrevin in Native Plasma Membranes. In: PLoS Biology 4 (2006), Nr. 10, S. e330

[155] Zwilling, D. ; Cypionka, A. ; Pohl, W. H. ; Fasshauer, D. ; Walla, P. J. ; WAHL, M. C. ; JAHN, R.: Early endosomal SNAREs form a structurally conserved SNARE complex and fuse liposomes with multiple topologies. In: Embo $J 26$ (2007), Nr. 1, S. 9-18 


\section{Publikationsliste}

1. Chidambaram S, Müllers N, Wiederhold K, Haucke V, von Mollard GF. Specific interaction between SNAREs and epsin N-terminal homology (ENTH) domains of epsin-related proteins in trans-Golgi network to endosome transport. J Biol Chem. 2004 Feb 6;279(6):4175-9.

2. Sørensen JB, Wiederhold K, Müller EM, Milosevic I, Nagy G, de Groot BL, Grubmüller H, Fasshauer D.

Sequential N- to C-terminal SNARE complex assembly drives priming and fusion of secretory vesicles. EMBO J. 2006 Mar 8;25(5):955-66.

3. Holt $\mathrm{M}^{*}$, Varoqueaux $\mathrm{F}^{*}$, Wiederhold $\mathrm{K}^{*}$, Takamori S, Urlaub H, Fasshauer D, Jahn R.

Identification of SNAP-47, a novel Qbc-SNARE with ubiquitous expression. J Biol Chem. 2006 Jun 23;281(25):17076-83. (*, gleichberechtigte Autoren)

4. Nagy G, Milosevic I, Wiederhold K, Sørensen JB

The SNAP-25 linker as an adaption towards fast exocytosis.

Manuskript eingereicht.

5. Wiederhold K, Fasshauer D

Thermodynamic properties of neuronal SNARE assembly.

Manuskript in Vorbereitung.

6. Wiederhold K, Fasshauer D

Biophysical investigations of the Synaptobrevin binding to the 1:1 SNARE acceptor complex.

Manuskript in Vorbereitung. 


\title{
Lebenslauf
}

\author{
Name: Katrin Wiederhold \\ Geburtsdatum: 23.06.1978 \\ Geburtsort: Bad Salzungen \\ Staatsangehörigkeit: deutsch
}

\section{Schulbildung:}

$1985-1986$

Grundschule Geisa

$1986-1992$

Lorenz-Kellner-Schule Heiligenstadt

$1992-1997$

Staatliches Gymnasium Heiligenstadt

$06 / 1997$

Abitur

\section{Studium:}

09/1997 - 09/1998

Studium der Rechtswissenschaften an der GeorgAugust-Universität Göttingen

09/1998-03/2004 Studium Biologie (Diplom) an der Georg-AugustUniversität Göttingen

06/2003 - 03/2004 Diplomarbeit am Max-Planck-Institut für Biophysikalische Chemie, Abteilung Neurobiologie, Göttingen

Titel der Arbeit: Charakterisierung der Interaktionen von synaptischen SNARE-Proteinen mit dem N-Typ Kalziumkanal

$04 / 2004$

Diplom in Biologie

Hauptfach: Biochemie, Nebenfächer: Mikrobiologie und Organische Chemie

\section{Doktorarbeit:}

seit $04 / 2004$

Doktorarbeit am Max-Planck-Institut für Biophysikalische Chemie, Abteilung Neurobiologie, Arbeitsgruppe Strukturelle Biochemie, Göttingen 